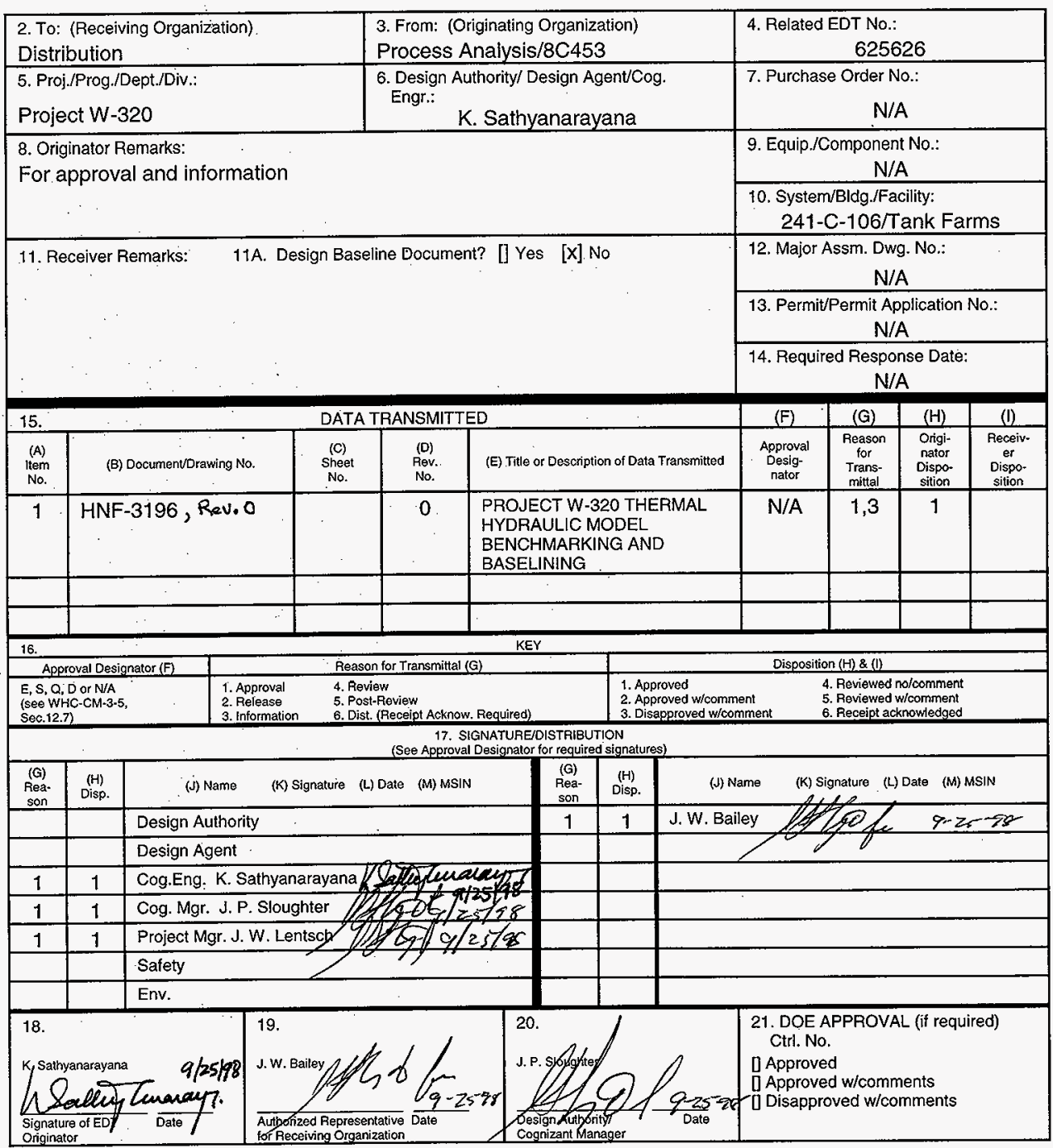

BD-7400-172-2 (05/96) GEF097 


\title{
PROJECT W-320 THERMAL HYDRAULIC MODEL BENCHMARKING AND BASELINING
}

D. M. Ogden

John Marvin, Inc., West Richland, WA 99353

K. Sathyanarayana and B. A. Crea

Numatec Hanford Company, Richland, WA 99352

\section{U.S. Department of Energy Contract DE-AC06-96RL13200}

\author{
EDT/ECN: 625626 \\ UC: 512 \\ Org Code: $8 \mathrm{C} 453$ \\ B\&R Code: EW3130010 \\ Charge Code: D2MA1 \\ Total Pages: $27_{\text {ga }} 89$
}

Key Words: Thermal Analyses, 241-C-106, 241-AY-102, Project W-320

Abstract: Project $W$-320 will be retrieving waste from Tank 241-C-106 and transferring the waste to Tank 241-AY-102. Waste in both tanks must be maintained below applicable thermal limits during and following the waste transfer. Thermal hydraulic process control models will be used for process control of the thermal limits. This report documents the process control models and presents a benchmarking of the models with data from Tanks 241-C-106 and 241-AY-102. Revision 1 of this report will provide a baselining of the models in preparation for the initiation of sluicing.

TRADEMARK DISCLAIMER. Reference herein to any specific commercial product, process, or service by trade name, trademark, manufacturer, or otherwise, does not necessarily constitute or imply its endorsement, recommendation, or favoring by the United States Government or any agency thereof or its contractors or subcontractors.

Printed in the United States of America. To obtain copies of this document, contact: Document Control Services, P.O. Box 950, Mailstop H6-08, Richland WA 99352, Phone (509) 372-2420: Fayo09) 376-4989.

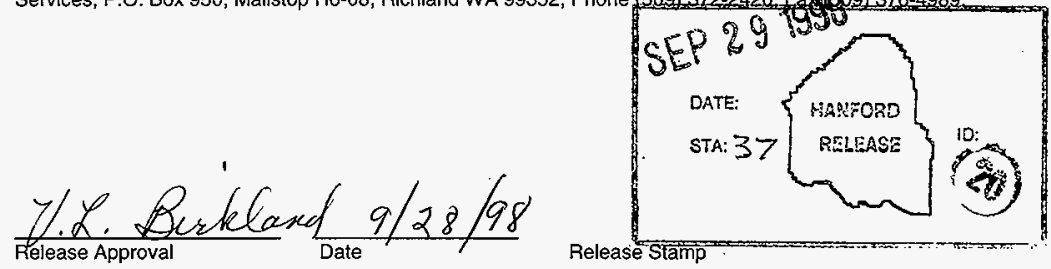

\section{Approved for Public Release}


HNF-3196, Rev. 0

\title{
PROJECT W-320 THERMAL HYDRAULIC MODEL BENCHMARKING AND BASELINING
}

\author{
D.M. Ogden \\ John Marvin, Inc. \\ Richland, Washington \\ K. Sathyanarayana \\ Numatec Hanford Corporation \\ Richland, Washington \\ B.A. Crea \\ Numatec Hanford Corporation \\ Richland, Washington \\ Issued by \\ Numatec Hanford Corporation \\ - Richland, Washington
}

for the

\begin{abstract}
U.S. DEPARTMENT OF ENERGY
RICHLAND OPERATIONS OFFICE

RICHLAND, WASHINGTON
\end{abstract}


HNF-3196, Rev. 0

CONTENTS

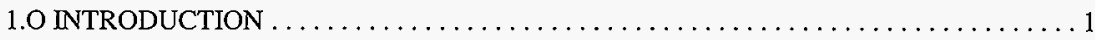

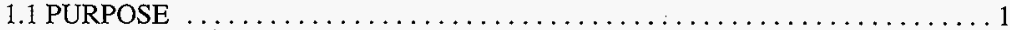

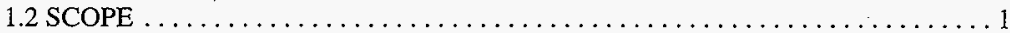

2.0 BENCHMARK THERMAL HYDRAULIC MODEL DESCRIPTION $\ldots \ldots \ldots \ldots \ldots \ldots 4$

2.1 PROCESS CONTROL THERMAL MODELS $\ldots \ldots \ldots \ldots \ldots \ldots \ldots \ldots \ldots$

2.1.1 GOTHIC 1-D Model of Tank $241-\mathrm{C}-106 \ldots \ldots \ldots \ldots \ldots \ldots \ldots$

2.1.2 GOTHIC 1-D Model of Tank 241-AY-102 $\ldots \ldots \ldots \ldots \ldots \ldots \ldots$

2.1.3 Best Estimate Thermal Parameters $\ldots \ldots \ldots \ldots \ldots \ldots \ldots \ldots \ldots$

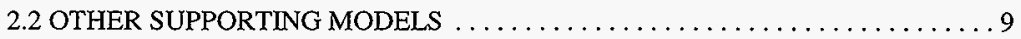

2.2.1 GOTH 2-D Model of Tank 241-C-106 . . . . . . . . . . . . . 9

2.2.2 GOTH 1-D Model of Tank 241-AY-102 ................ 9

2.2.3 GOTH-SNF 2-D model of Tank 241-AY-102 .............. 9

3.0 TANK 241-C-106 BENCHMARK ANALYSES $\ldots \ldots \ldots \ldots \ldots \ldots \ldots \ldots \ldots \ldots \ldots$

3.1 DESCRIPTION OF BENCHMARK CASES $\ldots \ldots \ldots \ldots \ldots \ldots \ldots \ldots \ldots \ldots$

3:1.1 Normal Operation for $1996-1998 \ldots \ldots \ldots \ldots \ldots \ldots \ldots \ldots \ldots \ldots$

3.1.1.1 Tank 241-C-106 Temperature Instrumentation .......... 18

3.1.1.2 Temperature Data Overview ................... 18

3.1.1.3 Inferred Thermal Parameters from Temperature Data . . . . . . 19

3.1.1.4 Water Addition Data ....................... 20

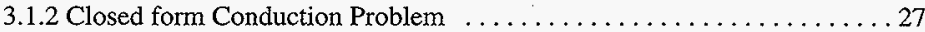

3.2 RESULTS OF 241 -C-106 BENCHMARK ANALYSES $\ldots \ldots \ldots \ldots \ldots \ldots 28$

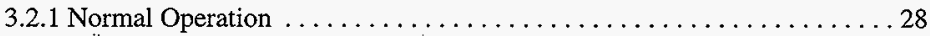

3.2 .2 Closed form Conduction Solution $\ldots \ldots \ldots \ldots \ldots \ldots \ldots \ldots \ldots \ldots \ldots, 29$

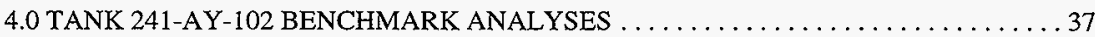

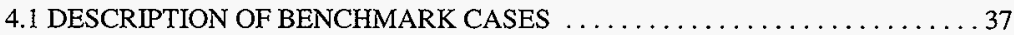

4.1.1 Normal Operation with Primary Ventilation $\ldots \ldots \ldots \ldots \ldots \ldots . \ldots . \ldots . \ldots$

4.1.2 Normal Operation with Primary and Low Annulus System Flow . . . . . 39

4.1.3 Normal Operation with Primary and High Annulus System Flow . . . . . 40

4.2 RESULTS OF 241-AY-102 BENCHMARK ANALYSES ............. 48

4.2.1 Benchmark for Normal Operation With Primary Ventilation ......... 48

4.2.2 Benchmark for Normal Operation With Primary and Low Annulus Flow

4.2.3 Benchmark for Normal Operation With Primary and High Annulus Flow 
HNF-3196, Rev. 0

5.0 TANK 241-AY-102 UNCERTAINTY ANALYSES $\ldots \ldots \ldots \ldots \ldots \ldots \ldots \ldots \ldots \ldots . \ldots \ldots$

5.1 METHODOLOGY . . . . . . . . . . . . . . . . . . . . . . 62

5.1.1 Description of Uncertainty Analyses Methodology $\ldots \ldots \ldots \ldots \ldots \ldots 62$

5.1.2 Uncertainty Analysis Parameters $\ldots \ldots \ldots \ldots \ldots \ldots \ldots \ldots \ldots \ldots$

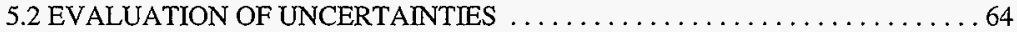

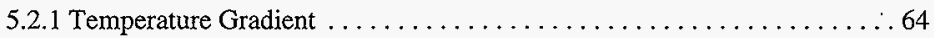

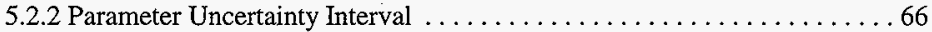

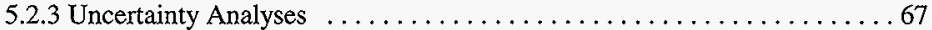

5.2.3.1 Initial Conservative Estimate ..................6. 67

5.2.3.2 Preliminary Estimate of Uncertainty Reduction $\ldots \ldots \ldots \ldots 68$

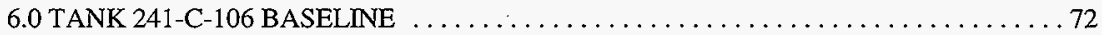

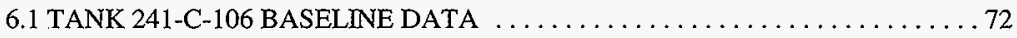

6.1.1 Baseline Temperature Data ....................... 72

6.1 .2 Ventilation System Operation ....................... 72

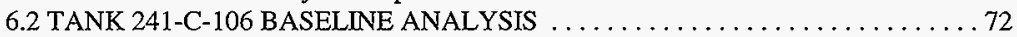

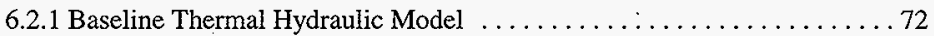

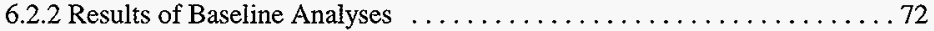

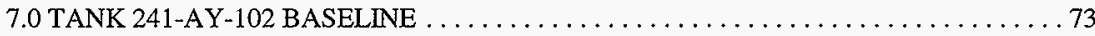

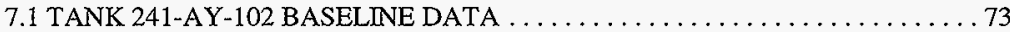

7.1 .1 Temperature History . . . . . . . . . . . . . . . . . . 73

7.1.2 Three -Dimensional Temperature Distribution ............... 73

7.1 .3 Primary and Annulus System Operation $\ldots \ldots \ldots \ldots \ldots \ldots \ldots \ldots \ldots$

7.1.4 Tank 241-AY-102 Waste Level ........................ 73

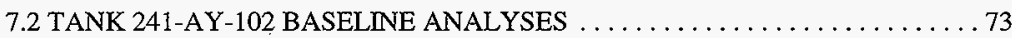

7.2.1 Baseline Thermal Hydraulic Model $\ldots \ldots \ldots \ldots \ldots \ldots \ldots \ldots \ldots .73$

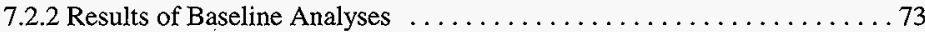

8.0 PROCESS CONTROL ANALYSES DEFINITION ................... 80

8.1 TANK 241-C-106 PROCESS CONTROL ANALYSES DEFINITION . . . . . . 80

8.2 TANK 241-C-106 PROCESS CONTROL ANALYSES DEFINITION . . . . . . 80

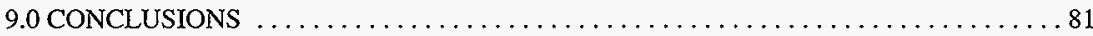

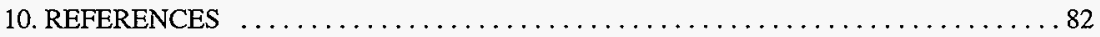


HNF-3196, Rev. 0

\section{FIGURES}

Figure 2.1 Tank 241-C-106 Heat Estimate by Heat Transfer Mode. $\ldots \ldots \ldots \ldots \ldots \ldots \ldots 1$

Figure 2.2 Schematic of GOTHIC Tank 241-C-106 Model. . . . . . . . . . . . . . . 12

Figure 2.3 GOTHIC Waste Conductor Noding. . . . . . . . . . . . . . . . . . 13

Figure 2.4 GOTHIC 1-D Process Control Model for Tank 241-AY-102 . . . . . . . . . 14

Figure 2.5 Tank 241-AY-102 Annulus Ventilation Floor Flow Channels . . . . . . . . . . 15

Figure 2.6 Top View of Distributed Parameter Volume 2 s . . . . . . . . . . . . . . . 16

Figure 2.7 Tank 241-AY-102 Waste Conductor Noding ..................... 17

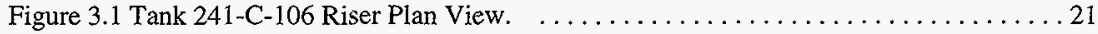

Figure 3.2 Riser 14 Dome and Waste Temperatures. ....................... 22

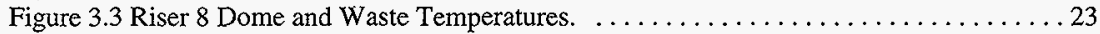

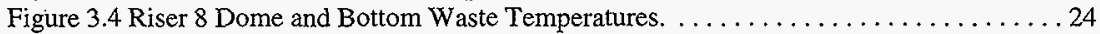

Figure 3.5 Exponential Curve Fit to Riser 8 Maximum Waste Temperature. ............. 25

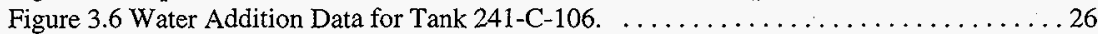

Figure 3.7 Waste Temperature Profile After Incremental Sluicing. . . . . . . . . . . . . 30

Figure 3.8 Closed Form Conduction Solution for Incremental Sluicing. . . . . . . . . . . 31

Figure 3.9 Comparison of GOTHIC Analyses With Dome Space and Riser 8 Data. . . . . . . 32

Figure 3.10 Comparison of Waste Heat Capacity. . . . . . . . . . . . . . . . . . 33

Figure 3.11 Comparison of Accumulative Evaporation Rates. .................. 34

Figure 3.12. Comparison With Riser 8 Temperature Distribution. ................. 35

Figure 3.13 GOTHIC Solution for Closed Form Conduction Problem. ............... 36

Figure 4.1 Tank 241-AY-102 Temperature Data for Benchmark Analyses. . . . . . . . . 41

Figure 4.2 Tank 241-AY-102 Operating Level of Supernate Pool. . . . . . . . . . . . . 42

Figure 4.3 Meteorological Data for Benchmark Analyses. .................... 43

Figure 4.4 Tank 241-AY-102 Temperature Data for Period $1 . \ldots \ldots \ldots \ldots \ldots \ldots \ldots \ldots$

Figure 4.5 Annulus System Flow and Pressure for 1997. . . . . . . . . . . . . . 45

Figure 4.6 Tank 241-AY-102 Temperature Data for Period 2. .................. 46

Figure 4.7 Tank 241-AY-102 Temperature Data for Period 3. ................. 47

Figure 4.8 Comparison Predicted Concrete Temperatures With Data for Period $1 . \ldots \ldots \ldots .51$

Figure 4.9 Comparison of Predicted Supernate Temperatures With Data. . . . . . . . . 52

Figure 4.10 Predicted Evaporation Rates During Period $1 \ldots \ldots \ldots \ldots \ldots \ldots \ldots \ldots \ldots$

Figure 4.11 Comparison of Predicted Evaporative Losses With Corrected Tank Level Data. . . 54

Figure 4.12 Waste Temperature Distribution During Period $2 \ldots \ldots \ldots \ldots \ldots \ldots \ldots \ldots$

Figure 4.13 Heat Removal by the Annulus Ventilation System at Low Flow. . . . . . . . . . 56

Figure 4.14 Comparison of Supernate and Sludge Temperatures................. 57

Figure 4.15 Comparison of Predicted Temperatures With Data During Period 2. . . . . . . 58

Figure 4.16 Predicted Concrete Temperatures Without Preheating. . . . . . . . . . . . . 59

Figure 4.17 Waste Temperature Distribution at the End of Period 2. . . . . . . . . . . 60

Figure 4.18 Comparison of Predicted Temperatures With Data During Period $3 \ldots \ldots \ldots \ldots 61$

Figure 7.1 Schematic of Tank 241-AY-102 Thermal Couple Locations. ............. 74 
HNF-3196, Rev. 0

Figure 7.2 Insulating Concrete Temperatures at 7 Foot Radius $\ldots \ldots \ldots \ldots \ldots \ldots \ldots$

Figure 7.3 Insulating Concrete Temperatures at 21 Foot Radius. . . . . . . . . . . . 76

Figure 7.4 Insulating Concrete Temperatures at 37 Foot Radius. . . . . . . . . . . . 77

Figure 7.5 Tank 241 -AY-102 Supernate Temperatures . . . . . . . . . . . . . . . . 78

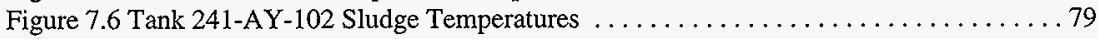

\section{TABLES}

Table 2.1. Best Estimate Thermal Parameters. . . . . . . . . . . . . . . . . . . . . 8

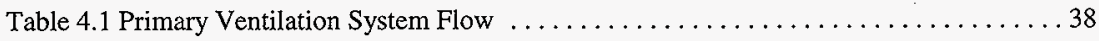

Table 5.1 Summary of Process Control Model Uncertainty Analyses. . . . . . . . . . . . . 70

Table 5.2 Process Control Model Uncertainty Analyses With Updated Thermal Parameters . . 71 
HNF-3196, Rev. 0

\section{O INTRODUCTION}

\subsection{PURPOSE}

Project W-320 is scheduled to begin sluicing waste from Tank 241-C-106 and transferring the waste to Tank 241-AY-102 in September of 1998. The waste in both tanks must be maintained below applicable temperature limits during and following the Project W-320 sluicing activities. These temperature requirements are identified in Carothers 1998. The maximum waste temperatures can not be measured directly for Tanks 241-C-106 or 241-AY102. Furthermore, the thermal inertia of the waste in both tanks, will delay the time to reach quasi-steady temperatures (seasonal variations do not allow a true steady state) by many months. For these reasons, thermal hydraulic analyses are required to assure that the waste temperatures for both tanks remain below the required temperature limits. The Process Control Plan identifies the thermal modeling results input for the Project W-320 process control strategy.

The first purpose of this report is to document the thermal models which will support Project W-320 process control. These models are a subset of thermal models used to support the project safety analyses and project planning activities (Ogden/ Sathya 1998a). These models have been compared with field data for Tanks 241-C-106 and 241-AY-102, to provide a benchmark of the process control thermal models. The second objective of this report is to document the results of the benchmark analyses. Prior to the initiation of the Project W-320 sluicing activities, the thermal models used for process control must be initialized to the actual tank and meteorological conditions. This is the baselining of the thermal models. The final purpose of this report is to document the baselining of the thermal models and the baseline or initial data for both Tanks 241-C-106 and 241-AY-102. The tank model baseline will provide the basis for comparing changes in tank conditions after the initiation of sluicing.

\subsection{SCOPE}

Best estimate thermal parameters for Projects W-320 were documented (Ogden/Sathya 1998a). These parameters were used for the benchmark analyses for the process control models. Small modifications to the Best Estimate Thermal Parameters were made to provide a good comparison with tank data. The Best Estimate Thermal Parameters and other supporting information is provided in Section 2.0 .

Two thermal hydraulic models will be used for process control thermal analyses for Project W-320. These models will be used to make an assessment of the heat balance in the sluicing and receiver tanks during the Project W-320 activities. This assessment will provide an estimate of the heat load in both tanks throughout the W-320 sluicing campaigns. The thermal hydraulic models will also be used to determine the maximum quasi-steady state waste temperatures in both tanks to verify that temperature limits are not exceeded. In addition to the 
two process control models, other thermal hydraulic models will be used to provide additional independent assessment of the tank heat loads and to investigate the effects of possible nonuniform waste settling in Tank 241-AY-102. The process control supporting thermal hydraulic models are presented in Section 2.0.

Section 3.0 presents the results of the benchmark analyses for the Tank 241-C-106 process control thermal hydraulic model. The Tank 241-C-106 model benchmark analyses include a comparison with:

- $\quad$ Normal tank operations from 1996 to 1998.

- Closed form conduction solution with step change in boundary condition.

Section 4.0 presents the results of the benchmark analyses for the Tank 241-AY-102 process control thermal hydraulic model. The Tank 241-AY-102 process control model benchmark analyses include a comparison with:

- Normal operation with primary ventilation only.

- Normal operation with low flow annulus cooling.

- Normal operation with high flow annulus cooling.

For the purpose of the WRSS process control thermal model, the maximum bottom waste temperature for Tank $241-\mathrm{AY}-102$ requires not to exceed $215^{\circ} \mathrm{F}$, which is the Limiting Condition of Operation (LCO). This temperature limit is related to the applicable TSR limit (FDH 1998) which is $250^{\circ} \mathrm{F}$ for the tank bottom waste. The maximum temperature is not directly measured but will be calculated using the process control thermal model. The thermal hydraulic analyses is subject to uncertainty as a result of uncertainties in the thermal hydraulic input parameters, and model approximations. An uncertainty analysis was performed to estimate the uncertainty in the calculated maximum waste temperature. This uncertainty will be added to the predicted maximum waste temperature to provide an additional margin of safety. The uncertainty analysis are presented in Section 5.0.

The thermal hydraulic models must be initialized to actual tank and meteorological conditions just prior to the initiation of sluicing. This initialization or baselining of the thermal hydraulic models is accomplished by performing analyses with actual meteorological conditions and tank operation history, for a period of several months prior to sluicing. The baseline activities also include a thorough evaluation of the tank data over a sufficient period of time, to identify baseline thermal behavior, including seasonal variations and normal operation behavior. This will provide a good understanding of the normal tank thermal behavior which will serve as a baseline for evaluating changes due to the Project W-320 sluicing. The thermal hydraulic model and tank data baselines are presented in Section 6.0 for Tank 241-C-106 and Section 7.0 for Tank 241-AY-102. 


\section{HNF-3196, Rev. 0}

Section 8.0 provides an overview of the process control thermal analyses that will be performed for Tanks 241-C-106 and 241-AY-102. These analyses have been generally defined by the PCP but require a more detailed definition of the analyses and supporting assumptions.

The conclusions of the benchmarking and baselining activities presented in this report are provided in Section 9.0.

Rev. 0 of this report will provide the benchmarking analyses results. With the exception of some limited Tank 241-AY-102 data, the baselining analyses results (Sections 6.0, 7.0 and 8.0) will be provided in Rev. 1 of this report. 
HNF-3196, Rev. 0

\subsection{BENCHMARK THERMAL HYDRAULIC MODEL DESCRIPTION}

Process control thermal models have been developed for Tank 241-C-106 and Tank 241AY-102. The GOTHIC ${ }^{1}$ computer code is used for developing these models. These models are described in the following sections.

\subsection{PROCESS CONTROL THERMAL MODELS}

\subsubsection{GOTHIC 1-D Model of Tank 241-C-106}

GOTHIC is a multi-phase, multi-dimensional thermal hydraulic computer code developed for the Electric Power Research Institute. It is particularly well suited for performing the analyses presented in this report because of its mechanistic treatment of the mass transfer from the supernatant pool. The heat is removed from the tank through sensible heat (convection), latent heat (evaporation ) and conduction through the soil. The later is smaller than the latent and sensible heat transfer. Figure 2.1 shows an estimate of the heat load in Tank 241-C-106 and includes the contribution from the three modes of heat removal (Ogden/Sathya 1998a). This estimate was made using the tank level data, water addition data, ventilation rates, and meteorological data. The sensible and evaporative heat removal are dynamic, with sensible heat removal dominating during the winter and evaporative heat removal dominating during the summer. The GOTHIC code contains the appropriate models to simulate this dynamic heat removal.

Figure 2.2 shows a schematic of the GOTHIC model for Tank 241-C-106. The tank dome space is modeled as a lumped parameter volume. The mass transfer between pool and dome space is calculated based upon dome and liquid temperatures and dome space relative humidity. The inlet flow condition to the dome space is modeled as the $1 \mathrm{~F}$ fluid boundary. The ventilation flow rate and meteorological conditions are specified by this flow boundary condition. Meteorological data (temperature and humidity) for calender years 1994 through 1997, which was obtained from Pacific Northwest National Laboratory world wide web site ( http://terrassa.pnl.gov:2008/HMS), were used in the analysis. The monthly averaged values were used. The $2 \mathrm{P}$ boundary condition provides a constant pressure for the ventilation outlet. Boundary condition $3 \mathrm{~F}$ is a fluid boundary condition which provides the makeup water for evaporation. The water is added on a continuous basis rather than the batch water additions seen in Figure 3.6.

The waste and supernatant of Tank 241-C-106 are modeled as one-dimensional conductor components. The noding for the conductors is shown in Figure 2.3. The tank liquid level

${ }^{1}$ GOTHIC is a proprietary computer code of the Electric Power Research Institute. 
operates between 74 and 79 inches. An average value of 76 inches was selected for the conductor length. A value of $0.53 \mathrm{Btu} / \mathrm{lbm}-{ }^{\circ} \mathrm{F}$ was used for the specific heat of the waste. This is based upon the particle and liquid specific heats and an assumed particle weight fraction of 50\%, as discussed in Section. 2.1.3. The waste was modeled with two conductors. The first inner conductor (shown as conductor 1 in Figure 2.2) represents the waste out to a radial distance of 25 feet $(2 / 3$ the distance from the tank center to the side wall). The second outer conductor (conductor 3 in Figure 2.2) represents the remaining waste. The waste was modeled as two conductors to provide a better representation of the Riser 8 thermocouple tree data. Figure 3.3 shows the data from thermocouples 1,3 and 6 of the Riser 8 thermocouple tree. Comparison of these temperatures with a 2-D conduction solution shows that these temperatures are lower than would be expected (Thurgood 1995). An explanation for this behavior is a small convective liquid channel surrounding the tree. The effect of this is seen in Figure 3.3. TC 1 and 3 are near the bottom and middle of the waste (axial location). TC 6 , which is in the dome space, oscillates as a result of ambient temperature variations and periodic water additions. These oscillations are seen immediately both at the locations of TC 3 and TC 1 . The thermal inertia of the waste would dampen these high frequency oscillations (high relative to the annual temperature cycle) if the heat transfer surrounding the thermocouple tree was the result of waste conduction only. This apparent liquid convection was simulated with the GOTHIC 1-D conductor with an increased thermal conductivity. This detail of the model is not needed for the process control simulations which will predict the center tank bottom temperatures and then determine a tank heat load estimate. However, prediction of the Riser 8 temperatures are used for monitoring the tank temperatures prior to sluicing.

The heat load of the conductor was based upon the Project W- 320 best estimate heat load. A value of $118,000 \mathrm{Btu} / \mathrm{hr}$ for September of 1998 was used. The GOTHIC model used a half life for the radionuclide decay of 28 years as discussed in Section 3.1.1.3.

The soil over the tank was modeled as a 1-D conductor as shown in Figure 2.2 as conductor 2. The conductor boundary conditions are the dome space temperature and the ambient temperature. This conductor provides only a small fraction of the overall heat removal. Measured thermal conductivity of SX Farm soil (Bouse 1975) were used. The waste and dome temperatures were shown through parametric analyses not to be sensitive to the selection of soil properties.

Soil below and to the side of the tank was simulated with a second soil conductor shown in Figure 2.2 as conductor 6 . This conductor is provided to account for the small portion of the tank heat which does not go through the tank dome space. The length of the 1-D conductor was adjusted to provide the same soil heat loss determined from the GOTH 2-D model used to analyze the Tank 241-C-106 1994 process test (Thurgood 1995). 
HNF-3196, Rev. 0

The 1-D GOTHIC model was further benchmarked using 2-D GOTH analyses performed for the 1994 Process Test of Tank 241-C-106 (Thurgood 1995). Thurgood demonstrated that the maximum waste temperatures during the peak summer conditions were approaching local saturation conditions. The local saturation temperature was estimated to be $228^{\circ} \mathrm{F}$. The thermal conductivity for the 1-D GOTHIC conductor was selected to give a maximum waste temperature consistent with the Thurgood 1995 2-D GOTH analysis.

\subsubsection{GOTHIC 1-D Model of Tank 241-AY-102}

The GOTHIC code will be used for the Tank 241-AY-102 process control thermal model. The GOTHIC model is shown in Figure 2.4. The dome space is modeled as a single lumped parameter control volume and is shown in the figure. Attached to the dome volume are three boundary conditions. The boundary condition labeled $1 \mathrm{~F}$, provides the primary system ventilation flow. The ventilation flow rate and ambient conditions are specified. The specified ambient conditions include, pressure, temperature and relative humidity. The SF boundary conditions provide makeup water to replace the evaporated water. A single average value is used $(.008 \mathrm{lbm} / \mathrm{s})$. The $2 \mathrm{P}$ boundary condition models the ventilation outlet which is modeled as a pressure boundary condition.

A one-dimensional (1-D) thermal conductor component is used to model the soil above the tank dome. The thickness of the conductor was assumed to be seven feet. Conduction of heat through the soil accounts for only a small part of the energy removal from the tank. Sensible and latent heat account for most of the heat removal. The assumed value of soil conductivity was $0.4 \mathrm{Bu} / \mathrm{ft}-\mathrm{hr}-{ }^{\circ} \mathrm{F}$. This value is consistent with measured soil conductivities for soils in The SXFarm (Bouse 1975).

Figure 2.5 shows a schematic of the floor of Tank 241-AY-102. There are three definable regions corresponding to the branching of the slot flow channels of the annulus ventilation system. Each of these three regions is modeled as a 1-D GOTHIC conductor component. The outer, middle and inner regions correspond to thermal conductors 3, 4 and 5 in Figure 2.4. The conductors each connect to the liquid pool in the lumped parameter volume representing the dome. The other end of the conductor is connected to Volume $2 \mathrm{~s}$ which is a distributed parameter volume subdivided into four volumes. The top view of the distributed parameter volume $2 s$ and the placement of the thermal conductor connection, is shown in Figure 2.6. Subvolumes 2 through 4 represent the inner, middle and outer flow channels of the annulus ventilation system. The heat transfer coefficient for Side B of each conductor was set to obtain the efficiency factor for each region determined by the 3-D thermal hydraulic model reported in Ogden/Sathya 1998a. The benchmark with the Tank 241-AY-102 data provides a confirmation of these computed values. 
The noding of the waste thermal conductors is shown in Figure 2.7. Side A represents the dome space liquid pool and side B the annulus flow channels. The supernate pool is included in the conductor to enable faster computational speed for the model. This is modeled as a high conductivity material with a small temperature gradient to model the result of natural convection in the pool. A small amount of supernate is included in the lumped parameter dome volume to account for the evaporation. The existing waste in Tank 24l-AY-102 is approximately one foot in depth. This is shown in Figure 2.7. All the power is assumed to be generated in the nonconvective waste, with no power generation in the supernate pool. Evaluation of the tank data during sluicing may indicate that a fraction of the heat (after sluicing is initiated) is generated in the supernate from soluble $\mathrm{Cs}^{137}$. The model allows for power to be added to the supernate component of the thermal conductor.

Cooling air for the slot flow channels of the annulus ventilation system is provided to the center of the tank floor through four, four inch pipes as shown schematically in Figure 2.5. These pipes enter through penetrations at the top of the tank side wall and run in the annulus between the tank concrete wall and inner steel liner to the bottom of the tank. At low ventilation flows, this provides significant preheating of the ventilation air. Heat conductor number 5 shown in Figures 2.5 and 2.6, provides this preheating of the annulus ventilation inlet air. The 1-D conductor is connected to the supernate pool in the lumped parameter volume 1 and the first volume of the distributed parameter volume 2s. This preheating is discussed further in Section 4.2 .

There are two boundary condition components attached to the annulus flow volume $2 \mathrm{~s}$. Boundary Condition $3 \mathrm{~F}$ establishes the annulus flow and ambient temperature. Boundary condition 4P represents the annulus ventilation outlet. 
HNF-3:196, Rev. 0

\subsubsection{Best Estimate Thermal Parameters}

The process control models for both 241-C-106 and 241-AY-102 used the Project W-320 best estimate thermal parameters. The parameters are summarized in Table 2.1.

Table 2.1. Best Estimate Thermal Parameters.

\begin{tabular}{|c|c|}
\hline Best Estimate Parameters & $\begin{array}{l}\text { Best Estimate } \\
\text { Value }\end{array}$ \\
\hline \multicolumn{2}{|l|}{ Tank 241-C-106 Parameters } \\
\hline $\begin{array}{l}\text { Fluffing Factor } \\
2 \text { sigma range }\end{array}$ & $\begin{array}{c}1.4 \\
1.0 \text { to } 1.8\end{array}$ \\
\hline Liquid Thermal Conductivity (Btu/hr-ft- $\left.{ }^{\circ} \mathrm{F}\right)$ & 0.35 \\
\hline Particle Thermal Conductivity (Btu/hr-ft- $\left.{ }^{\circ} \mathrm{F}\right)$ & 5.0 \\
\hline $\begin{array}{l}\text { Transferred Waste Thermal Conductivity with } \\
1.4 \text { fluff factor }\left(B t u / h r-f t-{ }^{\circ} \mathrm{F}\right)\end{array}$ & 0.41 \\
\hline Liquid Heat Capacity $\left(B t u / \mathrm{lb}_{\mathrm{m}}{ }^{\circ} \mathrm{F}\right)$ & 0.8 \\
\hline Particle Heat Capacity $\left(\mathrm{Btu} / \mathrm{lb}_{\mathrm{m}}-{ }^{\circ} \mathrm{F}\right)$ & 0.2 \\
\hline Sludge Heat Capacity $\left(B t u / \mathrm{lb}_{\mathrm{m}}-{ }^{\circ} \mathrm{F}\right)$ & 0.53 \\
\hline Total Heat Load (Btu/hr) (1998) & 118,000 \\
\hline $\begin{array}{l}\text { C-106 Heat Load Distribution (Btu/hr) } \\
0 \text { to } 2 \text { feet (from waste surface) } \\
2 \text { to } 6 \text { feet }\end{array}$ & $\begin{array}{c}16,900 \\
101,100\end{array}$ \\
\hline \multicolumn{2}{|l|}{ Tank 241-AY-102 Parameters } \\
\hline Sludge Thermal Conductivity (Btu/hr-ft- $\left.{ }^{\circ} \mathrm{F}\right)$ & 0.35 \\
\hline Sludge Heat Capacity (Btu/lbm- $\left.{ }^{\circ} \mathrm{F}\right)$ & 0.6 \\
\hline $\begin{array}{l}\text { AY-102 Heat Load (Btu/hr) (1998) } \\
0 \text { to } 1 \text { foot (from tank bottom) }\end{array}$ & 41,200 \\
\hline
\end{tabular}


HNF-3196, Rev. 0

\subsection{OTHER SUPPORTING MODELS}

The process control thermal models were discussed in the previous section. These models have been benchmarked with tank data, as presented in Section 4.0 and 5.0. The other thermal hydraulic models, used during the Project W-320 sluicing activities, will not be used for process control analyses, but will be used to support these activities. These models are briefly discussed in the following sections.

\subsubsection{GOTH 2-D Model of Tank 241-C-106}

The Tank 241-C-106 Process Control Model discussed in Section 2.1.1 is a 1-D thermal model. This model is adequate for its intended use as shown in Section 4.0. The dominant path for heat transfer from Tank 241-C-106 is through the dome space. However, there is a limited multi-dimensional heat transfer through the tank bottom and side wall. This behavior has been evaluated with other 2-D thermal models ( Bander 1993, Thurgood 1995). The Tank 241-C-106 was extensively studied for 1994 Process Test (1995) with a 2-D GOTH model presented in Ogden/Sathya 1998a. This model provided a good tank heat load estimate which has been included in the evaluation of the best estimate heat load for 241-C-106. The 2-D GOTH model and the evaluation of the 1994 Process Test were used in the benchmarking of the 1-D process control model for Tank 241-C-106. The evaluation of the process test has provided a benchmark for the GOTH model. No further use of this model is intended during the W-320 sluicing activities.

\subsubsection{GOTH 1-D Model of Tank 241-AY-102}

A 1-D GOTH model was used to evaluate the heat load for Tank 241-AY-102 as reported by Ogden/Sathya 1998a. Variations of this 1-D model have been used extensively for thermal analyses for the aging waste tanks (Sathya 1993,1997). During the sluicing activities this model will be used to provide a second independent evaluation of the heat load for Tank 241-AY-102. The model was partially benchmarked with Tank 241-AY-102 data, as part of the heat load evaluation. The model is also useful for evaluating the waste temperature distribution, with no annulus ventilation system flow or evaluation of the average temperature distribution, for radial average condition. The model will not be used for process control analyses but will provide an independent and supporting analyses of the estimated tank heat load for 241-AY-102.

\subsubsection{GOTH-SNF 2-D model of Tank 241-AY-102}

The process control model for Tank 241-AY-102 uses 1-D conductors to simulate axial and radial temperature distributions in Tank 241-AY-102. This is possible because the tank diameter ( 75 feet) is much larger than the waste thickness. However, there are azimuthal temperature variations due to potential flow channel blockages, which will need to be evaluated. 
HNF-3196, Rev. 0

These are discussed in Section 5.0. A 3-Dimensional conduction model will be developed to study these azimuthal temperature variations. The GOTH-SNF computer code (Thurgood 1998a,b) will be used to develop the 3-D model. GOTH-SNF is a version of the GOTH computer code used extensively for waste tank applications and has been modified for use in the Spent Nuclear Fuels Program. The GOTH code was integrated with the COBRA-TF computer code (Thurgood 1998a,b). This integration allows the use of 3-D conductors while maintaining other valuable features of GOTH, including the tank evaporation rate which is very important for waste tank modeling. The GOTH-SNF 3-D model will be used to evaluate possible 3-D temperature variations. 
HNF-3196, Rev. 0

Figure 2.1 Tank 241-C-106 Heat Estimate by Heat Transfer Mode.

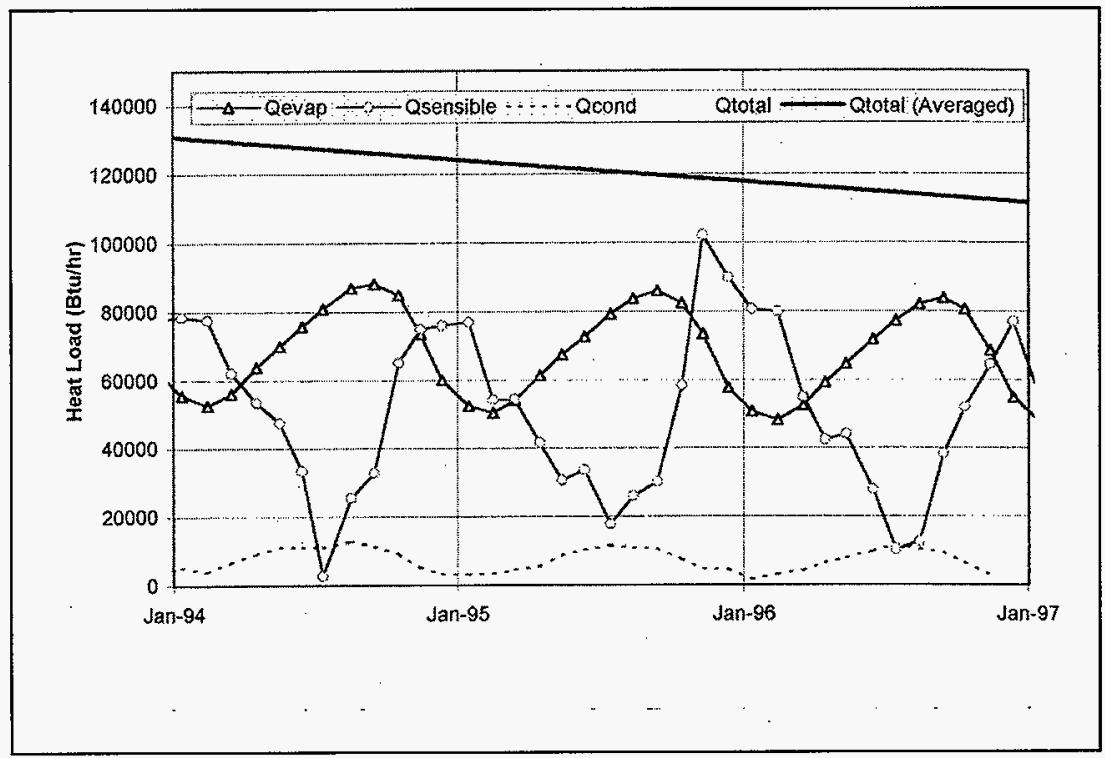


HNF-3196, Rev. 0

Figure 2.2 Schematic of GOTHIC Tank 241-C-106 Model.

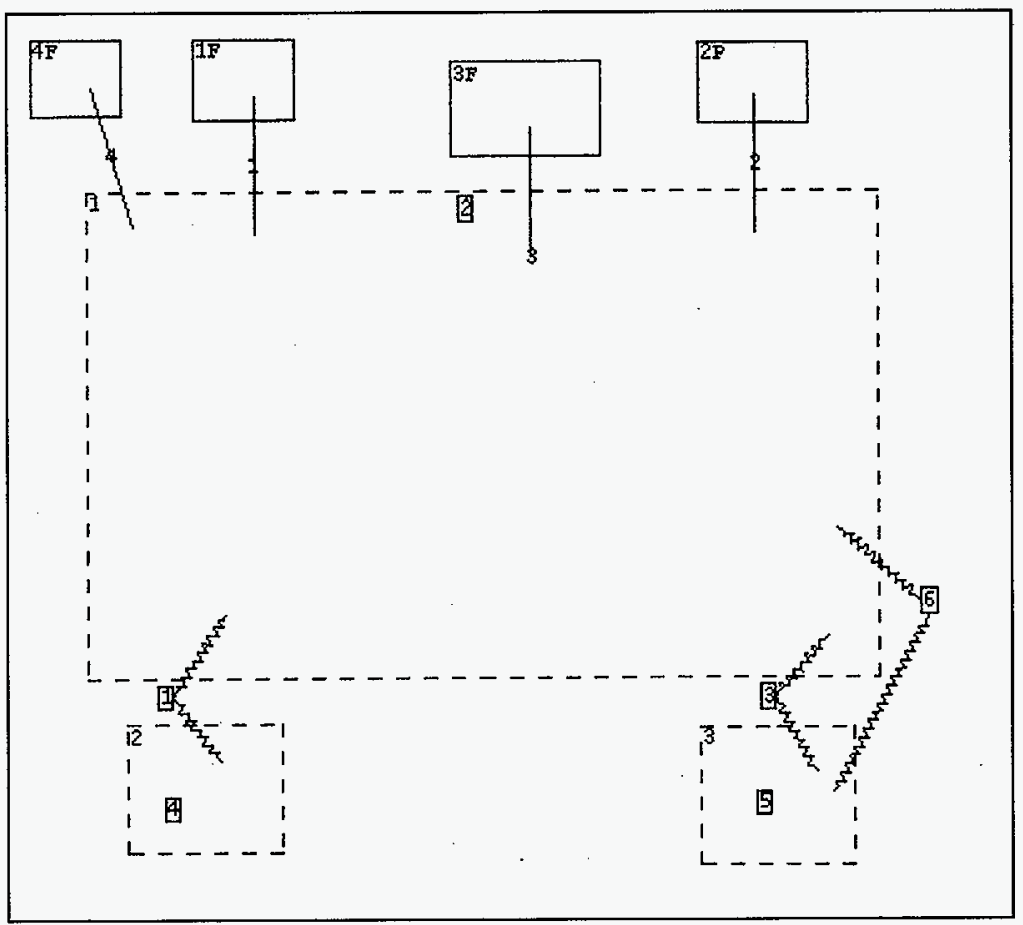


HNF-3196, Rev. 0

Figure 2.3 GOTHIC Waste Conductor Noding.

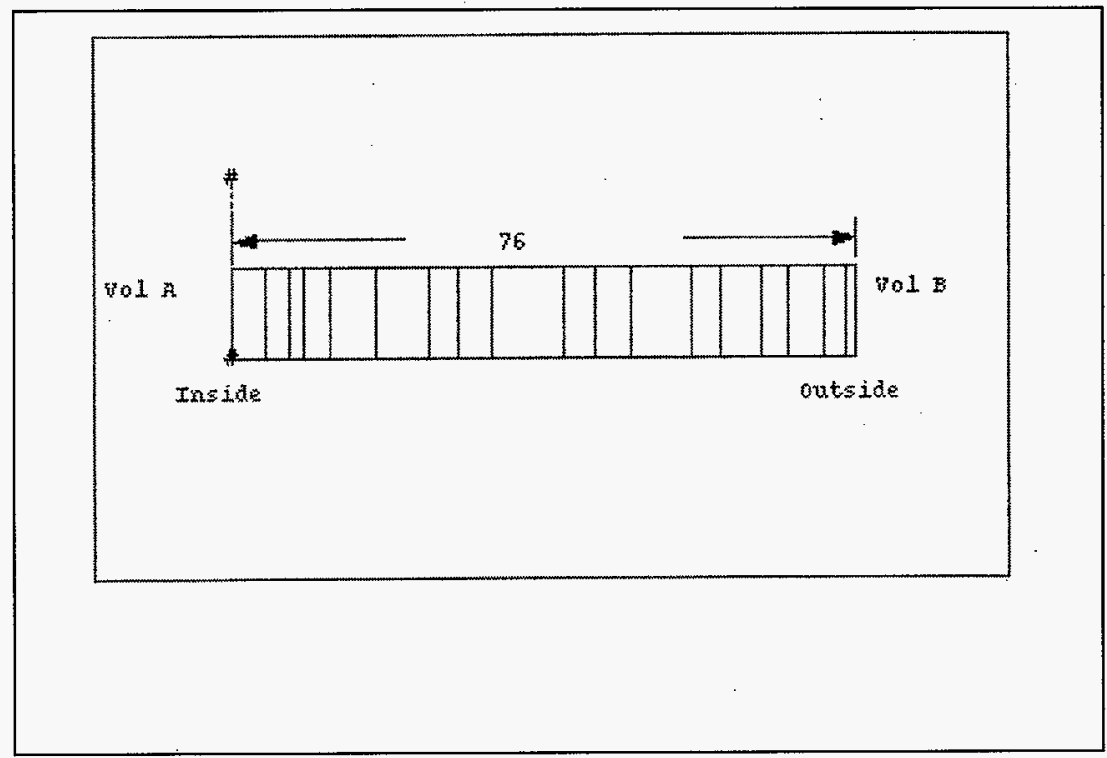


HNF-3196, Rev. 0

Figure 2.4 GOTHIC 1-D Process Control Model for Tank 241-AY-102.

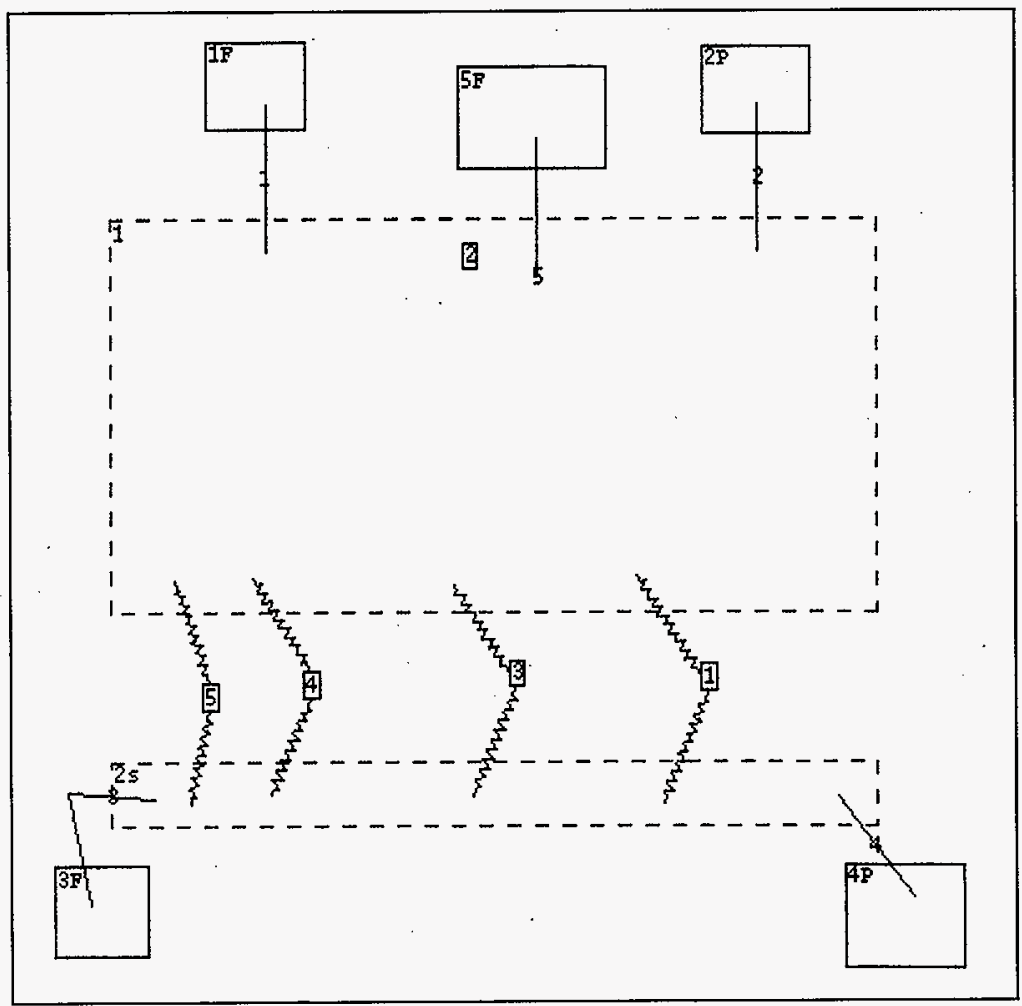


HNF-3196, Rev. 0

Figure 2.5 Tank 241-AY-102 Annulus Ventilation Floor Flow Channels.

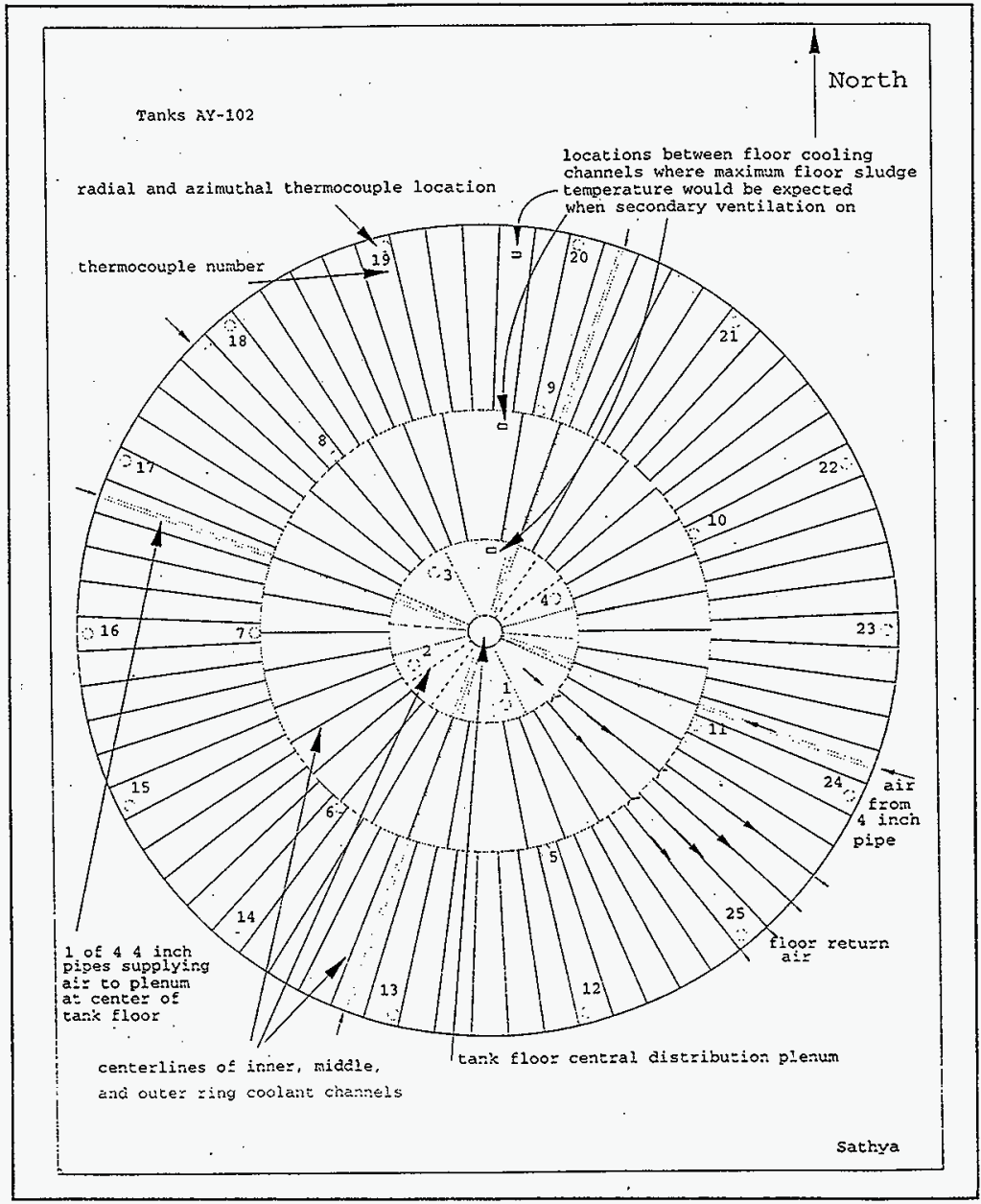


HNF-3196, Rev. 0

Figure 2.6 Top View of Distributed Parameter Volume 2s.

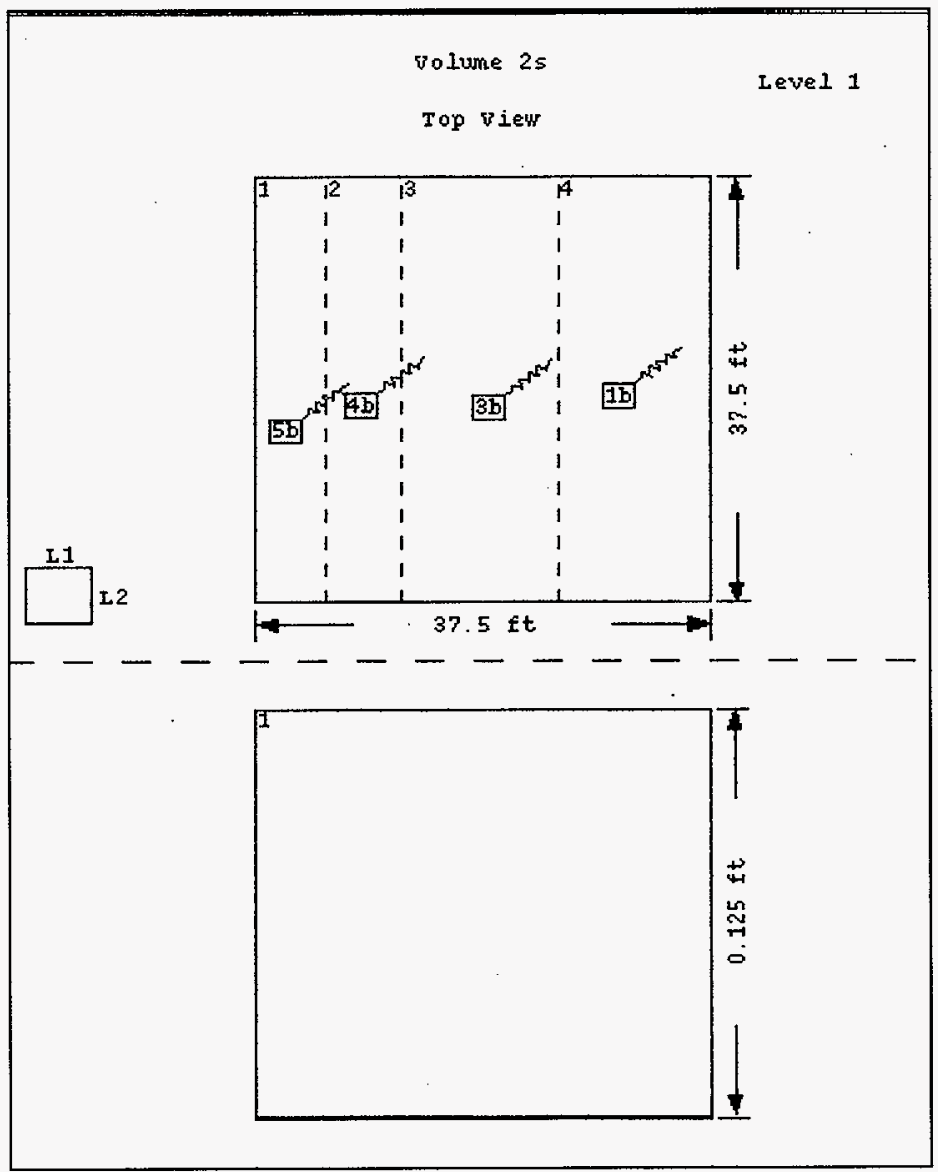


HNF-31.96, Rev. 0

Figure 2.7 Tank 241-AY-102 Waste Conductor Noding.

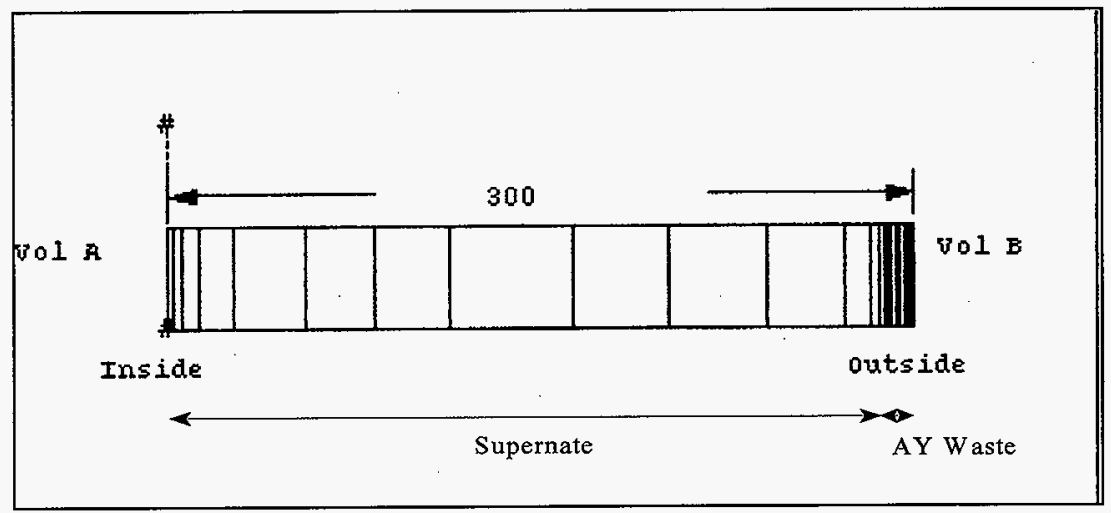


HNF-3196, Rev. 0

\subsection{TANK 241-C-106 BENCHMARK ANALYSES}

Section 3.0 and 4.0 provide a description of the benchmark analyses for the two process control models. The benchmarking is intended to provide the best possible thermal model to perform the process control analyses for both Tanks 241-C-106 and 241-AY-102. This activity is not intended to be a code validation or verification function. The selected computer code has been developed for the Electric Power Research Institute (EPRI) and has received extensive verification and validation. The GOTH and GOTHIC computer codes have further been validated against tank data (Sathya 1996) and have been used extensively for a wide range of tank applications. The tank data used for the benchmark analyses is limited and some of the data, such as ventilation flow rates, are uncertain. The purpose of the benchmark analyses is to provide the best simulation and comparison with the tank data. Uncertain or missing information will require reasonable assumptions to provide the necessary initial and boundary conditions to perform the benchmark analyses. The models were modified and improved as part of the benchmark activities to provide the best match with the available data. The range of the data used for the benchmark for both tanks is broad enough to provide a good test of the models.

\subsection{DESCRIPTION OF BENCHMARK CASES}

\subsubsection{Normal Operation for 1996 - 1998}

This section provides an overview of the Tank 241-C-106 data used to benchmark the GOTHIC thermal hydraulic model.

\subsubsection{Tank 241-C-106 Temperature Instrumentation}

Tank 241-C-106 is equipped with two thermocouple trees which provide temperature measurements through the waste and dome space. The riser plan view is shown in Figure 3.1. The thermocouple trees are located in Risers 8 and 14. Riser 14 is located about half-way between the tank center and the wall. Riser 8 is located near the wall. Each of the thermocouple trees is equipped with six or more thermocouples. They are spaced every two feet starting one foot from the tank bottom. The data from the thermocouple trees are recorded by the Tank Monitoring and Control System (TMACS). A daily temperature reading is maintained by the Surveillance Analysis Computer System (SACS). The data shown in this report was obtained from the SACS system.

\subsubsection{Temperature Data Overview}

Typical temperature data for Tank 241-C-106 are shown in Figures 3.2 and 3.3. The figures show the temperature data for thermocouples 1,3 and 6 . These represent the bottom waste, middle waste and dome space temperatures. The data for Riser 14 is shown in Figure 3.2. This data shows that the annual temperature variation in the tank has a period of one year. 
Superimposed on the annual cycle are shorter period oscillations. These are pronounced in the waste thermocouples \{Thermocouple 1 (TC1) and TC3)\}, and less pronounced in the dome space thermocouple data. These oscillations are the result of the periodic water additions. Notice that the peak annual temperatures for the waste are offset from the dome space temperatures. This is more clearly seen in the Riser 8 data shown in Figure 3.3. The waste temperature data is not significantly effected by the water additions. Note also that the maximum waste temperatures are higher than those at Riser 14, which is closer to the tank center and thus should have higher temperatures. The most likely explanation for the Riser 14 temperature oscillations and the depressed temperatures, is likely presence of a small gap around the tree which allows liquid convection to occur (Thurgood 1995). Local cooling from the convection depresses the waste temperatures. This small gap communicates with the supernatant pool and is effected by the water additions, resulting in the temperature osciliations shown in Figure 3.2. The same is true for Riser 8 but to a smaller degree. This is discussed in 2.1.1.

Only the waste temperature data for Riser 8 was used for this evaluation. The dome space temperatures from both trees were compared and agree very well. Riser 8 is near the wall of the tank and does not measure the maximum waste temperature which occurs at the tank center. However, the decay in the bottom waste temperature, seen in Figure 3.3, was used to verify the radionuclide decay for the tank.

\subsubsection{Inferred Thermal Parameters from Temperature Data}

The measured tank temperature data was used for the evaluation. Additional information can be inferred from the tank data. This includes the total heat capacity for the Tank 241-C-106 waste and the radionuclide decay rate. Both parameters are important for the present evaluation.

\section{- Waste Heat Capacity}

Figure 3.4 shows the bottom waste and dome space temperatures measured at the location of Riser 8 . Both data curves clearly show the annual variation in temperature. Figure 3.4 shows that the waste near the tank bottom does not reach seasonal maximum temperatures until approximately 45 days after the dome space reaches the seasonal maximum temperature. Lag time is a result of the heat capacity of the waste and supernatant. The best estimate waste heat capacity can be verified by comparing offset, predicted by the GOTHIC model, to the tank temperature data. The best estimate value for the waste specific heat is $0.5 \mathrm{Btu} / \mathrm{lbm}-{ }^{-} \mathrm{F}$. This is based upon an assumed particle specific heat of $0.2 \mathrm{Btu} / \mathrm{lbm}-{ }^{\circ} \mathrm{F}$, a liquid value of $0.8 \mathrm{Btu} / \mathrm{lbm}-{ }^{\circ} \mathrm{F}$ and a particle weight fraction of $50 \%$. 
HNF-3196, Rev. 0

\section{- Radionuclide Decay}

Riser 8 temperature data for thermocouples 1 and 6 is shown in Figure 3.5. The data for TC1 clearly shows the effects of radionuclide decay. Most of the heat for Tank $241-\mathrm{C}-106$ comes from ${ }^{137} \mathrm{Cs}$ and ${ }^{90} \mathrm{Sr}$. These isotopes have half-lives of 30 and 27.7 years respectively. The GOTHIC model uses an average value of 28 years. A best fit exponential curve is shown in Figure 3.5. The half-life derived from the exponential time constant is 28.6 years, which is consistent with the ${ }^{137} \mathrm{Cs}$ and ${ }^{90} \mathrm{Sr}$ half- lives. Thus, the data shows that the bottom waste temperature decays at the radionuclide decay rate.

Figure 3.5 also shows the dome space temperature. While there is some temperature decay, the rate of decay is small. This is an indication of the dynamics between sensible and evaporative heat removal. Just as the ratio of heat removal between sensible and evaporative changes seasonally, it changes slowly as the power decays, keeping the dome temperature near constant.

\subsubsection{Water Addition Data}

Tank 241-C-106 is cooled through convective and evaporative cooling. The record of water additions provides excellent data for evaluating the evaporation rate from the tank. These data are very useful for benchmarking the GOTHIC model. Figure 3.6 shows the record of water additions from January of 1994 to January of 1997. The data after January 1994 was used for this evaluation. The large water addition in July of 1994 was made following the completion of the process test for Tank 241-C-106. There had been no water additions for the previous four months. 
HNF-3196, Rev. 0

Figure 3.1 Tank 241-C-106 Riser Plan View.

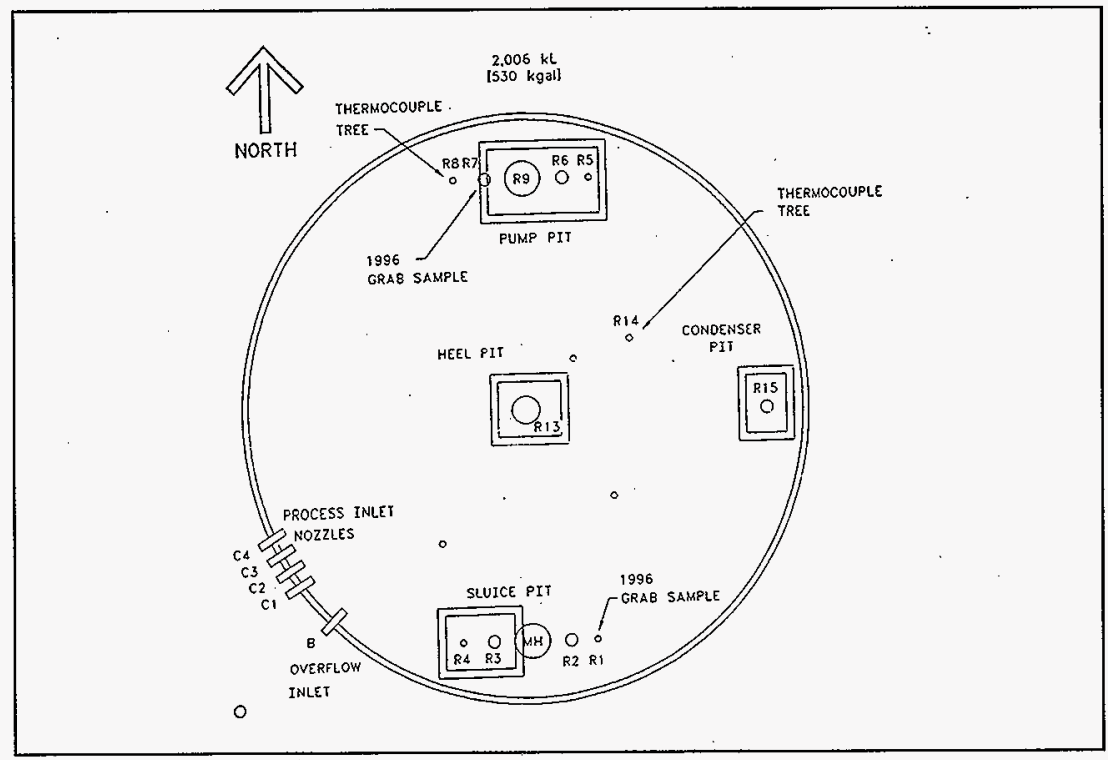


HNF-3196, Rev. 0

Figure 3.2 Riser 14 Dome and Waste Temperatures.

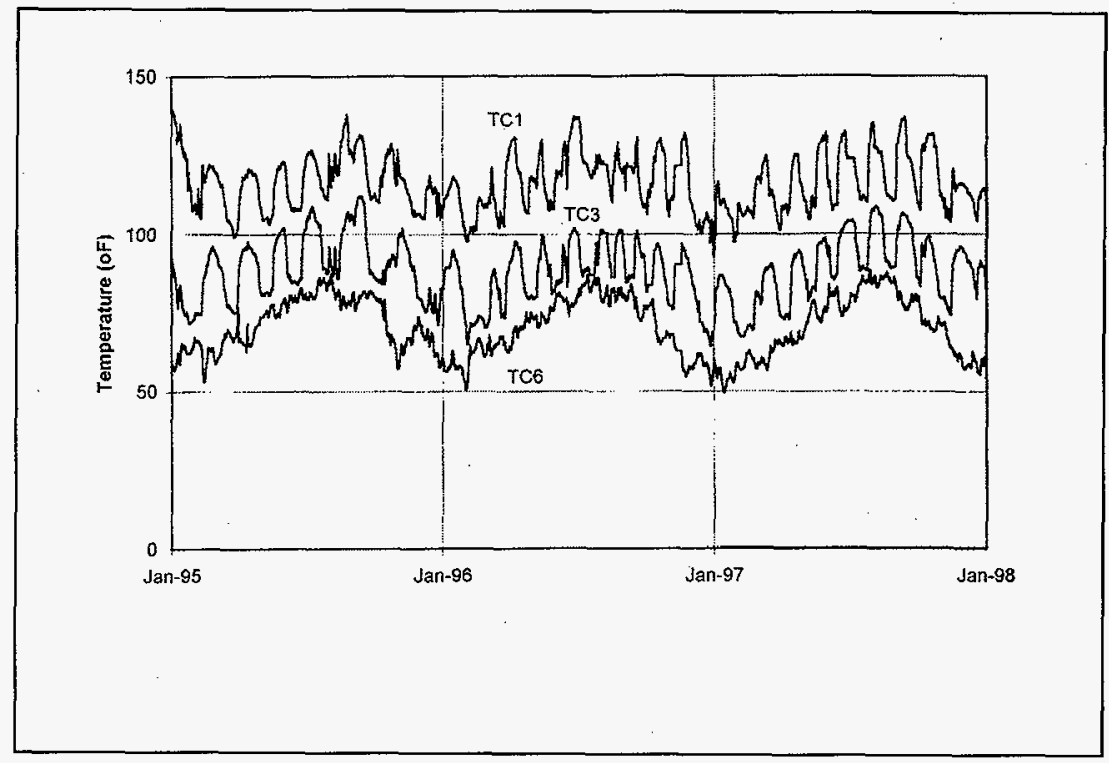


HNF-3196, Rev. 0

Figure 3.3 Riser 8 Dome and Waste Temperatures.

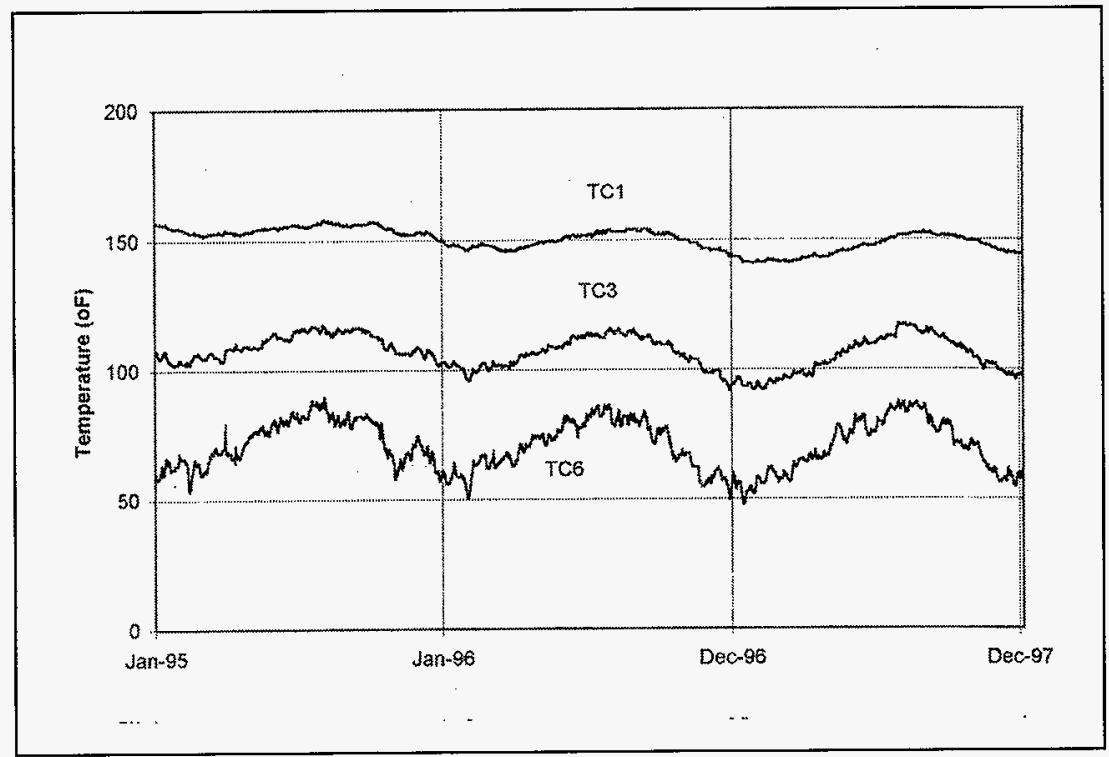


HNF-3196, Rev. 0

Figure 3.4 Riser 8 Dome and Bottom Waste Temperatures.

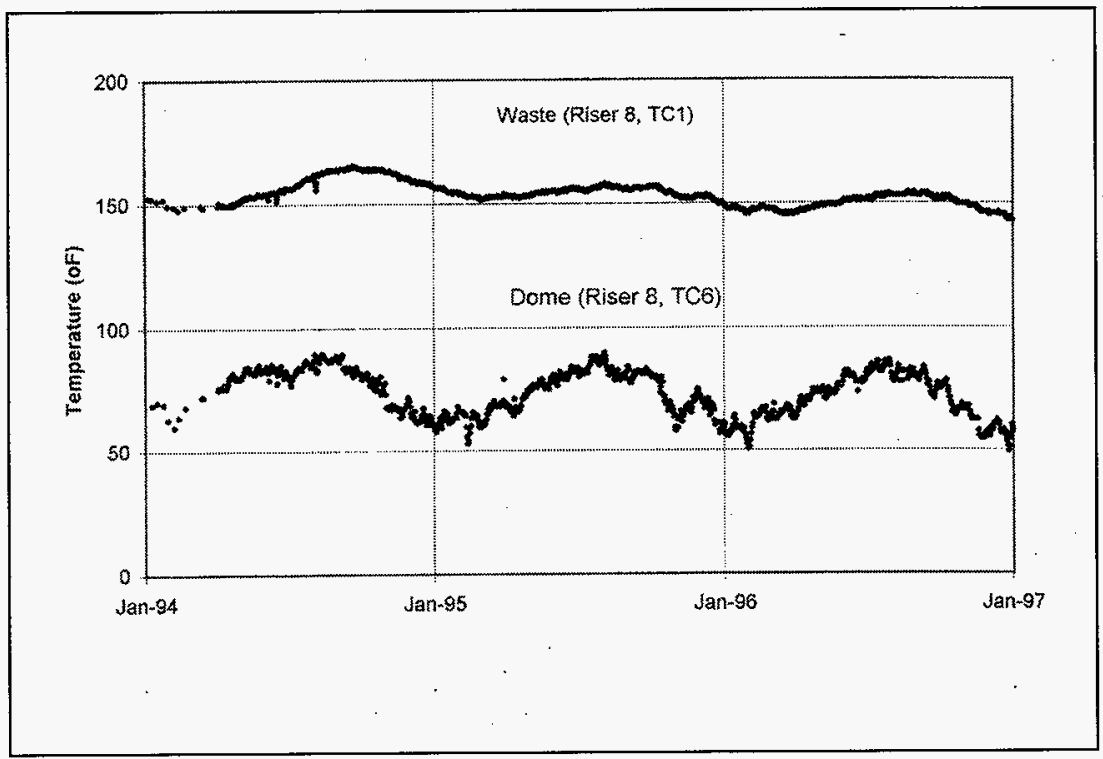


HNF-3196, Rev. 0

Figure 3.5 Exponential Curve Fit to Riser 8 Maximum Waste Temperature.

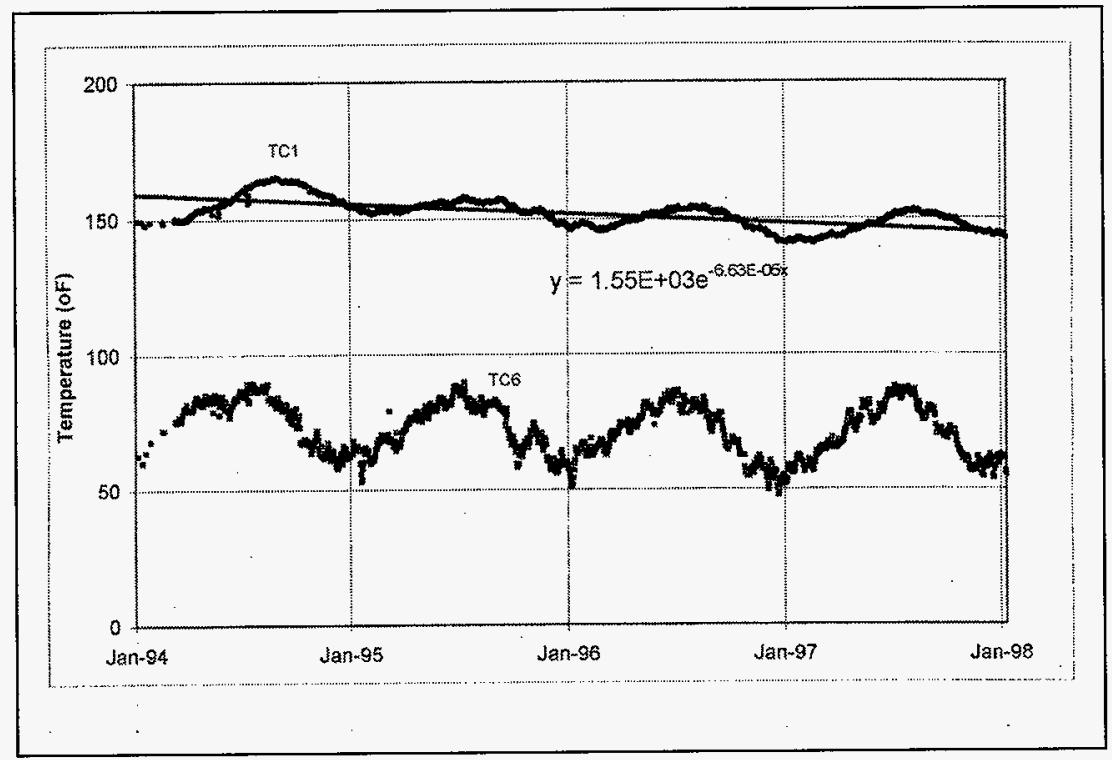


HNF-3196, Rev. 0

Figure 3.6 Water Addition Data for Tank 241-C-106.

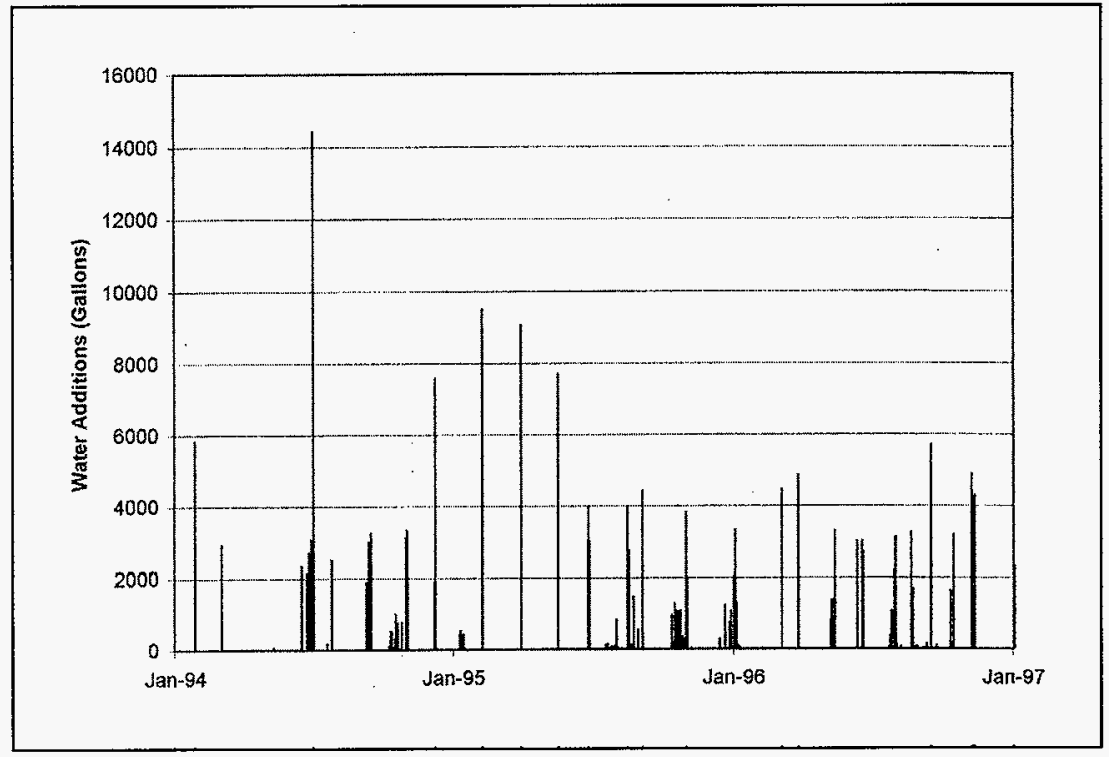


HNF-3196, Rev. 0

\subsubsection{Closed form Conduction Problem}

The quasi-steady state axial temperature profile for Tank 241-C-106 is parabolic. The temperature difference between the waste surface temperature and any point in the waste can be approximated by (Welty 1974):

$$
T(x)-T_{\text {sufface }}=\frac{q\left(\dot{L}^{2}-x^{2}\right)}{2 K}
$$

where :

$$
\begin{array}{ll}
\mathrm{T}(\mathrm{x}) & =\text { Waste temperature at vertical elevation } \mathrm{x} . \\
\mathrm{T}_{\text {surface }} & =\text { Waste surface temperature. } \\
\mathrm{q} & =\text { Volumetric heat generation rate. } \\
\mathrm{L} & =\text { Waste depth. } \\
\mathrm{x} & =\text { Vertical elevation measured from bottom of waste. } \\
\mathrm{K} & =\text { Waste thermal conductivity. }
\end{array}
$$

with boundary conditions:

and

$$
\mathrm{T}_{\text {surface }} \text { at the top of the slab }(\mathrm{x}=\mathrm{L}) \text {. }
$$

$\mathrm{dT} / \mathrm{dx}=0$ at the bottom of the slab ( $\mathrm{x}=0$, adiabatic).

The bottom boundary condition is approximated by an adiabatic boundary. In reality there is a small heat flux.

After each increment of sluicing, the new waste surface will be subjected to a step decrease in surface temperature. The initial temperature profile and the new profile immediately following an increment of sluicing, is shown in Figure 3.7. The new waste surface is subjected to a step change in temperature. The waste will immediately begin rejecting energy to establish a new quasi-steady state temperature with a reduced conduction length, resulting from the increment of sluicing. The GOTHIC model must account for the rejected heat during this transient to perform an energy balance for the tank and determine the remaining heat load in the tank.

A closed form solution can be obtained for a semi-infinite slab, with one adiabatic boundary and a step change in temperature at the second boundary (Carslaw and Jaeger 1959). The solution for a 5.75 foot (69 inches) slab with thermal properties representative of Tank 241C-106, was reported in Ogden/Sathya 1998a. The solution for a one foot incremental change in conduction length (resulting from sluicing) is shown in Figure 3.8. The transient behavior of the 
HNF-3196, Rev. 0

slab is represented by the temperature profiles from seven days to one year after the step change in conduction length. The process control thermal model for Tank $241-\mathrm{C}-106$ will be benchmarked against this closed form solution.

The GOTHIC model for the closed form conduction problem is a single 1-D conductor with one adiabatic boundary and the second boundary at $90^{\circ} \mathrm{F}$. The thermal parameters are those used for the analyses reported in Ogden/Sathya 1998a. They are consistent with the best estimate parameters summarized in Table 2.1 with the exception of the heat load. The heat load for the slab is $110,000 \mathrm{Btu} / \mathrm{hr}$. This is sufficiently close to the best estimate parameters for the purpose of the benchmark analyses.

\subsection{RESULTS OF 241-C-106 BENCHMARK ANALYSES}

\subsubsection{Normal Operation}

The GOTHIC model was benchmarked with tank data discussed in Section 3.1.1. Tank data for calender years 1994 through 1997 were used for the benchmarking. Figure 3.9 shows a comparison of temperatures predicted ${ }^{2}$ by the GOTHIC model with the Riser 8 temperature data. The figure shows the Riser 8 Thermocouple 1 data, which is the temperature near the tank wall at the bottom of the tank, and the tank dome space temperature. However, the rate of temperature decay can be compared. The model correctly predicts that the bottom waste temperature decay is very close to the actual radionuclide decay with a 28 year half-life seen in the data. There is nearly a $20^{\circ} \mathrm{F}$ drop in temperature from 1994 to 1997.

The temperature predictions with the Tank 241-C-106 process control thermal model agrees with the riser 8 data. As discussed in section 3.1.1.3, the dome space temperature does not decay at the same rate as the radionuclides. This is correctly predicted by the GOTHIC model.

Figure 3.10 shows the GOTHIC and tank temperature for the waste and dome space for calender years 1995 and 1996. The delay in waste peak temperatures can clearly be seen at this scale. An approximate 45 day delay for the peak waste temperature (Section 3.1.1.3) was predicted with the GOTHIC model using the combined waste specific heat of $0.5 \mathrm{Btu} / \mathrm{lbm}-{ }^{\circ} \mathrm{F}$. The dynamics of the seasonal variation of waste temperatures are well modeled with the GOTHIC model.

The evaporation rate for the GOTHIC model and tank data can also be compared. Figure 3.11 shows a comparison of the accumulative water addition data derived from the record of

${ }^{2}$ GOTHIC analysis file name c6bench. 
HNF-3196, Rev. 0

water additions shown in Figure 3.6. These data are compared with the accumulative evaporation predicted by the GOTHIC model. There is close agreement with the tank data.

Figure 3.12 shows the temperature distribution for the Riser 8 thermocouple tree. This temperature distribution was in early September for 1996, near the time of maximum waste temperature. The simple model of the Riser 8 thermocouple tree predicts the axial temperature quite well.

\subsubsection{Closed form Conduction Solution}

GOTHIC analyses ${ }^{3}$ were performed to compare with the closed form conduction solution, for a slab with a step change in boundary conditions as discussed in Section 3.1.2. The results of the GOTHIC analyses is shown in Figure 3.13. The sluicing is simulated by reducing the conduction length by one foot while maintain the same boundary temperature as shown in Figure 3.13. One day after the simulated sluicing, the temperature two feet down from the new waste surface is still at the initial temperature. This agrees well with the closed form solution shown in Figure 3.8. After seven days the bottom waste temperature has just begun to decrease. At 21 days the bottom waste temperature is $210^{\circ} \mathrm{F}$, which agrees with the closed form solution. After one year the bottom waste temperature has decreased to $180^{\circ} \mathrm{F}$ which again agrees with the closed form solution. The GOTHIC conductor model reproduces the results of the closed form solution very well.

The results of the normal operation benchmark (Section 3.2.1) and the step boundary temperature change benchmark, demonstrates the applicability of the GOTHIC process control model, for Tank 241-C-106. The GOTHIC process control model can simulate the important thermal hydraulic phenomenon prior to, during and following the sluicing of Tank 241-C-106. The model can provide a good prediction of the maximum waste temperature and remaining tank heat load.

${ }^{3}$ GOTHIC analysis file name benchmark. 
HNF-3196, Rev. 0

Figure 3.7 Waste Temperature Profile After Incremental Sluicing.

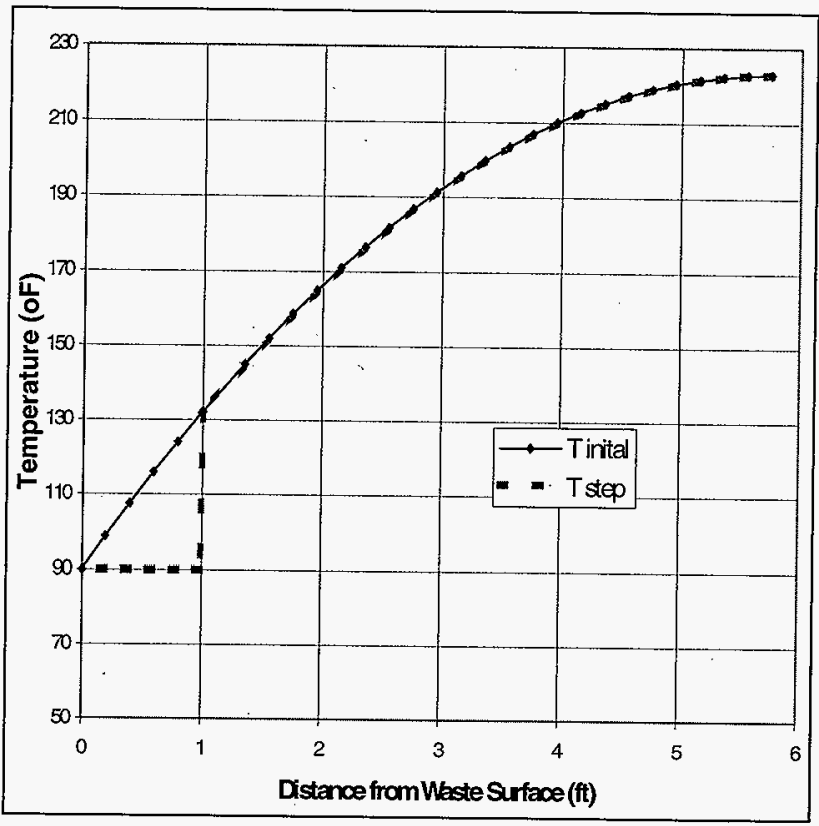


HNF-3196, Rev. 0

Figure 3.8 Closed Form Conduction Solution for Incremental Sluicing.

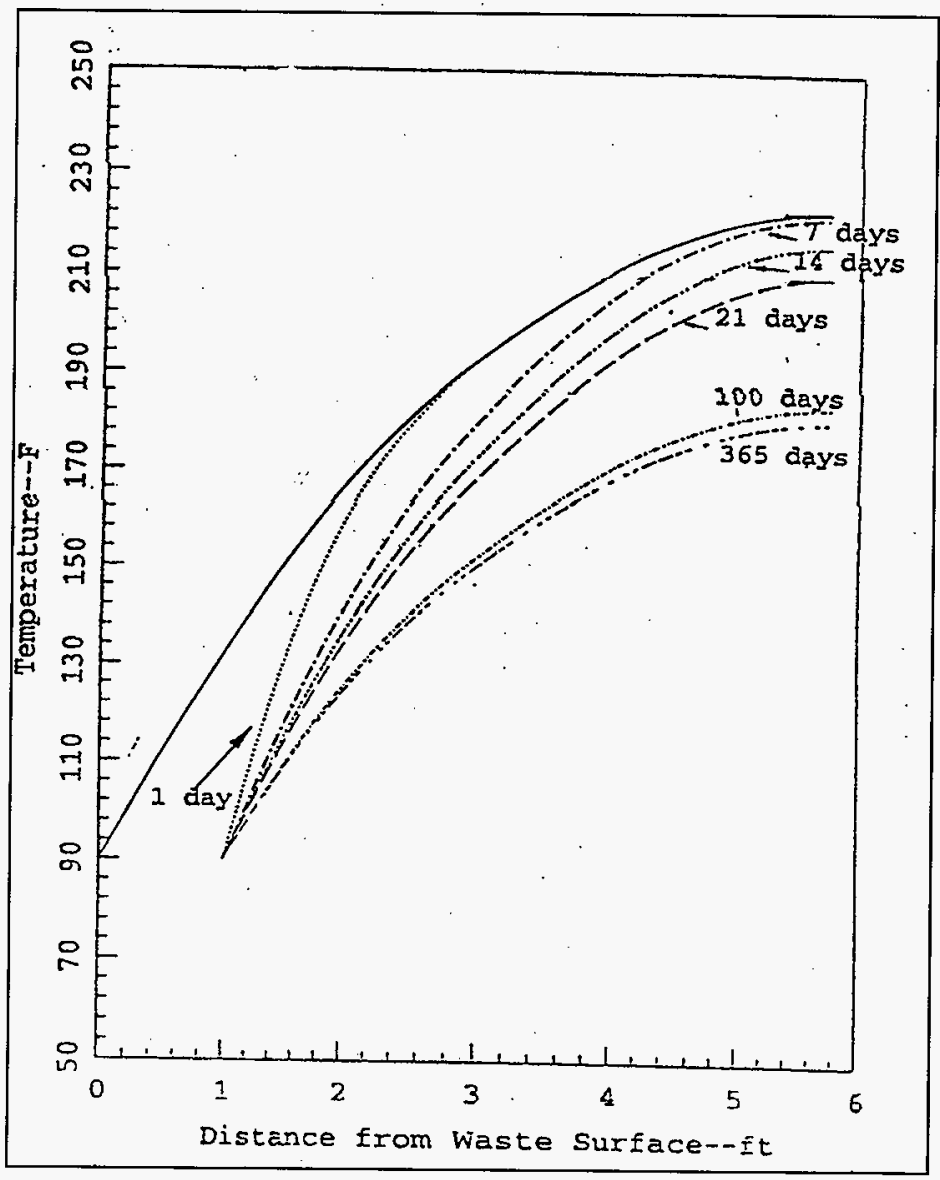


HNF-3196, Rev. 0

Figure 3.9 Comparison of GOTHIC Analyses With Dome Space and Riser 8 Data.

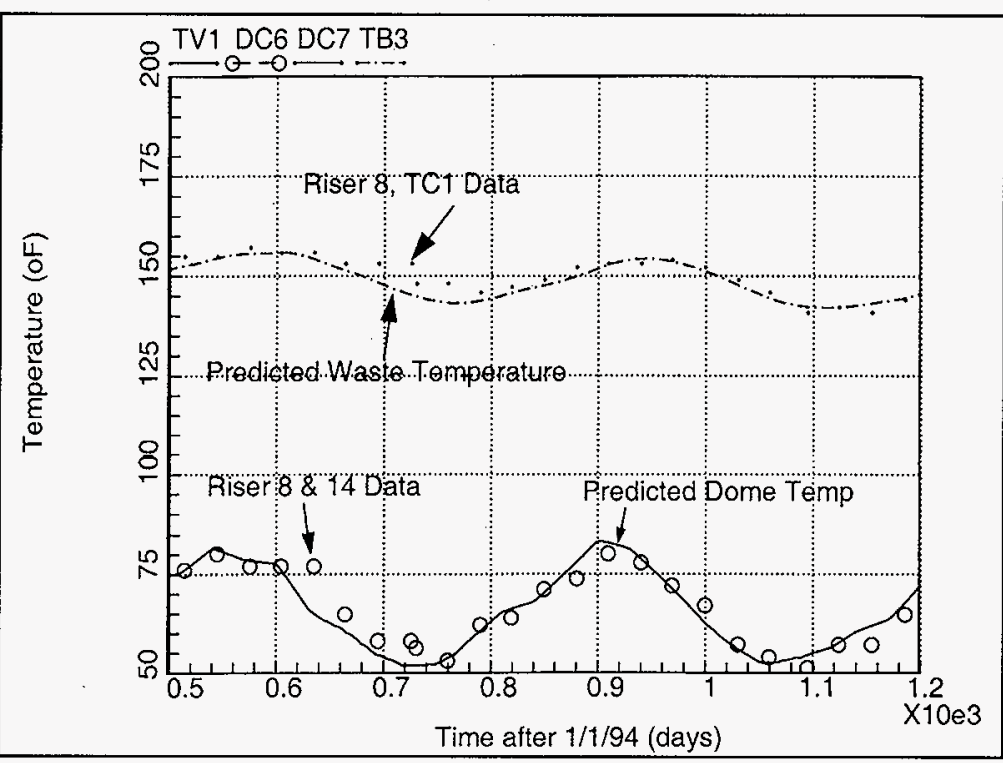


HNF-3196, Rev. 0

Figure 3.10 Comparison of Waste Heat Capacity.

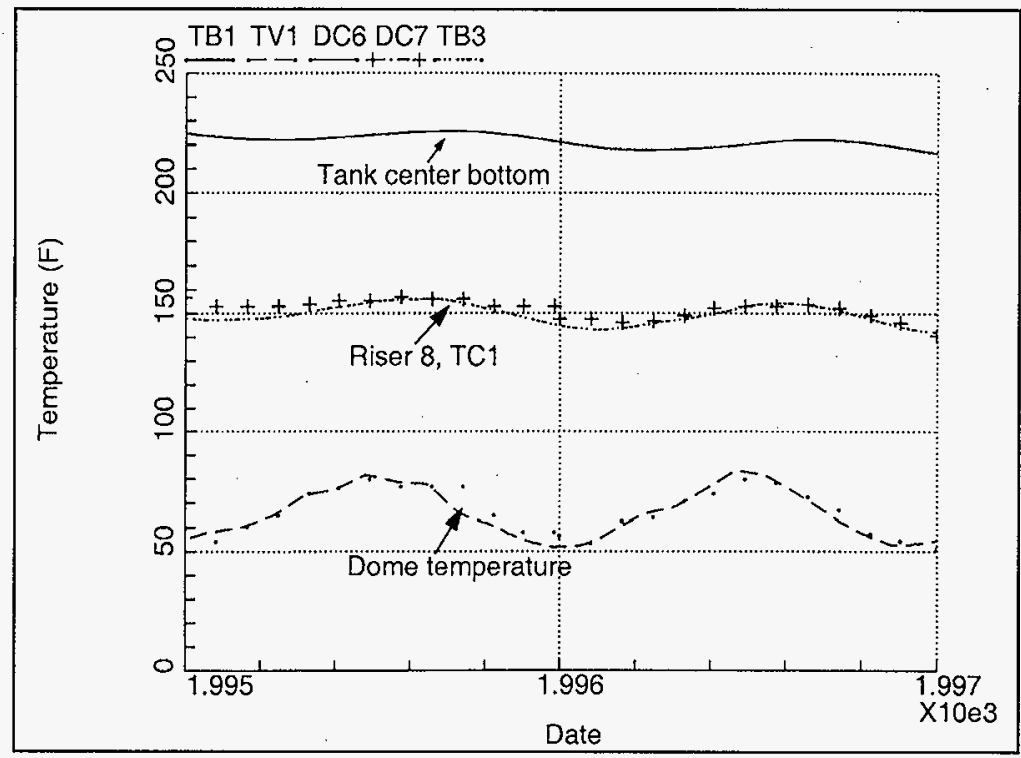


HNF-3196, Rev. 0

Figure 3.11 Comparison of Accumulative Evaporation Rates.

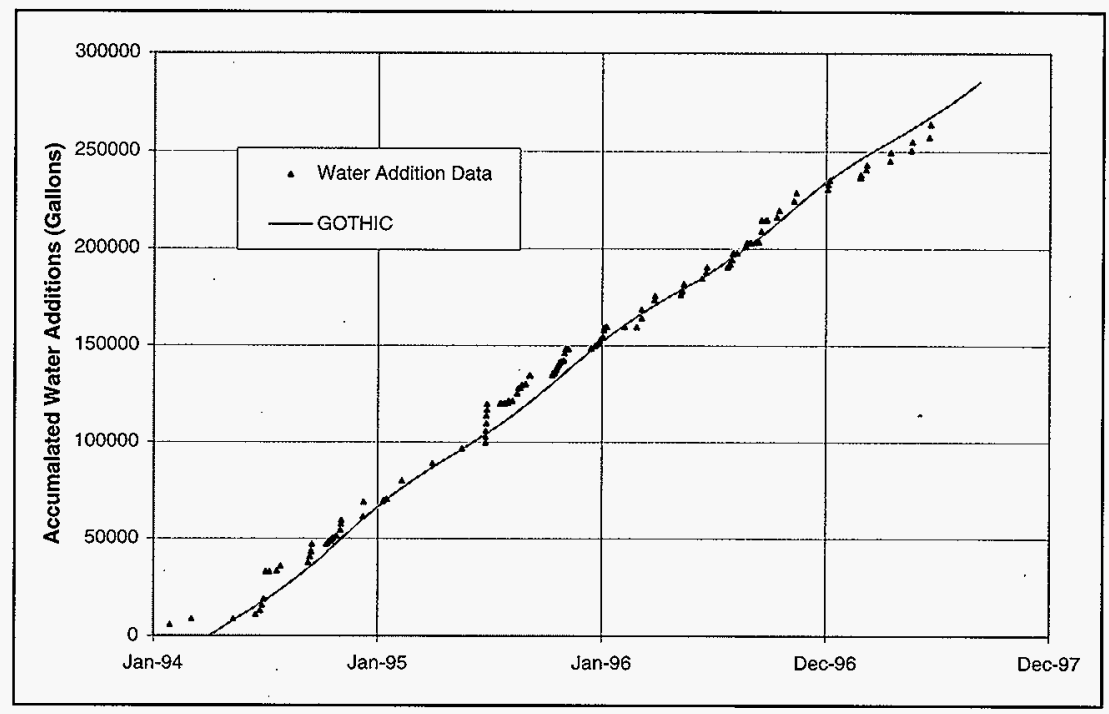


HNF-3196, Rev. 0

Figure 3.12. Comparison With Riser 8 Temperature Distribution.

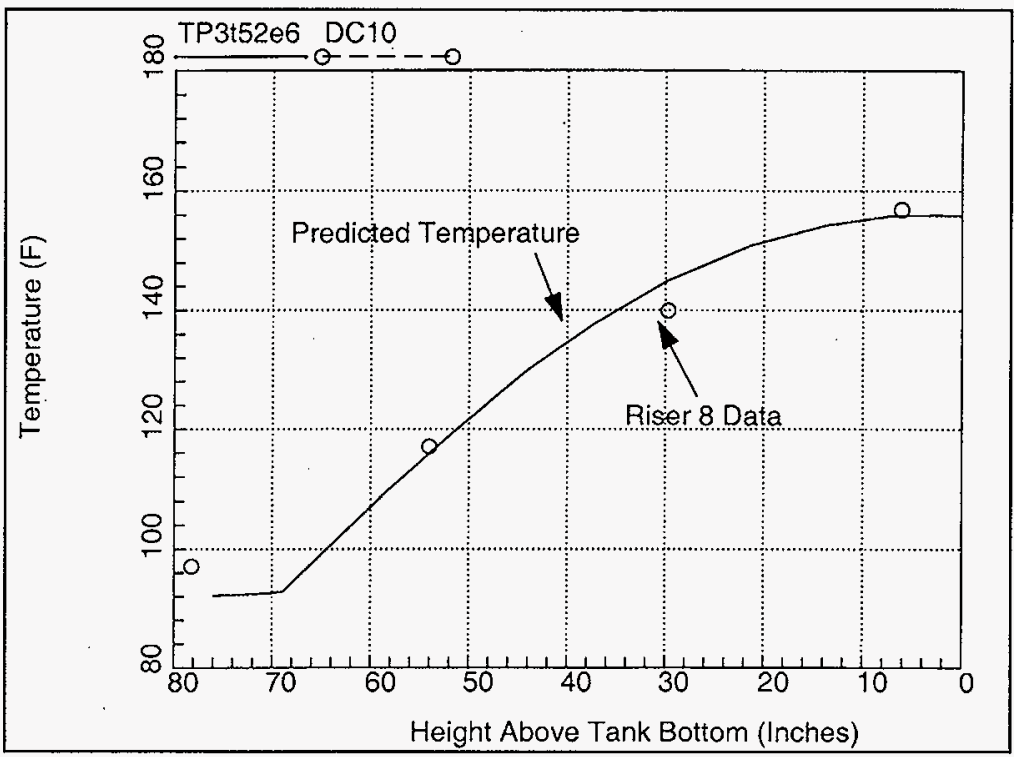


HNF-3196, Rev. 0

Figure 3.13 GOTHIC Solution for Closed Form Conduction Problem.

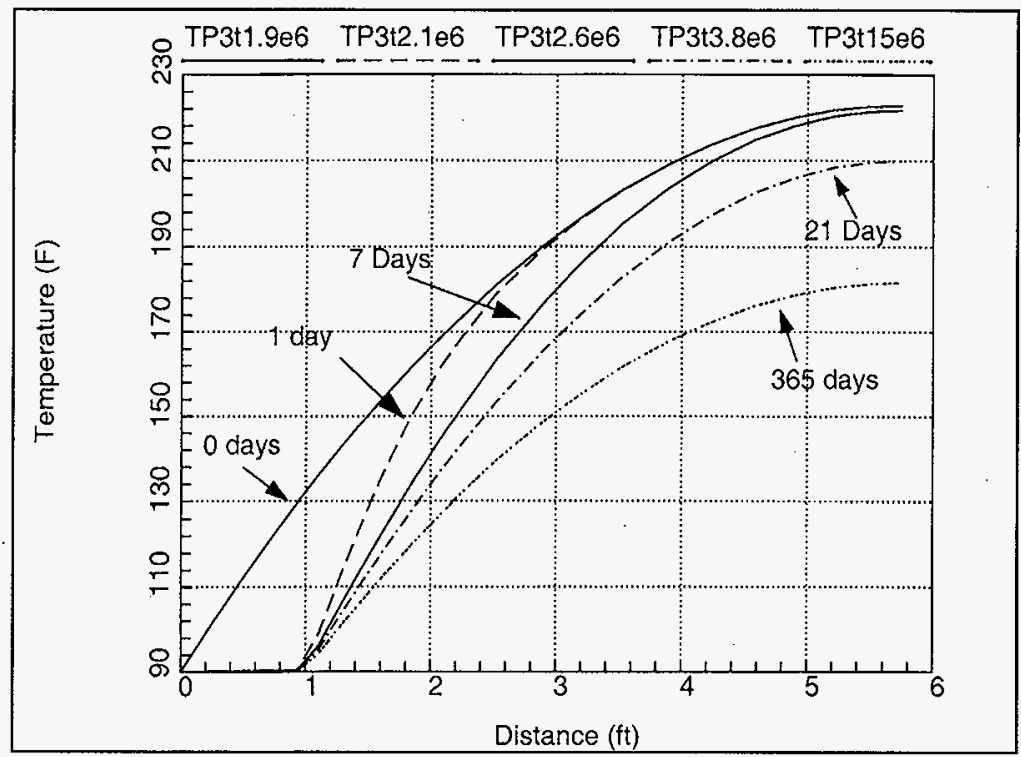


HNF-3196, Rev. 0

\subsection{TANK 241-AY-102 BENCHMARK ANALYSES}

\subsection{DESCRIPTION OF BENCHMARK CASES}

Figure 4.1 shows the set of temperature data which will be used for the benchmark of the 241-AY-102 process control model, discussed in Section 2.1.2. These data were obtained from a more complete set of data presented in Section 7.0. Suspect data was omitted. Figure 4.1 shows representative insulating concrete temperatures at the 7 foot and 21 foot radial locations. The 21 $\mathrm{ft}$ and $7 \mathrm{ft}$ temperatures are the same during periods of no annulus ventilation system operation. The thermocouple locations can be seen in Figure 2.5. Figures 7.2 and 7.3 show a more complete set of data for these radial locations. There is 10 to $12{ }^{\circ} \mathrm{F}$ variation is temperatures at the seven foot location and up to a $20^{\circ} \mathrm{F}$ spread at the 21 foot location. The process control model does not model the azimuthal temperature variation. For the purpose of the model benchmarking, the two thermocouples with the highest temperatures were averaged to give the curves shown in Figure 4.1.

Figure 7.4 shows the measured insulating concrete temperatures at the 37 foot radial location. Comparison with Figures 7.2 and 7.3 show that these temperatures are lower than the other radial locations. This is probably due to conduction through the steel liner to the supernate pool and heat loss to the soil. This data will not be used for the benchmark analyses since the process control model does not attempt to model this minor effect.

The measured supernate temperatures are shown in Figure 7.5. Because of natural convection in the pool, the temperatures are essentially the same with the exception of February to May of 1995. Figure 4.2 shows the measured level of the supernate in Tank 241-AY-102. During February to May time period the supernate level was reduced to well below the 300 inch level. Thus, the thermocouples at the 300 inch level were not in the supernate and were reading dome space temperatures.

The measured sludge temperatures are shown in Figure 7.6. The thermocouples are approximately three to four inches off the bottom of the tank. The highest temperature reading was used for the purpose of the benchmark analyses.

Figure 4.1 indicates three separate periods used for the benchmark of the 241-AY-102 process control model. The first period is normal tank operation with only the primary ventilation system (241-A-702) operating. This provides a good benchmark of the energy removal from the tank through evaporation and sensible heat removal. Period 2 includes operation of the annulus ventilation system at low flow. This is seen in Figure 4.1 by the sharp decrease in the insulating concrete temperatures at the seven foot radial location in February of 1997. This period provides a benchmark of both the primary and annulus system heat removal 
HNF-3196, Rev. 0

from the tank for an extended period of time and the transient temperature response when the annulus system operation is initiated or terminated. Period 3 , includes operation of the annulus ventilation system at high flow rates. This is evidenced in Figure 4.1 by the large decrease in insulating concrete temperature at both 7 and 21 feet radial locations. The period of operation is short, but the concrete and waste temperature effects are great.

Data for the 3 period of operation are discussed in the following sections.

\subsubsection{Normal Operation with Primary Ventilation}

During the first period of operation identified in Figure 4.1, only the primary ventilation system was operating. Flow measurements for the primary system flow in Tank 241-AY-102 were not measured. However, the total primary system ventilation for the Aging Waste Facilities (AWF), AY and AZ tanks, was measured. Quarterly stack flow measurements are obtained for the purposes of air quality monitoring (Crummel 1998). These measurements are summarized in Table 4.1. There are four tanks connected to the AWF primary ventilation system. It will be assumed that the flow split between the tanks is equal so that the flow used for the 241-AY-102 benchmark is $25 \%$ of the measured stack flow, as shown in Table 4.1 . The flow measurements are assumed to be constant for the quarter prior to the measurement.

Table 4.1 Primary Ventilation System Flow

\begin{tabular}{|c|c|c|}
\hline & $\begin{array}{c}\text { Measured } \\
\text { Stack Flow } \\
\text { (cfm) }\end{array}$ & $\begin{array}{c}25 \% \\
\text { Stack Flow } \\
\text { (cfm) }\end{array}$ \\
\hline Feb 1996 & 2815 & 704 \\
\hline May 1996 & 2888 & 722 \\
\hline July 1996 & 2717 & 679 \\
\hline Oct 1996 & 3086 & 772 \\
\hline Feb 1997 & 3295 & 824 \\
\hline May 1997 & 2867 & 717 \\
\hline Aug 1997 & 2753 & 688 \\
\hline Nov 1997 & 2777 & 694 \\
\hline Feb 1998 & 2724 & 681 \\
\hline & Average & 720 \\
\hline
\end{tabular}

The operating supernate level for Period 1 was assumed to be 300 inches which is shown in Figure 4.2. Other parameters discussed in Section 2.1.3 describing the best estimate thermal parameters included a settled waste level of one foot with a heat load of $41,200 \mathrm{Btu} / \mathrm{hr}$. Ambient temperature and relative humidity data was obtained from the Hanford Weather Station. 
HNF-3196, Rev. 0

Monthly average data was used as summarized in Figure 4.3.

Figure 4.4 shows the Tank 241-AY-102 temperature data for Period 1. Also shown in the figure is the ambient temperature. The sinusoidal variation in the temperature data is due the annual variation is ambient temperatures and humidity. The ambient air temperatures increase followed by the supernate, sludge and insulating concrete temperatures. There is roughly a 2.5 month lag time in the tank heat-up. This is due to the large thermal mass of the supernate pool.

\subsubsection{Normal Operation with Primary and Low Annulus System Flow}

The second period of operation used for the benchmarking of the process control thermal model is shown in Figure 4.1. In February of 1996, the annulus ventilation system operation was initiated. The wall annulus piping was not blocked at this time, resulting in a relatively low flow to the floor of the tank. The annulus system pressure (vacuum) for this period of operation is shown in Figure 4.5. This data was obtained from operations data sheets (TF-OR-ER-AYAZ-D, Rev C-8, Page 5). The system initially operated at a -1.45 inches Water Gauge pressure (vacuum). The annulus ventilation system was turned off in May of 1997 for a short period and then the operation was initiated at approximately half the initial flow. Figure 4.4 also shows the estimated floor flow rate for the given annulus pressures. The flow estimates were obtained from previous flow measurements performed for Tank 241-AY-102 (Powell 1989). A flow floor of $210 \mathrm{cfm}$ was measured for an annulus pressure of $1.14 \mathrm{Inch}$ W.G and $180 \mathrm{cfm}$ for a pressure of 0.51 Inch W.G. This data waste extrapolated to give a flow of $225 \mathrm{cfm}$ at $-1.45 \mathrm{Inch}$ W.G. The annulus flow is shown in Figure 4.5.

The tank temperature data for Period 2 is shown in Figure 4.6. The insulating concrete temperatures at the seven foot radial location decrease sharply after the initiation of the flow. The concrete temperatures at the 21 foot radial location are much less effected. At the low ventilation flows shown in Figure 4.5, the ventilation air is heated quickly to near the floor temperature. Thus, the effect is significant near the center of the tank, but cooling is much less effective at larger radial distances. As seen in Figures 4.5 and 4.6, the annulus ventilation system is not operating for part of May of 1997. This is clearly seen in the seven foot radial temperatures. The ambient temperature reach a maximum in August of 1997. Tank temperatures continue to rise for several months. When the annulus system flow is terminated in November of 1997, the concrete temperatures at the seven foot radial locations increase quickly to the temperatures at the 21 foot radial location, which were not significantly effected by the low ventilation flow. 


\section{HNF-3196, Rev. 0}

\subsubsection{Normal Operation with Primary and High Annulus System Flow}

The last period of operation used for the benchmark evaluation, is shown in Figure 4.1. Period 3 includes operation of the annulus ventilation system at high vacuum and flow. The pressure (vacuum) and flow are constant during the operation of the system at high flows. The pressure was measured at 15.5 Inch W.G. vacuum with a corresponding flow rate estimated to be $1300 \mathrm{cfm}$. The wall annulus piping has been blocked and all the ventilation flow is directed to the tank bottom for cooling. The concrete temperatures for the 7 and 21 foot radial locations are shown in Figure 4.7. The annulus ventilation system is operating for less than one month. The supernate temperature does not respond to this short of a thermal transient. At this higher annulus flow rate the concrete temperatures at the 21 foot radius are clearly reduced. This data provides a good benchmark for the short term transient response to the operation of the annulus ventilation system at high flows and vacuums. 
HNF-3196, Rev. 0

Figure 4.1 Tank 241-AY-102 Temperature Data for Benchmark Analyses.

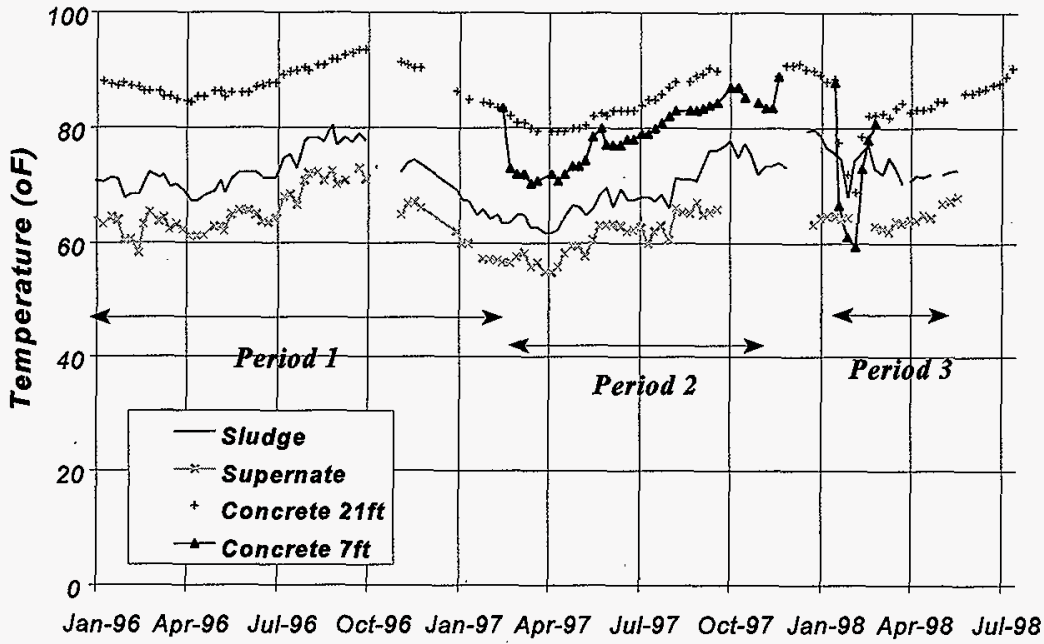


HNF-3196, Rev. 0

Figure 4.2 Tank 241-AY-102 Operating Level of Supernate Pool.

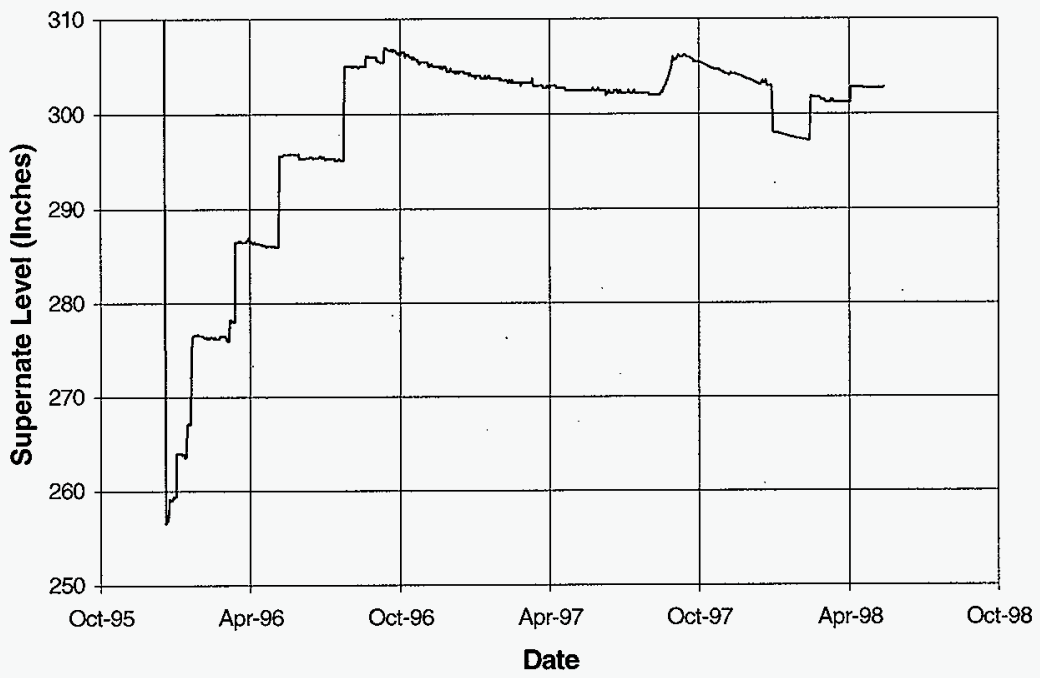


HNF-3196, Rev. 0

Figure 4.3 Meteorological Data for Benchmark Analyses.

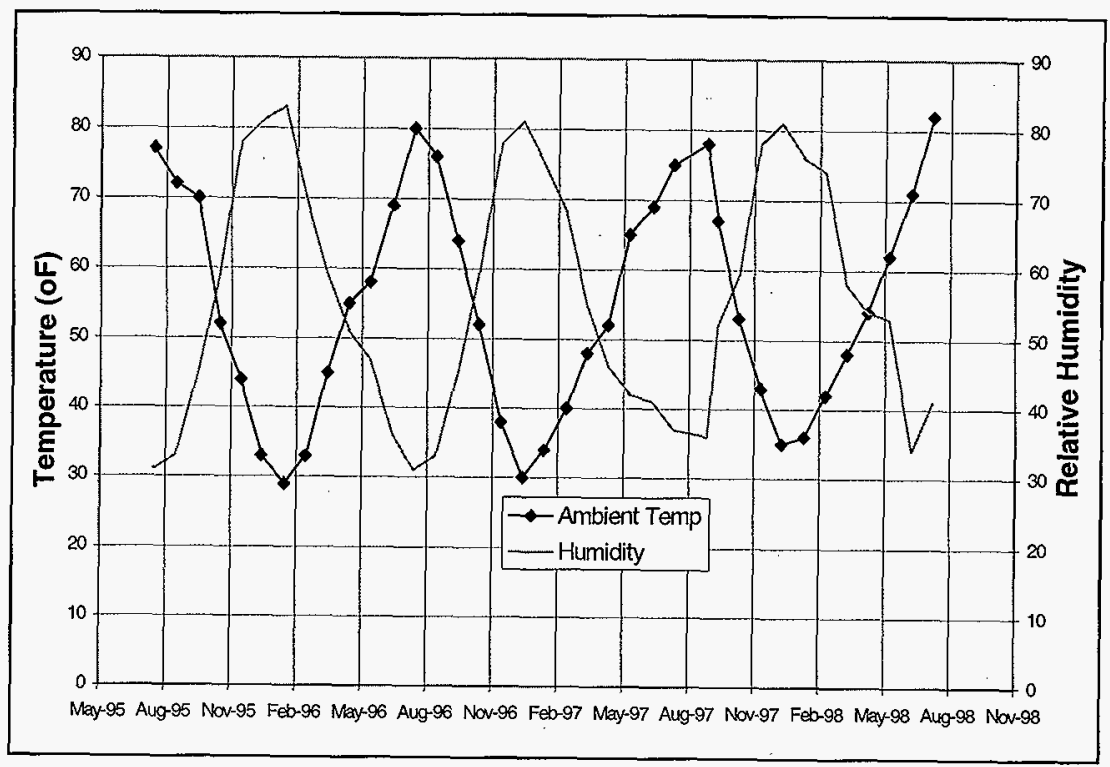


HNF-3196, Rev. 0

Figure 4.4 Tank 241-AY-102 Temperature Data for Period 1.

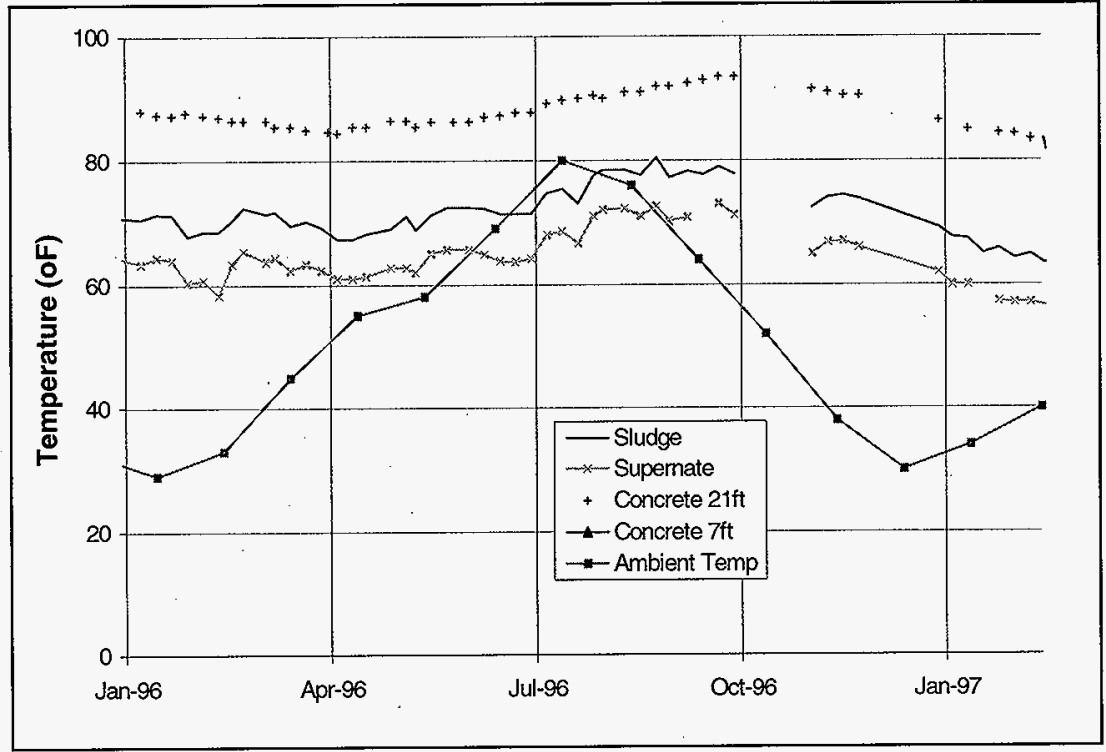


HNF-3196, Rev. 0

Figure 4.5 Annulus System Flow and Pressure for 1997.

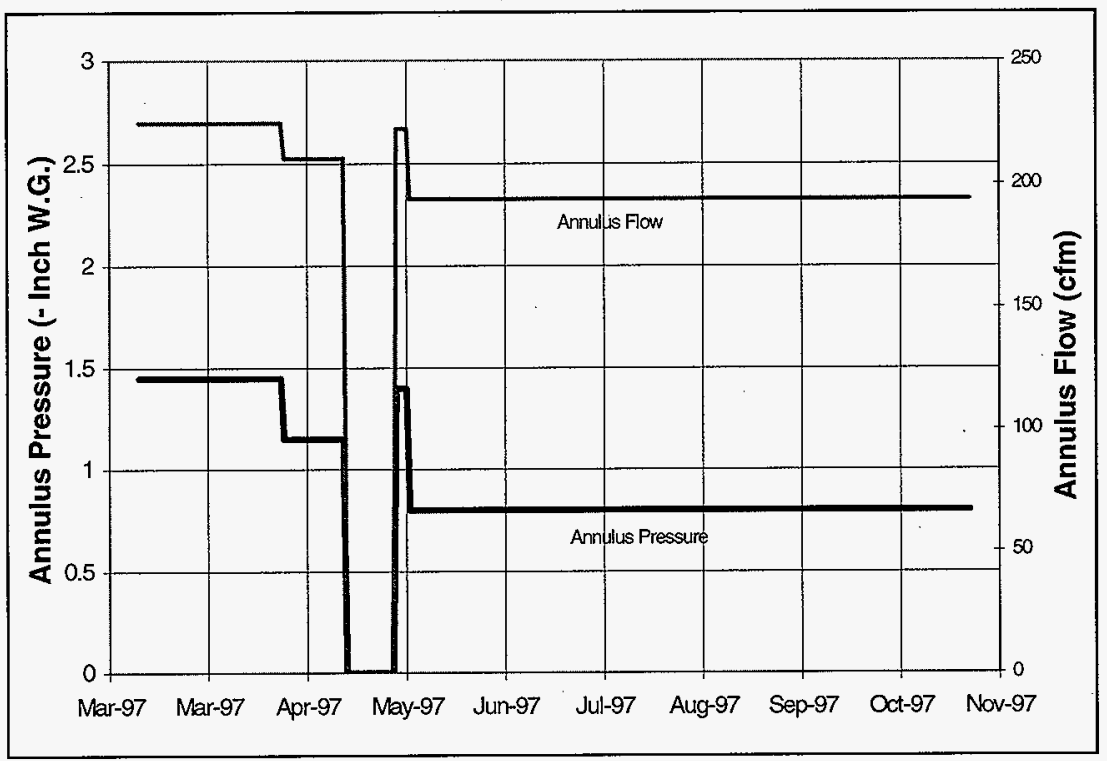


HNF-3196, Rev. 0

Figure 4.6 Tank 241-AY-102 Temperature Data for Period 2.

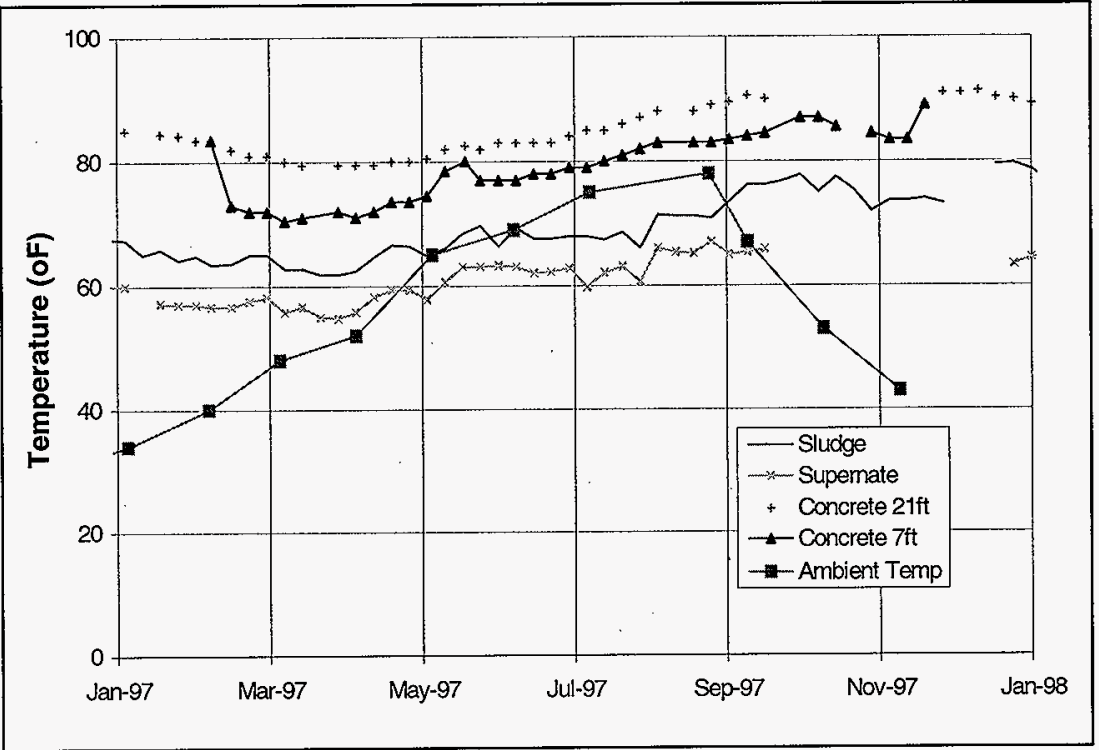


HNF-3196, Rev. 0

Figure 4.7 Tank 241-AY-102 Temperature Data for Period 3.

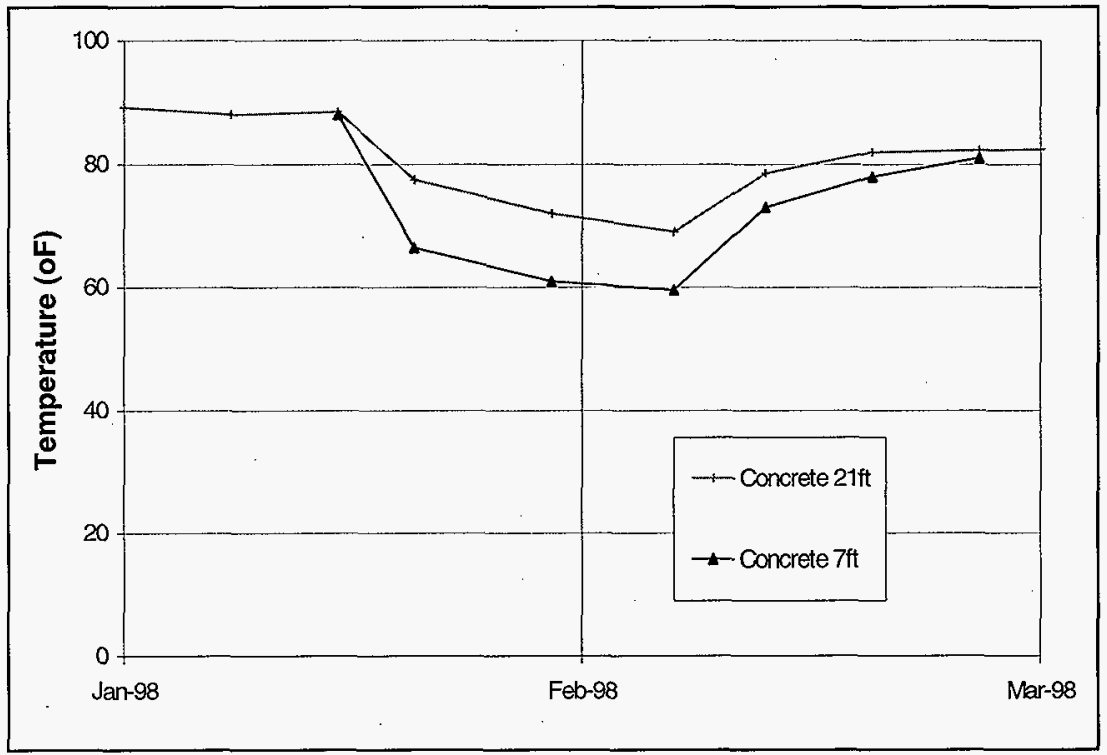


HNF-3196, Rev. 0

\subsection{RESULTS OF 241-AY-102 BENCHMARK ANALYSES}

\subsubsection{Benchmark for Normal Operation With Primary Ventilation}

The GOTHIC process control thermal model was used to evaluate the thermal behavior of Tank 241-AY-102, during the first period of operation. This provides a benchmark of the primary system energy removal for a complete annual cycle of meteorological data. Figure 4.8 compares the insulating concrete temperatures with the GOTHIC predicted temperatures. Since the annulus system is not on, the temperatures for the 7 and 21 foot radial positions are the same (there is not a noticeable radial temperature gradient with only 1 foot of waste and a 75 foot diameter tank). The model was initialized with a period of constant temperature for 10 million seconds. The predicted concrete temperature then followed the annual temperature cycle. The January 1,1996 date corresponds to 0 days on the graph. The predicted concrete temperatures closely match the data.

A comparison of supernate temperatures is shown in Figure 4.9. The prediction by the process control model, follows the annual ambient temperature cycle but is on the high side of the data. Parametric calculations have shown that the pool temperature to be sensitive to the primary ventilation flow rate. Sensitivity analyses were performed at an initial flow of $800 \mathrm{~cm}$, which is higher than the assumed value of $704 \mathrm{cfm}$, shown in Table 4.1. The actual flow split between the AY and AZ farm tanks is not known. A value of $800 \mathrm{cfm}$ or higher, is not unreasonable given the measured stack flow shown in Table 4.1. The increased flow decreased the supernate temperature, providing a better comparison with the data.

The predicted evaporation rate is shown in Figure 4.10. This rate varies annually from a maximum value of approximately $0.013 \mathrm{lbm} / \mathrm{s}(0.34$ inches/week) to a minimum of $0.006 \mathrm{lbm} / \mathrm{s}$ ( 0.16 inches/week). Figure 4.2 shows the supernate level for 241-AY-102. The condensate for the AY and AZ tanks is returned to the AY Farm tanks. Evidence of this condensate return can be observed in the level data. There are frequent small increases in the supernate level. Figure 4.2 shows that the level from June through September of 1997 changes very little. The GOTHIC analyses suggest that there should be, on the average, a $0.25 \mathrm{inch} /$ week level change from evaporation. Over three months this would amount to a three inch change in level, which is clearly not seen in Figure 4.2 during the summer of 1997. The level data was processed to try to account for the condensate return. All observed increases in level were assumed to be due to condensate return and were subtracted out of the data. Figure 4.11 shows the revised supernate level using this technique. Large supernate draw downs, seen in Figure 4.2 were added back to provide a continuously decreasing level plot. The graph was initialized at 300 inches. The predicted level decrease, due to the evaporation rate shown in Figure 4.10, is also shown in the

${ }^{4}$ GOTHIC analysis file name ay3 3 condb. 
figure. There is excellent agreement with the data.

\subsubsection{Benchmark for Normal Operation With Primary and Low Annulus Flow}

During the second period of operation the annulus ventilation system was operated at low flow as shown in Figure 4.5. The primary system removes most of the heat from the tank. Figure 4.12 shows the temperature distribution for the middle and outer waste conductors, at 457 and 630 days after 1/1/96. This is near the beginning and the end of the annulus ventilation system operation in 1997. The $\mathrm{x}$-axis represents the distance from the waste surface. The temperature gradient clearly shows that most of the heat flows toward the supernate and is removed by the primary ventilation system. Figure 4.13 shows an estimate of the energy removed by the annulus ventilation system (\% of total tank heat load), obtained by using the 21 . foot radial temperature, the ambient air temperature and the annulus flow rate. Near the beginning and end of the ventilation system operation, when the ambient temperatures are low, the annulus system removes about $20 \%$ of the total heat from 241-AY-102. However, during spring and summer conditions when the ambient temperatures are higher, the annulus system only removes between $5 \%$ and $10 \%$ of the tank heat load. Thus, the annulus ventilation system at low flow will have little effect on the supernate temperatures. Figure 4.14 shows the measured supernate and sludge temperatures. The sludge temperatures show the expected annual variation except when the annulus ventilation system is operated at high flow ( $\sim 800$ days after 1/1/96). The supernate temperatures are consistent with the sludge temperatures during the first period of operation. However, the data near 600 days after 1/1/96 appears to be low, relative to the previous winter conditions ( $~ 300$ days after $1 / 1 / 96)$ and does not increase consistent with the measured sludge temperatures. During this period, the heat-up of the pool drives the waste temperatures up. This data will be investigated further and included in the discussion of the baseline data. Because of this inconsistency, it was not used for the benchmark evaluation after 600 days.

Figure 4.15 shows a comparison of the predicted concrete temperatures at 7 and 21 feet radial positions with tank data. The operations of the annulus ventilation system at low flow reduces the temperature at the seven foot radial location by nearly $15^{\circ} \mathrm{F}$. The process control thermal model predicts this temperature drop to within several degrees. The temperature drop at the 21 foot location is also over predicted during the early period of annulus ventilation operation and will be investigated further.

Figure 4.16 shows the predicted ${ }^{5}$ concrete temperatures when the inlet annulus air is not preheated, as discussed in Section 2.1.2. The predicted temperatures are significantly lower than measured data when the ambient temperatures are low. This demonstrates the effect of the

${ }^{5}$ GOTHIC analysis file name ay3condc. 
HNF-3196, Rev. 0

preheating.

Figure 4.15 shows the predicted concrete temperatures after the annulus system was turned off for a short period of time ( $\sim 500$ days after $1 / 1 / 96)$. The temperatures slowly increase as the supernate temperature increases. The agreement with the data is reasonable. Near the end of the annulus system operation the concrete temperatures at the seven foot radial location are under-predicted, although the effect is small. When the annulus system is shut down, the concrete temperatures at the 7 foot radial location rise immediately to the temperatures at the 21 foot radial location (with only 1 foot of waste there is virtually no radial temperature gradient). This temperature change is a direct indication of the temperature gradient in the waste. This is seen in Figure 4.17 which shows that temperature distribution in the waste at the end of annulus ventilation system operation. The temperature difference on the annulus side of the heat conductor, between the inner and outer heat conductors, is approximately the difference seen in Figure 4.15 when the annulus flow is terminated. The best estimate thermal conductivity for the 241-AY-102 waste is shown in Table 2.1 and has a value near that of water. There was little basis for this number because of insufficient data to resolve the temperature gradient. The benchmark data provides further information. The thermal conductivity of the 241-AY-102 waste was decreased to a value of $0.30 \mathrm{Btu} / \mathrm{hr}-\mathrm{ft}-{ }^{\circ} \mathrm{F}$ to provide a good comparison with the seven foot concrete data with the assumed 1 foot thickness of the settled waste layer. This is closer to the lower estimate of water thermal conductivity (Reynolds 1997) of $0.28 \mathrm{Btu} / \mathrm{hr}-\mathrm{ft}-{ }^{\circ} \mathrm{F}$. A similar result can be obtained with a 15 inch layer with the best estimate thermal conductivity. This number will be further refined when waste temperature distribution data is obtained using the Multi-Instrument Tree moving thermocouple.

\subsubsection{Benchmark for Normal Operation With Primary and High Annulus Flow}

The final period of tank operation used for the benchmark of the process control thermal model, included operation of the annulus ventilation system at high flow. As discussed in Section 4.1.3, the system operated for a short time at high annulus vacuum and flow rate in the range of $1300 \mathrm{cfm}$. Figure 4.18 shows the comparison with the concrete temperature data at the 7 and 21 foot radial locations. The operation of the annulus system at high flow results in a rapid decrease in temperature, nearly $30^{\circ} \mathrm{F}$ at the 7 foot radial location and $20^{\circ} \mathrm{F}$ at the 21 foot radial location. The GOTHIC model predicts over a $5^{\circ} \mathrm{F}$ drop for the outer waste conductor. The process control thermal model provides a reasonable prediction of the concrete temperatures, during the thermal transient caused by the initiation, operation and termination of the annulus ventilation system. The temperatures quickly return to seasonal levels for primary system operation. The predicted temperatures following the operation of the annulus system agree very well with measured data. 
HNF-3196, Rev. 0

Figure 4.8 Comparison Predicted Concrete Temperatures With Data for Period 1.

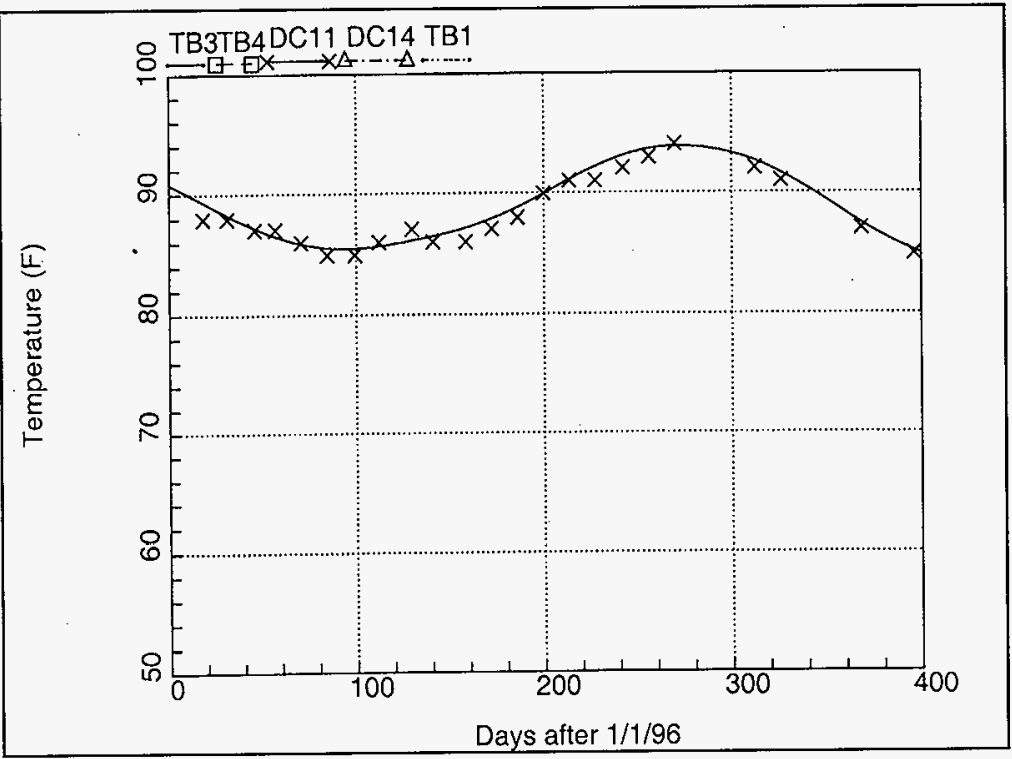


HNF-3196, Rev. 0

Figure 4.9 Comparison of Predicted Supernate Temperatures With Data.

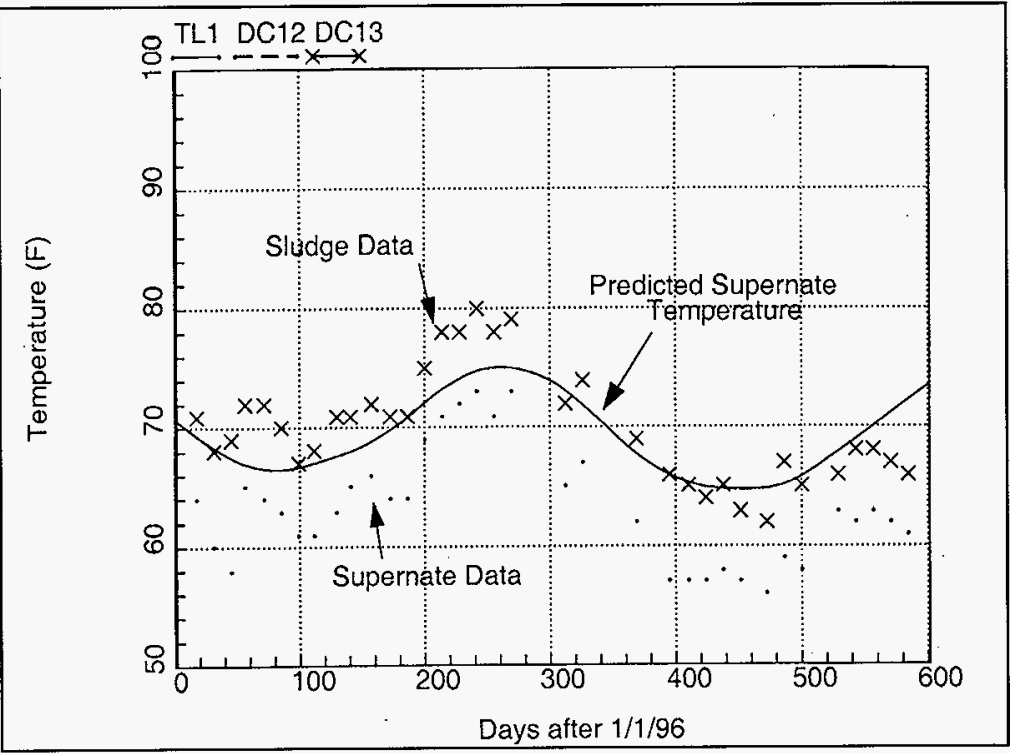


HNF-3196, Rev. 0

Figure 4.10 Predicted Evaporation Rates During Period 1.

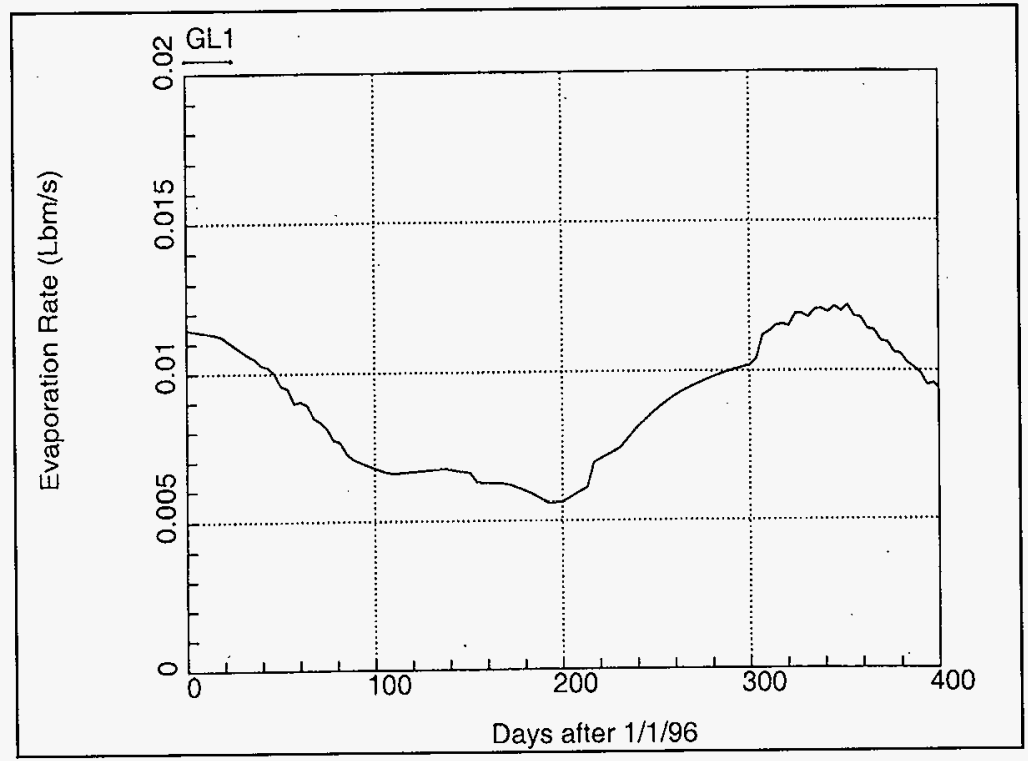


HNF-3196, Rev. 0

Figure 4.11 Comparison of Predicted Evaporative Losses With Corrected Tank Level Data.

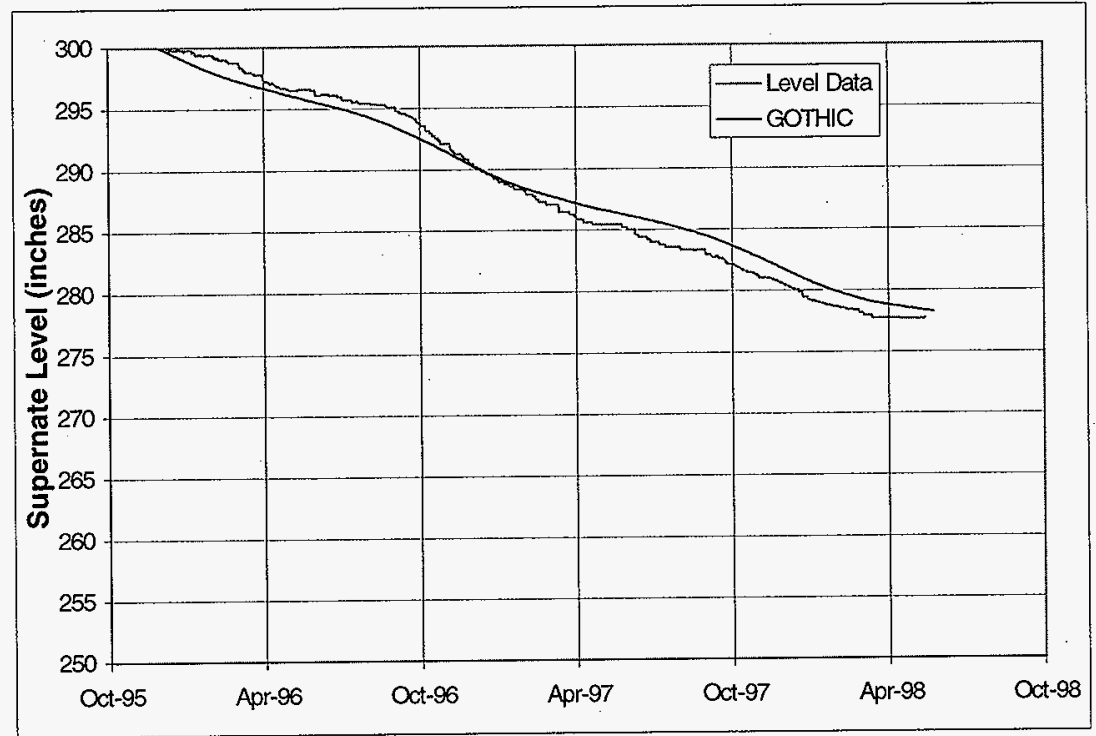


HNF-3196, Rev. 0

Figure 4.12 Waste Temperature Distribution During Period 2.

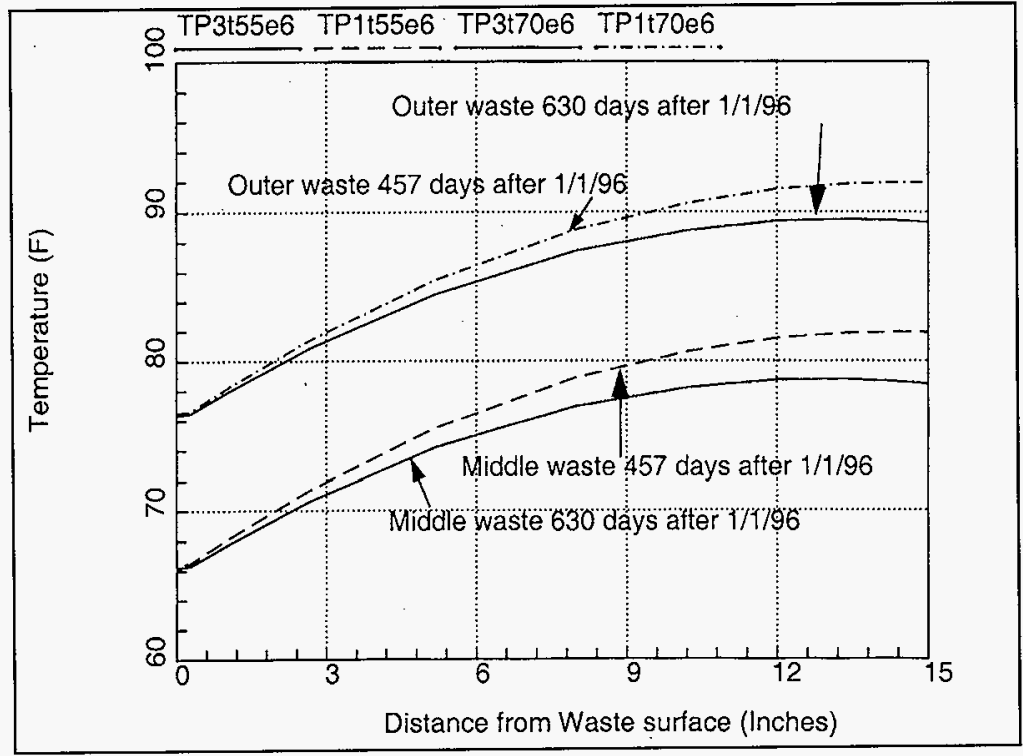


HNF-3196, Rev. 0

Figure 4.13 Heat Removal by the Annulus Ventilation System at Low Flow.

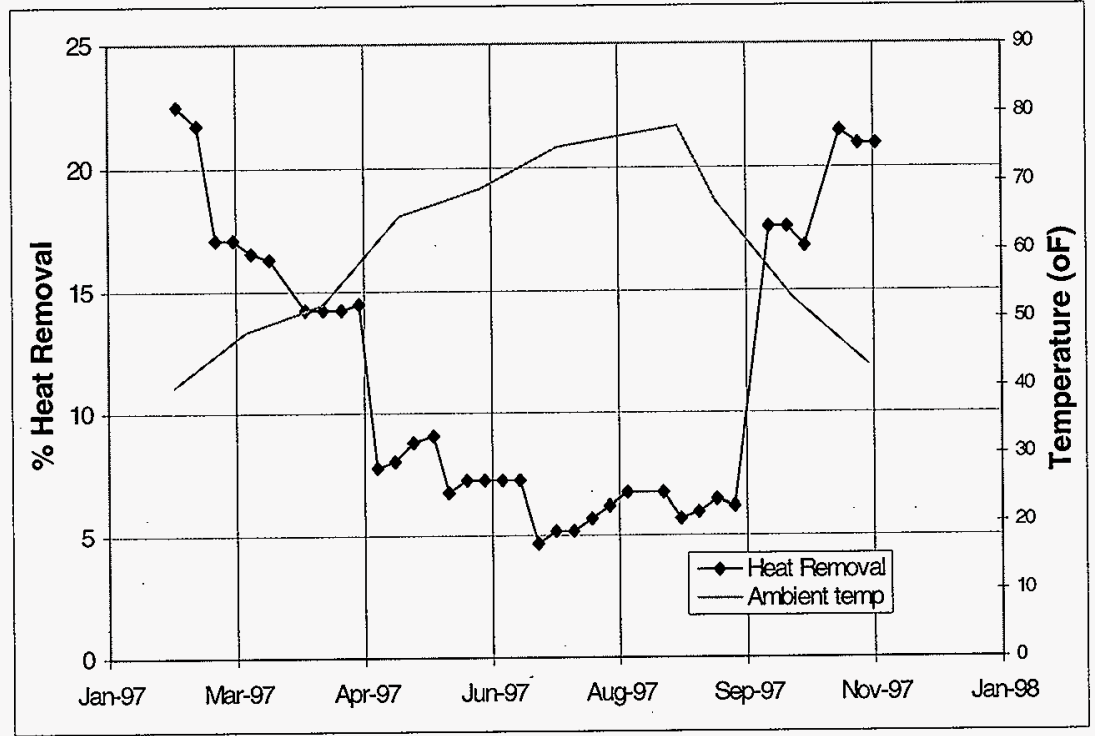


HNF-3196, Rev. 0

Figure 4.14 Comparison of Supernate and Sludge Temperatures.

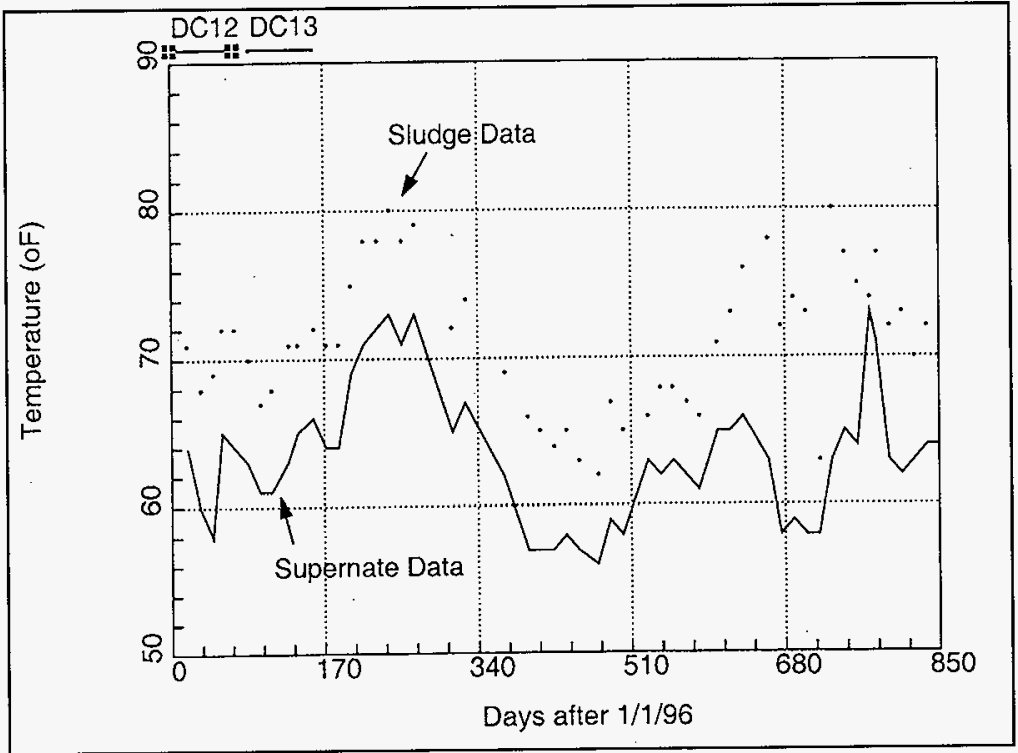


HNF-3196, Rev. 0

Figure 4.15 Comparison of Predicted Temperatures With Data During Period 2.

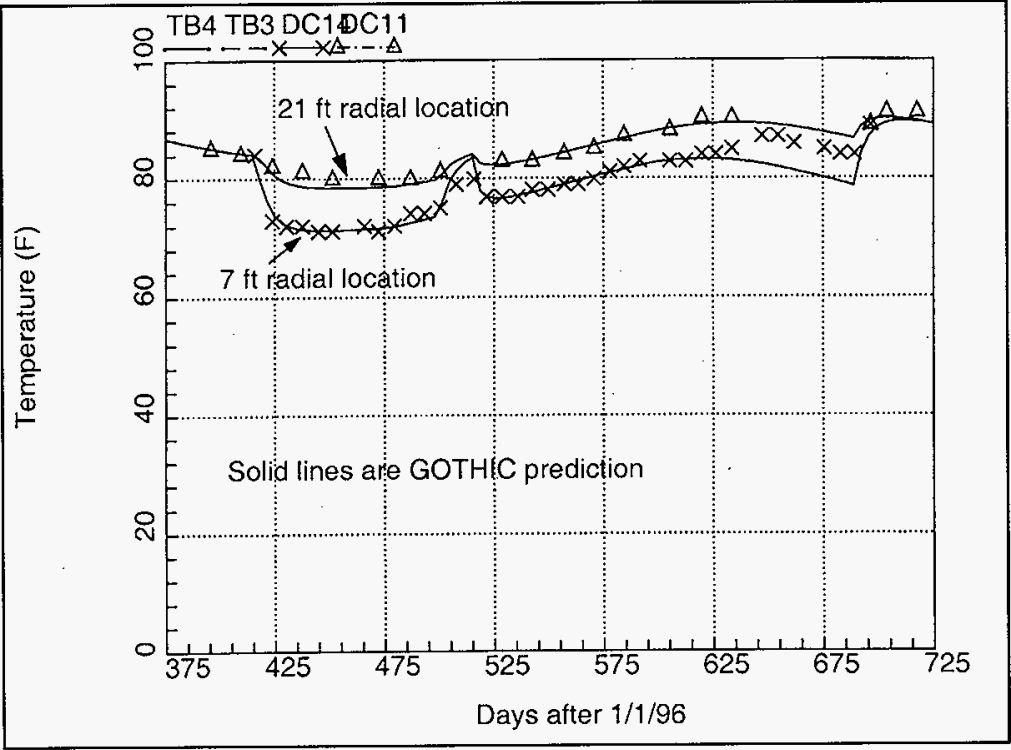


HNF-3196, Rev. 0

Figure 4.16 Predicted Concrete Temperatures Without Preheating.

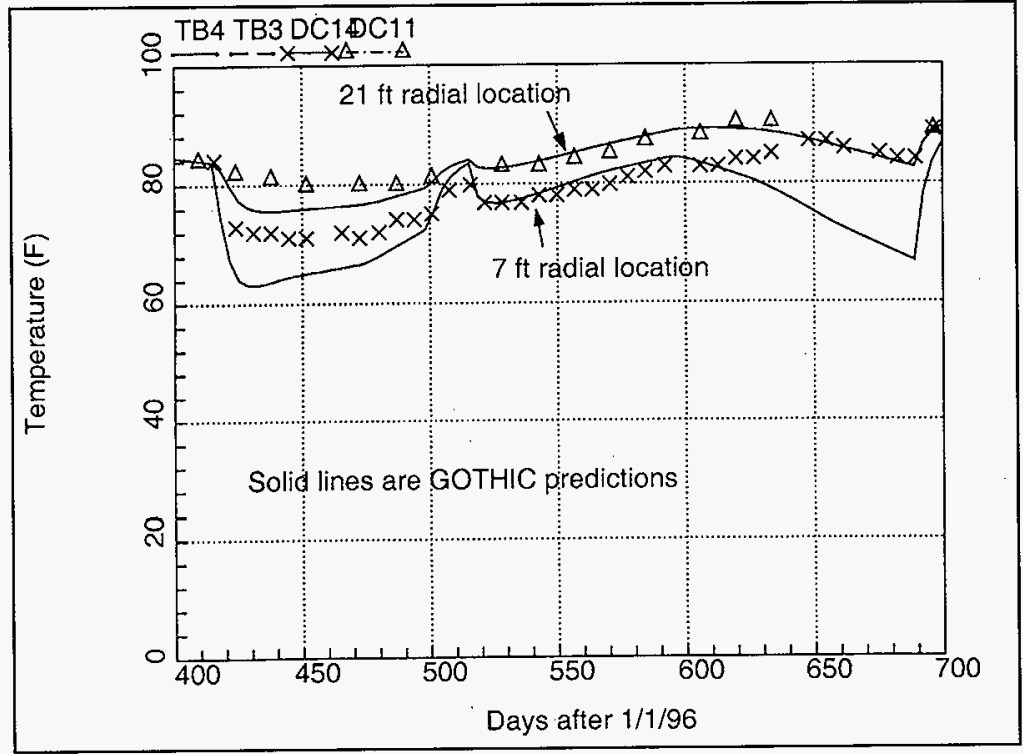


HNF-3196, Rev. 0

Figure 4.17 Waste Temperature Distribution at the End of Period 2.

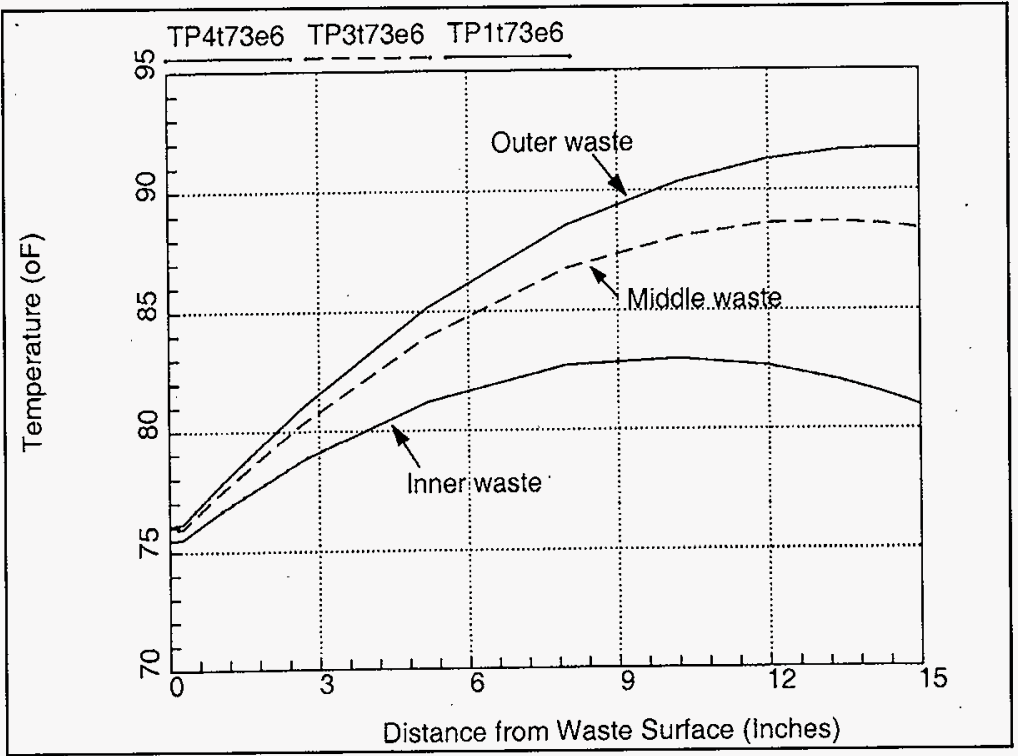


HNF-3196, Rev. 0

Figure 4.18 Comparison of Predicted Temperatures With Data During Period 3.

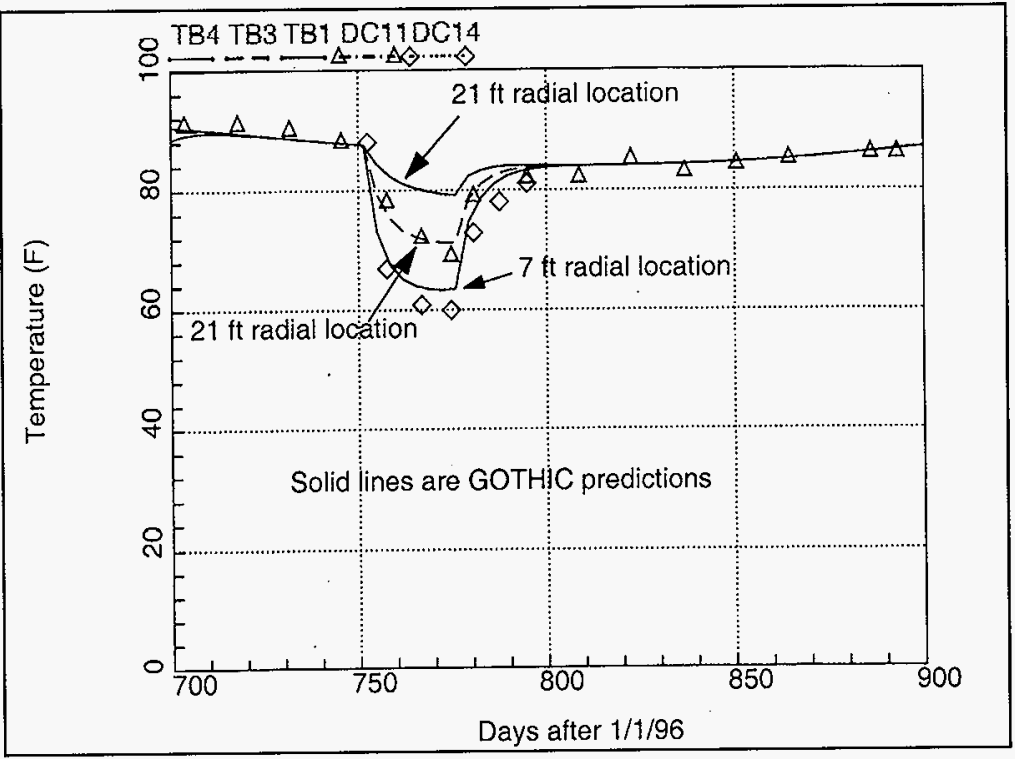


HNF-3196, Rev. 0

\subsection{TANK 241-AY-102 UNCERTAINTY ANALYSES}

The Tank 241-AY-102 Process Control Model will be used to predict the future maximum waste temperatures, following the transfer of waste from Tank 241-C-106. The thermal mass of the waste/supernate and the annual seasonal temperature variations require the prediction of the expected maximum temperature, with the process control thermal model described in previous sections. There are uncertainties associated with the prediction of the maximum waste temperatures. The primary source of these uncertainties are related to the thermal parameters, used in the process control model. An evaluation of the uncertainty in the predicted maximum waste temperature is described in the following sections.

The methodology discussed in the following section will be used to estimate the uncertainty in the predicted maximum waste temperature. This uncertainty will be high, given the current uncertainty in many of the input thermal parameters. However, as waste is transferred into tank 241-AY-102, the tank data will be evaluated and the actual in-tank values for many of the waste parameters will be obtained or inferred. This will greatly reduce the uncertainty in the thermal parameters and the overall uncertainty in the predicted maximum waste temperature. The sluicing will be conducted incrementally in three campaigns. The size of individual increments will be small. Also, the first campaign of sluicing will remove only about two feet of waste from Tank 241-C-106. This will ensure that the waste temperature limits will not be exceeded for the first campaign of sluicing. The thermal parameters will then be updated based upon tank data, which will provide a reduced uncertainty in the temperature predictions for the second campaign of sluicing. The uncertainty in the process control thermal analyses should be reduced to an acceptable level after the evaluation of waste thermal parameters through two campaigns. The uncertainty analyses presented in the following sections is intended to provide a methodology and a conservative estimate of the uncertainty.

Uncertainty analyses were not performed for the Tank 241-C-106 process control model. This model will have limited use during the first campaign of sluicing. Analyses have shown that with the chilling of Tank 241-C-106 prior to sluicing, there will be an adequate margin of safety to account for model uncertainties (Ogden/Sathya 1998b). In addition, the hold periods between the increments of sluicing for campaign 1 will provide even more subcooling margin. For these reasons, an uncertainty analyses was not performed for the $241-\mathrm{C}-106$ process control model.

\subsection{METHODOLOGY}

\subsubsection{Description of Uncertainty Analyses Methodology}

The uncertainty methodology used in the following section was taken from Single- 
HNF-3196, Rev. 0

Sample Uncertainty Analysis theory (Kline \& McClintock 1953, Moffat 1982). The predicted waste temperature is a function of a number of thermal parameters denoted by $\mathrm{X}_{\mathrm{i}}$. Each parameter can be expressed as a best estimate value plus an uncertainty interval as shown in Equation 1.

$$
X_{i}=\bar{X}_{i} \pm \delta X_{i}
$$

Where:

$$
\begin{aligned}
& X_{i}=\text { Independent variable } \\
& \bar{X}_{i}=\text { Best Estimate value of independent variable } \\
& \delta X_{i}=\text { Uncertainty estimate for independent variable }
\end{aligned}
$$

The uncertainty in the predicted maximum waste temperature is given by Equation 2 .

$$
\delta T_{w}=\left[\left(\frac{\partial T_{w}}{\partial X_{1}} \delta X_{1}\right)^{2}+\left(\frac{\partial T_{w}}{\partial X_{2}} \delta X_{2}\right)^{2}+\ldots+\left(\frac{\partial T_{w}}{\partial X_{i}} \delta X_{i}\right)^{2}\right]^{1 / 2}
$$

Where:

$$
\frac{\partial T_{w}}{\partial X_{i}}=\text { Temperature gradient for the } i^{\text {th }} \text { variable }
$$

Equation 2 is valid with the following assumptions:

- a mean value can be defined for each parameter

- the parameters vary linearly about the mean value

- the parameters are independent or uncorrelated 
HNF-3196, Rev. 0

If the odds of the true value of each thermal parameter lying within the stated interval are equal for all the parameters and the parameters are independent, then the equation gives the uncertainty for the maximum waste temperature with the same odds (Moffat 1982). Equation 2 will be used to evaluate the uncertainty of the predicted maximum waste temperature for Tank 241-AY-102.

\subsubsection{Uncertainty Analysis Parameters}

Ogden/Sathya 1998a performed a series of parametric thermal analyses to determine the sensitivity of the predicted waste temperature to important thermal parameters. These parameters included:

- 241-C-106 heat load distribution.

- Fluffing factor of transferred settled waste in Tank 241-AY-102.

- Waste thermal conductivity of transferred waste.

- 241-C-106 waste heat load.

- 241-AY-102 waste heat load.

- Soluble $\mathrm{Cs}^{137}$ in the supernate.

Other parameters may also contribute to uncertainty in the process control thermal analyses including:

- 241-AY-102 waste thermal conductivity.

- Meteorological data.

- Primary ventilation system flow rate.

- Annulus ventilation system flow rate.

- Modeling approximations.

These parameters will be considered in the uncertainty analyses presented in the next section.

\subsection{EVALUATION OF UNCERTAINTIES}

\subsubsection{Temperature Gradient}

The parameters used for the uncertainty analyses are shown in Table 5.1. Sensitivity analyses were performed for parameters 1 through 5 and 9 in Ogden/Sathya 1998a. The results of these analyses are summarized in the table, including the best estimate values (Ogden/Sathya 1998a), sensitivity values and the predicted maximum waste temperatures (The range of values used for the sensitivity analyses are not the parameter uncertainty interval which is discussed in the next section). The maximum waste temperature is also shown for the base case analyses. The temperature gradients can be obtained for these parameters by taking the difference in the 
predicted maximum temperatures and dividing by the difference in the value of the parameter. As an example, there were two sensitivity analyses performed for the fluffing factor as shown in Table 5.1. The difference in the maximum temperatures for the two cases is $59^{\circ} \mathrm{F}$. The difference in fluffing factor is 0.8 . The gradient in the predicted temperature, with respect to fluffing factor, is then $59^{\circ} \mathrm{F} / 0.8$ or $74^{\circ} \mathrm{F}$. The gradient for parameters 2 through 4 were calculated in the same way and are shown in the table. For parameter 5 (heat in the supernate), $30 \%$ of the transferred heat from Tank $241-\mathrm{C}-106$ was assumed to be in the form of soluble $\mathrm{Cs}^{137}$ which is in the supernate. The difference in the parameter is then $0.3 \times 118,000 \mathrm{Btu} / \mathrm{hr}$ or 35,000 $\mathrm{Btu} / \mathrm{hr}$. The temperature difference is obtained from the difference in the parametric analyses for item 5 and the base case analyses. The resulting temperature gradient is shown in the table.

Parameter six is the annulus ventilation system flow rate. The annulus flow was increased for the sensitivity case with increased C-106 heat load (parameter 3). The temperature difference is the $227^{\circ} \mathrm{F}-212^{\circ} \mathrm{F}$. The temperature gradient is shown in Table 5.1.

Parametric analyses for 7 and 8 was not included in Ogden/Sathya 1998a. The temperature gradient for these parameters have been estimated for the purpose of the initial uncertainty analyses (their contribution is small) as shown in Table 5.1. Parameter 9 was previously analyzed with the results shown in the table. However, while the temperature difference can be obtained by comparing to the base case, the parameter difference is difficult to define. The power distribution analyses assumed a distribution in Tank 241-C-106 which resulted in an adverse power distribution when the waste was transferred to Tank 241-AY-102 (places maximum power near the location of the maximum waste temperature). The temperature difference squared was assumed to be the variance as shown in the last column of the Table 5.1 for parameter 9 .

The uncertainty in meteorological data came primarily from the difference in temperature and relative humidity between the Hanford weather station and Tank 241-AY-102. This difference should be small. The gradient was conservatively estimated to be unity. A $1^{\circ} \mathrm{F}$ uncertainty in ambient temperature results in a $1^{\circ} \mathrm{F}$ uncertainty in waste temperature. The temperature difference between the weather station and the Hanford weather station was assumed to be $3^{\circ} \mathrm{F}$.

The process control model does not account for azimuthal temperature variations. The model can be baselined with the highest measured temperatures. This will bias the model conservatively to compensate for azimuthal variations seen in the measured temperature data. There is a quadrant of Tank 241-AY-102 which does have sufficient concrete or sludge thermocouples to observe azimuthal temperature variations. If individual flow channels are blocked in this quadrant, the resulting temperature variation can't be observed. Multidimensional thermal evaluation will be conducted with the model discussed in Section 2.2.3. This evaluation will provide an estimate of the azimuthal temperature variation which can exist 
as a result of blocked annulus slot flow channels. An absolute temperature variation of $20^{\circ} \mathrm{F}$ was assumed for the initial uncertainty analysis. The square of this number will be considered the variance. This will be revised upon the completion of the multi-dimensional thermal analyses.

In addition to the uncertainty in input parameters, there are uncertainties associated with the thermal model itself. This uncertainty may be the result of discretization error or physical models within the code. The benchmark analyses presented in Section 4.0 provides an estimate of uncertainty, although the differences are also associated with uncertainties in the input parameters and boundary conditions such as ventilation flow rates. An absolute temperature variation of $10^{\circ} \mathrm{F}$ was assumed for the initial uncertainty analysis. The square of this number will be considered the variance for the thermal model uncertainty.

\subsubsection{Parameter Uncertainty Interval}

The parameter uncertainty interval is defined to be that interval such that the actual value of the parameter has a high probability of lying within the interval. The selection of this interval is largely engineering judgement based upon all available information. A rigorous development of the uncertainty interval is not possible given the available data and information.

The interval for the fluffing factor is based upon the best estimate parameter evaluation presented in Ogden/Sathya 1998a. This value of the fluffing factor was estimated range from 1.0 (no fluffing) to 1.8 , with a best estimate of 1.4 . Thus, the parameter of uncertainty interval is $+/-$ 0.4 .

The uncertainty in the transferred waste thermal conductivity is due to the uncerainty in the particle and water conductivities shown in Table 2.1. The selection of the thermal conduction model was conservative which gives a small conservative bias to the process control thermal analyses. The waste thermal conductivity is dominated by the value for water. Therefore, most of the uncertainty is related to uncertainties in water conductivity. The conductivity of pure water is well known. However, the tank supernate contains other materials. The conductivity for pure water is $0.35 \mathrm{Btu} / \mathrm{hr}-\mathrm{ft}-{ }^{\circ} \mathrm{F}$. Reynolds 1997 suggests that the conductivity may be as low as $0.28 \mathrm{Btu} / \mathrm{hr}-\mathrm{ft}-{ }^{\circ} \mathrm{F}$. The uncertainty interval for the transferred waste thermal conductivity is assumed to be the difference in the stated conductivities for water or $+/-0.07 \mathrm{Btu} / \mathrm{hr}-\mathrm{ft}-{ }^{\circ} \mathrm{F}$.

A best estimate value for the Tank 241-C-106 heat load is provided in Ogden/Sathya 1998a. This evaluation includes a comparison of estimates derived from thermal analyses, water addition data and tank chemical samples. The most reliable estimate is provided by the water addition data. The thermal analyses and water addition estimates agree very well. The estimates agree to within $10 \%$. The parameter uncertainty estimate for the Tank 241-C-106 heat load was taken to be $15 \%$ or $+/-17,7000 \mathrm{Btu} / \mathrm{hr}$. A similar approach was used to estimate the heat load for 
HNF-3196, Rev. 0

the existing waste in 241-AY-102. The uncertainty interval for Tank 241-AY-102 was assumed to be $15 \%$ or $+/-6,180 \mathrm{Btu} / \mathrm{hr}$.

The expected heat load to remain in the supernate, after the transfer of waste from Tank 241-C-106, is highly uncertain. The best estimate thermal parameters reported in Ogden/Sathya 1998a, conservatively assumed that none remained in the supernate. For the purpose of the initial uncertainty analyses, it will be assumed that $10 \%$ heat in the supernate is a reasonable best estimate value for this parameter. The parameter uncertainty interval is assumed to $+/-10 \%$ (either there will be none or as high as $20 \%$ ). Stated in terms of heat load, this uncertainty interval is $+/-11,800 \mathrm{Btu} / \mathrm{hr}$.

The uncertainty in ventilation flow rates is probably less than most of the other thermal parameters since it can be measured directly. This uncertainty may be less than $10 \%$. For the purpose of this initial uncertainty estimate, the uncertainty interval for both the annulus and primary system flow rates will be assumed to be $+/-15 \%$, assuming an annulus flow rate of 1000 $\mathrm{cfm}$ and a primary ventilation flow of $500 \mathrm{cfm}$, the uncertainty intervals are $+/-150 \mathrm{cfm}$ for the annulus system and $+/-75 \mathrm{cfm}$ for the primary ventilation system.

The uncertainty interval for the 241-AY-102 waste thermal conductivity is assumed to be the same as the transferred waste thermal conductivity uncertainty since it's value is also dominated by the conductivity for water. The uncertainty interval is $+/-0.07 \mathrm{Btu} / \mathrm{hr}-\mathrm{ft}-{ }^{\circ} \mathrm{F}$.

As discussed previously, the uncertainty in the meteorological data is small. The uncertainty interval will be assumed to be $+/-3^{\circ} \mathrm{F}$. The square of the temperature differences for the remaining parameters are assumed to be the variance and thus the parameter uncertainty interval is assumed to be unity.

\subsubsection{Uncertainty Analyses}

\subsubsection{Initial Conservative Estimate}

Table 5.1 summarizes the results of the uncertainty analyses using the temperature gradients and parameter uncertainty intervals presented in the previous sections. The temperature gradients are multiplied by the parameter uncertainty intervals are shown in the final column of the table. These terms are squared and summed. The uncertainty interval for the maximum waste temperature is the square root of the sum. In Table 5.1 it is expressed as the relative uncertainty, which is normalized by the predicted maximum waste temperature for the base case of $215^{\circ} \mathrm{F}$. The relative uncertainty for the predicted maximum waste temperature is $22 \%$, which corresponds to $47^{\circ} \mathrm{F}$. Thus, $47^{\circ} \mathrm{F}$ must be added to the maximum waste temperature predicted by the process control model to account for the uncertainties described in the previous sections. This initial uncertainty is quite large. If the first campaign of W-320 
HNF-3196, Rev. 0

sluicing was to transfer all the waste allowed by the temperature limits of $241-\mathrm{AY}-102$, this uncertainty would reduce the amount of waste which could be transferred.

\subsubsection{Preliminary Estimate of Uncertainty Reduction}

Project W-320 will not transfer the maximum possible waste during the first campaign. Instead, approximately two feet of waste will be transferred in incremental steps to assure that the temperature limit for Tank $241-\mathrm{AY}-102$ is not exceeded. This will be followed by an evaluation period where the actual in-tank thermal parameters will be measured directly, or inferred from other measurements. This evaluation of thermal parameters will significantly reduce the initial uncertainty in the parameters and the overall uncertainty in the process control thermal model. Table 5.1 shows the relative contribution from each parameter. The last column essentially represents the variance for each parameter. The largest contribution comes from the uncertainty in the fluffing factor. The fluffing factor determines the thickness of the settled waste in Tank 241-AY-102. This parameter will be measured directly using a movable thermocouple to determine the location of the non-convective/convective waste interface. A second independent measurement will also be made using the ENRAF densitometer which will determine the location of the non-convective/convective by measuring the density difference. Thus the uncertainty in the fluffing factor will be greatly reduced.

The next significant uncertainty is the transferred waste thermal conductivity. The measurement of the axial temperature profile will allow for the assessment of the waste thermal conductivity.

The next significant uncertainty is in the heat load estimate for Tank 241-C-106. The uncertainty interval for this $\mathrm{C}-106$ heat load parameter was conservative for this initial evaluation. However, this uncertainty can be reduced. A heat load evaluation will be conducted for both Tanks 241-AY-102 and 241-C-106 following the first and the second campaigns of sluicing. Since Tank $241-\mathrm{AY}-102$ is better instrumented than Tank $241-\mathrm{C}-106$ and the evaluation will be conducted on two separate tanks, the uncertainty in the heat load should be reduced, providing a reduction in the process control model uncertainty.

The incremental sluicing and the three campaigns of sluicing will allow for the evaluation of the transferred heat for numerous increments of transferred waste. This will provide a much improved estimate of the heat load distribution in Tank 241-C-106 and reduce the uncertainty in the power distribution, which is not one of the largest uncertainties, but is still significant.

The final significant uncertainty shown in Figure 5.1 is due to the azimuthal temperature variations. This uncertainty will be evaluated using the $3-\mathrm{D}$ thermal analyses assuming blocked annulus flow channels. This uncertainty will be reduced through this evaluation. However, this will probably remain as one of the largest uncertainties. 
HNF-3196, Rev. 0

Table 5.2 shows the uncertainty analyses using reduced parameter uncertainties, which may be possible through the evaluations which will be conducted during sluicing. The overall uncertainty for this example is reduced to $13 \%$. This reduction is may be achievable. A reduction to $10 \%$ uncertainty is believed to be the best that could be achieved. 
HNF-3196, Rev. 0

Table 5.1 Summary of Process Control Model Uncertainty Analyses.

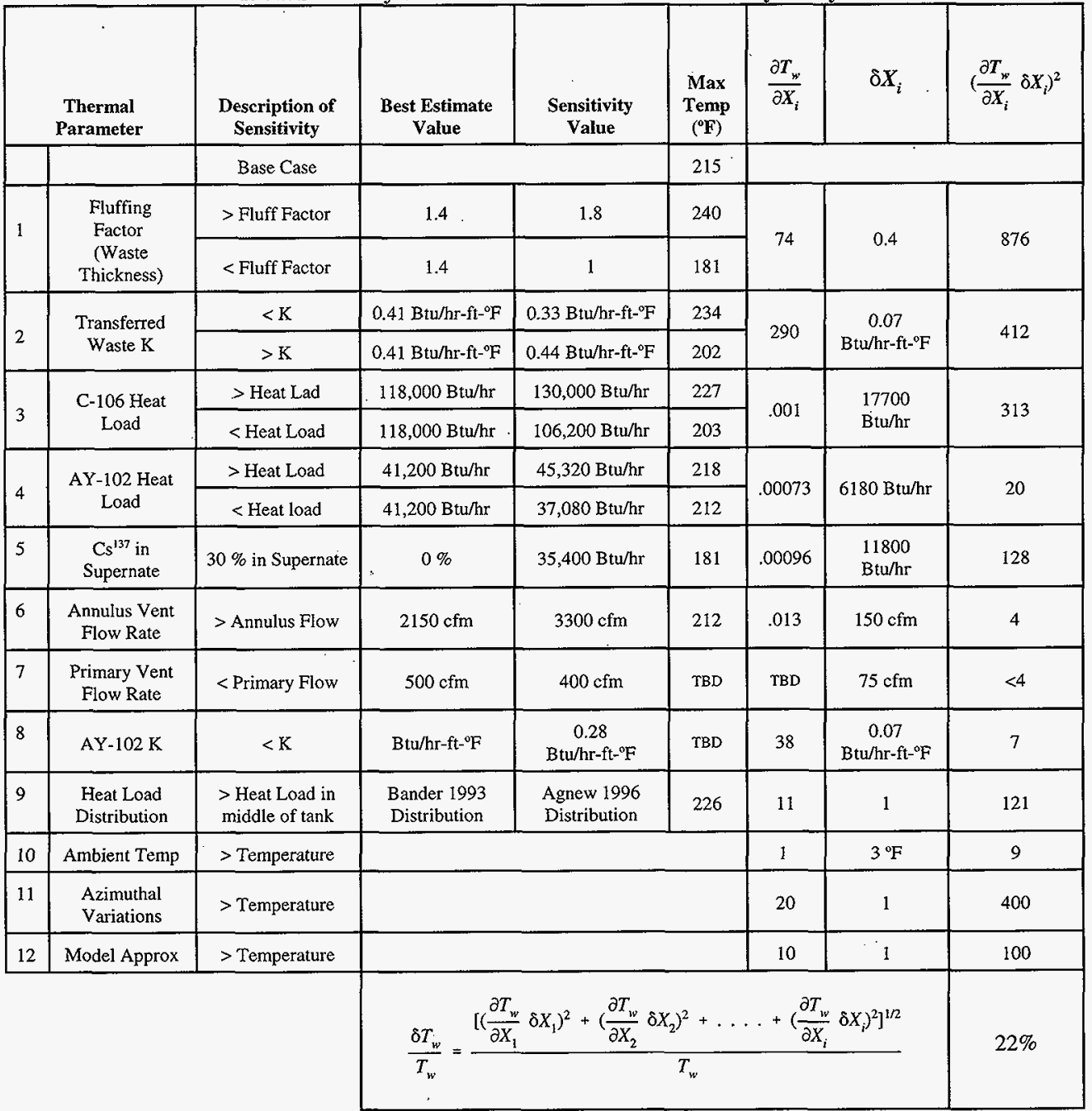


HNF-3196, Rev. 0

Table 5.2 Process Control Model Uncertainty Analyses With Updated Thermal Parameters.

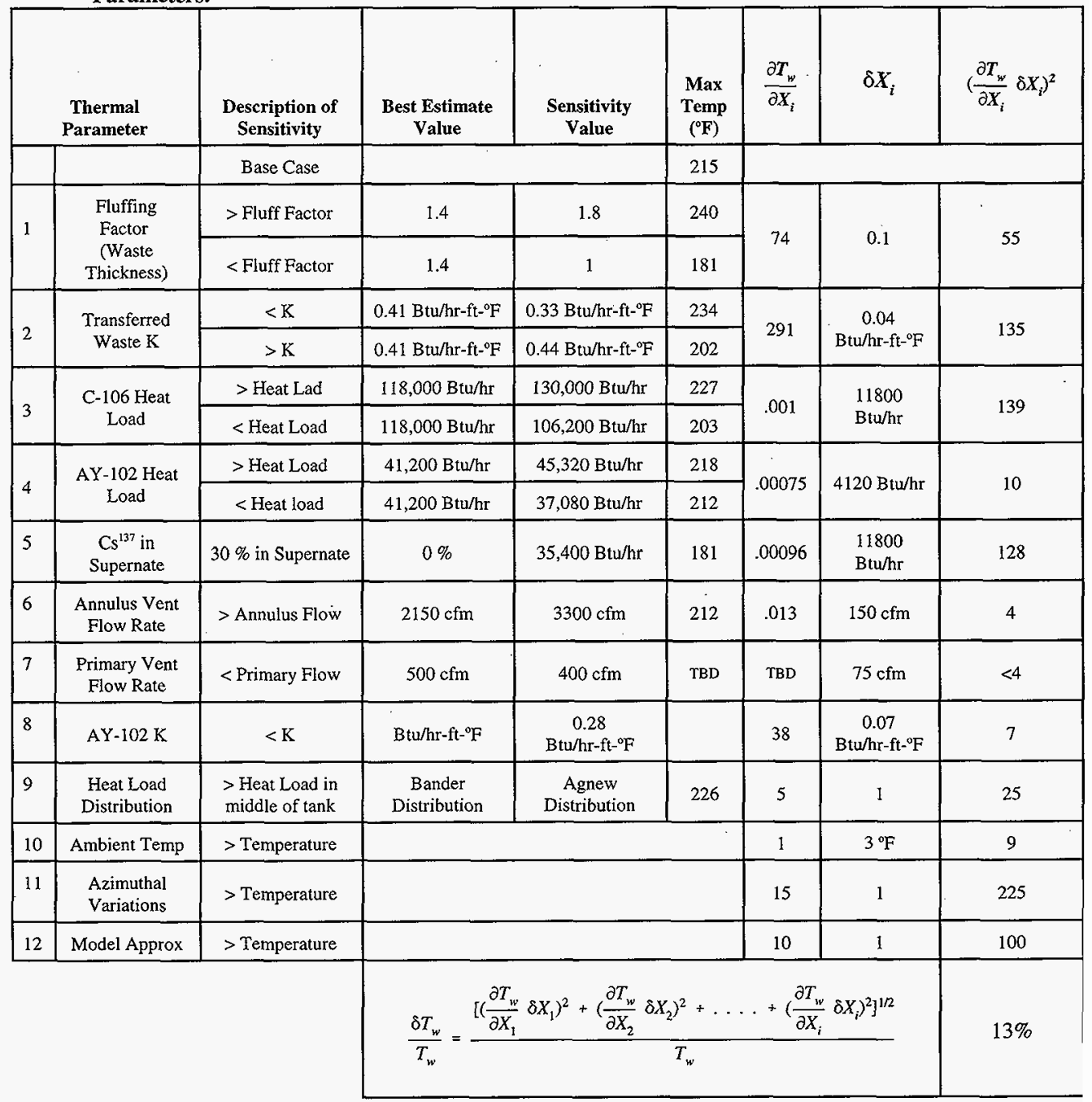


HNF-3196, Rev. 0

\subsection{TANK 241-C-106 BASELINE}

This section will be provided in Revision 1 of this report.

\subsection{TANK 241-C-106 BASELINE DATA}

6.1.1 Baseline Temperature Data

6.1.2 Ventilation System Operation

6.2 TANK 241-C-106 BASELINE ANALYSIS

6.2.1 Baseline Thermal Hydraulic Model

6.2.2 Results of Baseline Analyses 
HNF-3196, Rev. 0

\subsection{TANK 241-AY-102 BASELINE}

This section will be provided in Revision 1 of this report with the exception of Figures

7.2 through 7.6 which are provided for Revision 0 .

7.1 TANK 241-AY-102 BASELINE DATA

7.1.1 Temperature History

7.1.2 Three -Dimensional Temperature Distribution

7.1.3 Primary and Annulus System Operation

7.1.4 Tank 241-AY-102 Waste Level

7.2 TANK 241-AY-102 BASELINE ANALYSES

7.2.1 Baseline Thermal Hydraulic Model

7.2.2 Results of Baseline Analyses 
HNF-3196, Rev. 0

Figure 7.1 Schematic of Tank 241-AY-102 Thermal Couple Locations.

Provided by Revision 1 
HNF-3196, Rev. 0

Figure 7.2 Insulating Concrete Temperatures at 7 Foot Radius.

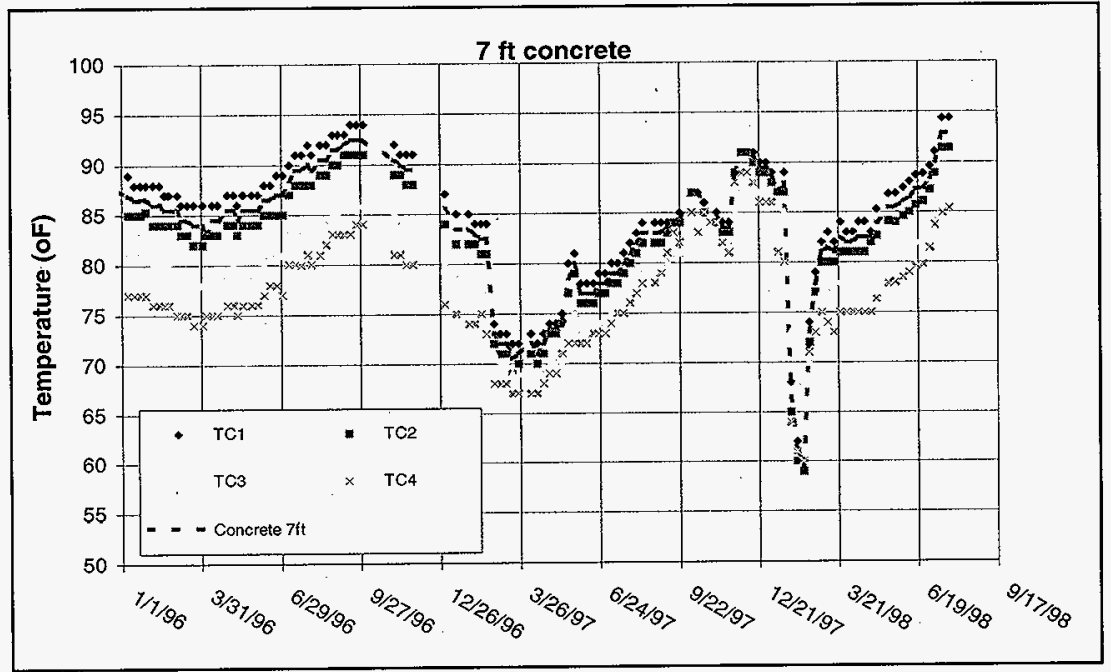


HNF-3196, Rev. 0

Figure 7.3 Insulating Concrete Temperatures at 21 Foot Radius.

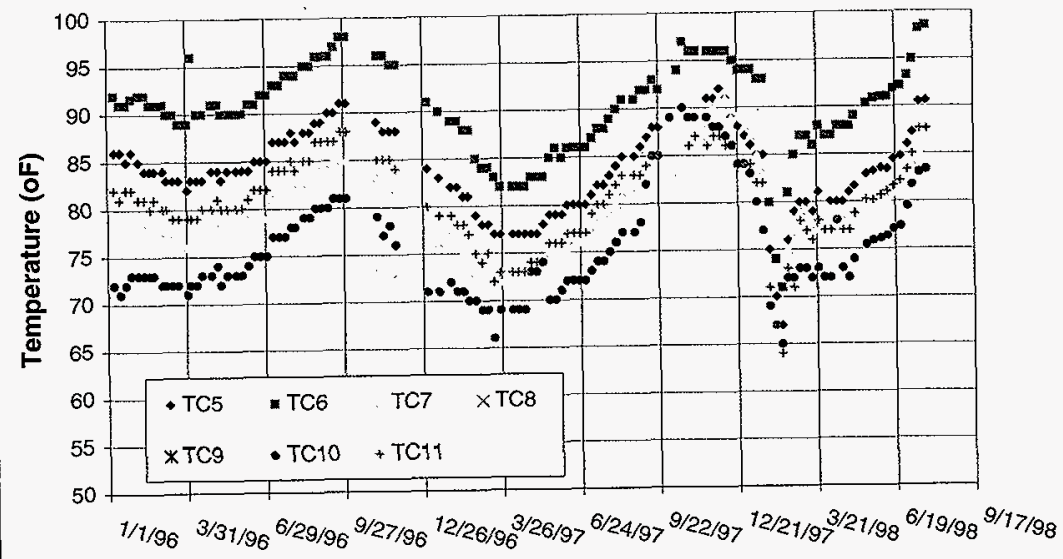


HNF-3196, Rev. 0

Figure 7.4 Insulating Concrete Temperatures at 37 Foot Radius.

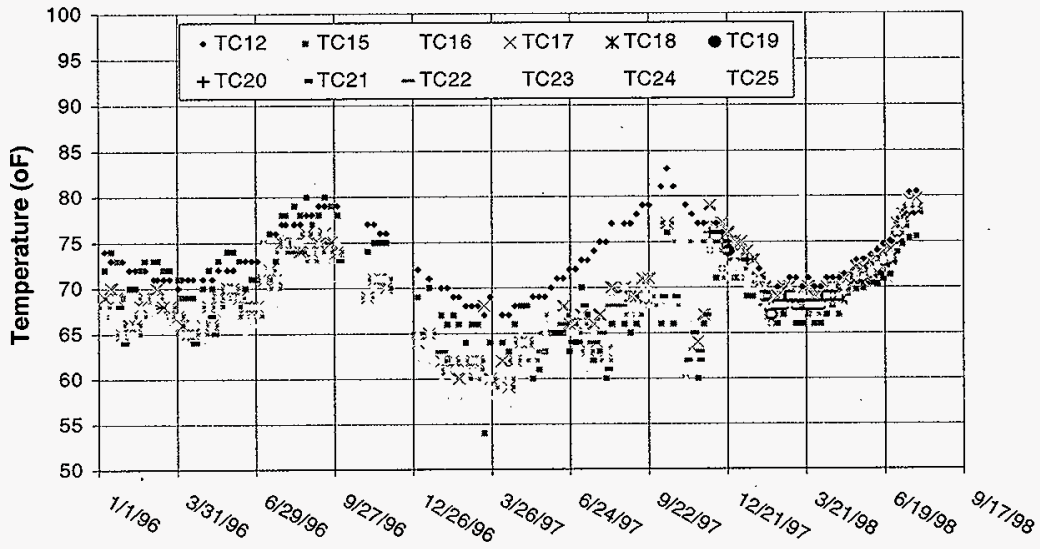


HNF-3196, Rev. 0

Figure 7.5 Tank 241-AY-102 Supernate Temperatures.

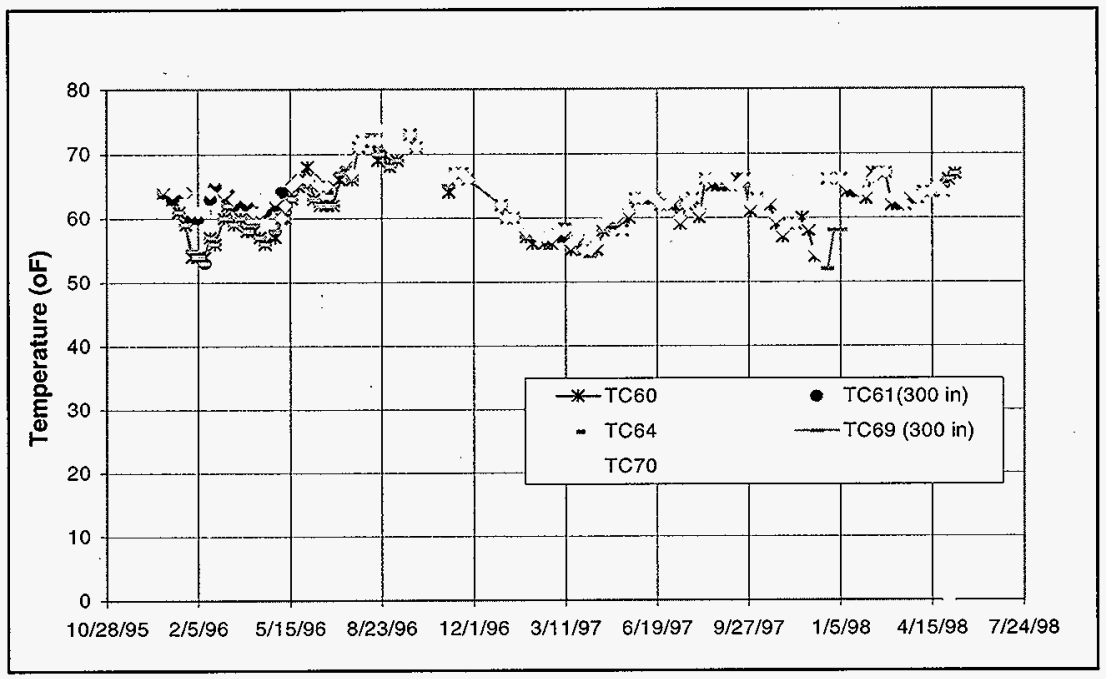


HNF-3196, Rev. 0

Figure 7.6 Tank 241-AY-102 Sludge Temperatures.

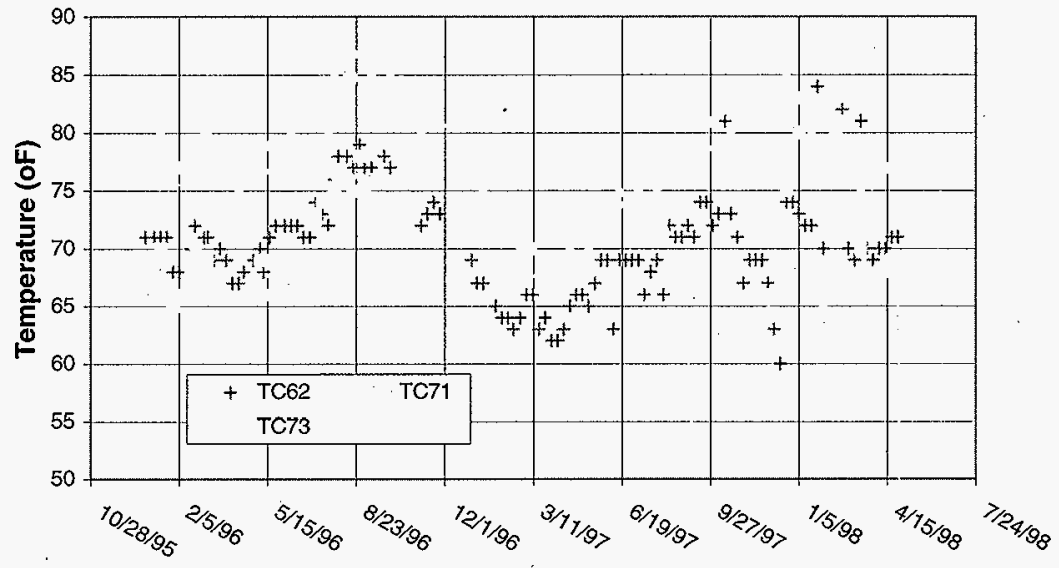


HNF-3196, Rev. 0

\subsection{PROCESS CONTROL ANALYSES DEFINITION}

Process control thermal analyses will be performed for Tank 241-C-106 and Tank 241AY-102 following each of the first two sluicing campaigns. The analyses will be performed with the thermal hydraulic models which have been presented in the previous sections. The analyses for Tank 241-C-106 will demonstrate that the maximum waste temperature remains below the local saturation temperature through the W-320 sluicing campaigns. Before these sluicing campaigns are allowed to begin, the process control analyses for Tank 241-AY-102 will demonstrate that the quasi-steady maximum waste temperatures remain below the applicable temperature limits. The following section provides a description of the process control analyses which will be conducted for Tanks 241-C-106 and 241-AY-102. This includes a discussion of the application of the temperature limits and the assumed operating parameters of the tank engineering systems (ventilation flow rates as an example)

\subsection{TANK 241-C-106 PROCESS CONTROL ANALYSES DEFINITION}

To be provided in Revision 1 of this document.

\subsection{TANK 241-C-106 PROCESS CONTROL ANALYSES DEFINITION}

To be provided in Revision 1 of this document. 
HNF-3196, Rev. 0

\subsection{CONCLUSIONS}

- The Tank 241-C-106 process control model adequately predicts the thermal hydraulic behavior of Tank 241-C-106 and can be used for the process control thermal analyses.

- The Tank 241-AY-102 process control model adequately predicts the thermal hydraulic behavior of Tank 241-AY-102 and can be used for the process control thermal analyses.

- The uncertainty analyses of Section 5.0 provides a reasonable representation of the 241AY-102 process control model uncertainty.

- The initial parameter uncertainty intervals provide a conservative estimate of the initial process control model uncertainty.

- Tank data obtained after the initiation of W-320 sluicing will reduce the uncertainty in important thermal parameters and reduce the process control model uncertainty. 
HNF-3196, Rev. 0

\section{REFERENCES}

Agnew, S.F., et. al., 1996, Hanford Tank Chemical and Radionuclide Inventories: HDW Model Rev. 3, LA-UR-96-858, Los Alamos National Laboratory, Los Alamos, New Mexico.

Bander, T.J., 1993, Revised Thermal History of Tank 241-C-106, WHC-SD-WM-ER-200, Westhinghouse Hanford Company, Richland, Washington.

Bander, T.J., 1995, Tank 24I-C-106 Process Test Report, WHC-SD-WM-ER-427, Rev. O, Westinghouse Hanford Company, richland, Washington.

Bouse 1975, Thermal Conductivity of Hanford Waste Tank Solids and SX Tank Farm Soil Samples, ARH-CD-378, Atlantic Richfield Hanford Company, Richland, Wash

Carothers, K.G. 1998, Tank 241-C-106 Waste Retrieval Sluicing System Process Control Plan, HNF-SD-WM-PCP-013, Revision 1, Fluor Daniel Hanford, Inc., Richland, Washington.

Carslaw, H. S., and J. C. Jaeger, 1959, Conduction of Heat in Solids, Oxford at the Clarendon Press, London.

Crummel 1998, Personal commumications with D.M. Ogden.

FDH 1998, Tank Waste Remediation System Technical Safety Requirements, HNF-SD-WMTSR-006, Rev. 1, Flour Daniel Hanford, Richland, Washington.

Kline, S. J. and F. A. McClintock, 1953, Describing Uncertainties in Single Experiments, Mechanical Engineering, Jan. 1953.

Moffat, R. J., 1982, Contributions to the Theory of Single-Simple Uncertainty Analysis, American Society of Mechanical Engineers, Journal of Fluids Engineering, June 1982, Vol. 104, pp. 250-260.

Ogden, D.M., K. Sathyanarayana, et.al. 1998a, Project W-320 SAR and Process Control thermal Analyses, HNF-SD-W320-ER-004, Rev 1, Numatec Hanford Company, Richland, Washington.

Ogden, D.M., K. Sathyanarayana, 1998b, Ventilation flow Requirements for Tank 24I-C-106, HNF-2554, Rev 0, Numatec Hanford Company, Richland, Washington. 
HNF-3196, Rev. 0

Reynolds, D. A., 1997, Chemical and Chemically Related Issues Associated with Sluicing Tank C-106 Waste to Tank AY-102, HNF-SD-WM-TI-756 Rev. 2, Flour Daniel Company, Richland, Washington.

Sathyanarayana, K., and B. C. Fryer, 1996, Evaluation of Potential and Consequences of Steam Bump in High Heat Waste Tanks andAssessment and Validation of GOTH Computer Code, WHC-SD-WM-CN-022, Rev. 0, Westinghouse Hanford Company, Richland, Washington.

Sathyanarayana, K., B. C. Fryer and M. J. Thurgood, 1993, Development of a Dynamic Computer Simulator for Aging Waste Tank Operations and Safety Assessment, WHC-SD-WM-ER-198, Rev. 0, Westinghouse Hanford Company, Richland, Washington.

Sathyanarayana, K., 1997, Evaluation of Waste Temperatures in AWF Tanks for Bypass Mode Operation of the 702-AZ Ventilation System, HNF-SD-W030-ER-004, Rev. 0, Numatec Hanford Corporation, Richland, Washington.

Thurgood 1995, GOTH Tank C-106 Thermal Hydraulic Analysis Related to the 1994 Process Test, NAI-940708-4, Numerical Applications Inc. for Westinghouse Hanford Company, Richland, Washington.

Thurgood 1998a, Technical Manual for GOTH_SNF Version 4.0, JMI-980306-2, John Marvin, Inc., West Richland, Washington.

Thurgood 1998b, Validation and Verification of the GOTH_SNF Code For Application to Thermal Analysis of Spent Nuclear Fuel, JMI-9602-4, Rev. 1, John Marvin, Inc, West Richland, Washington.

Welty. James R.. 1974, Engineering Heat Transfer, John Wiley \& Sons, New York. 


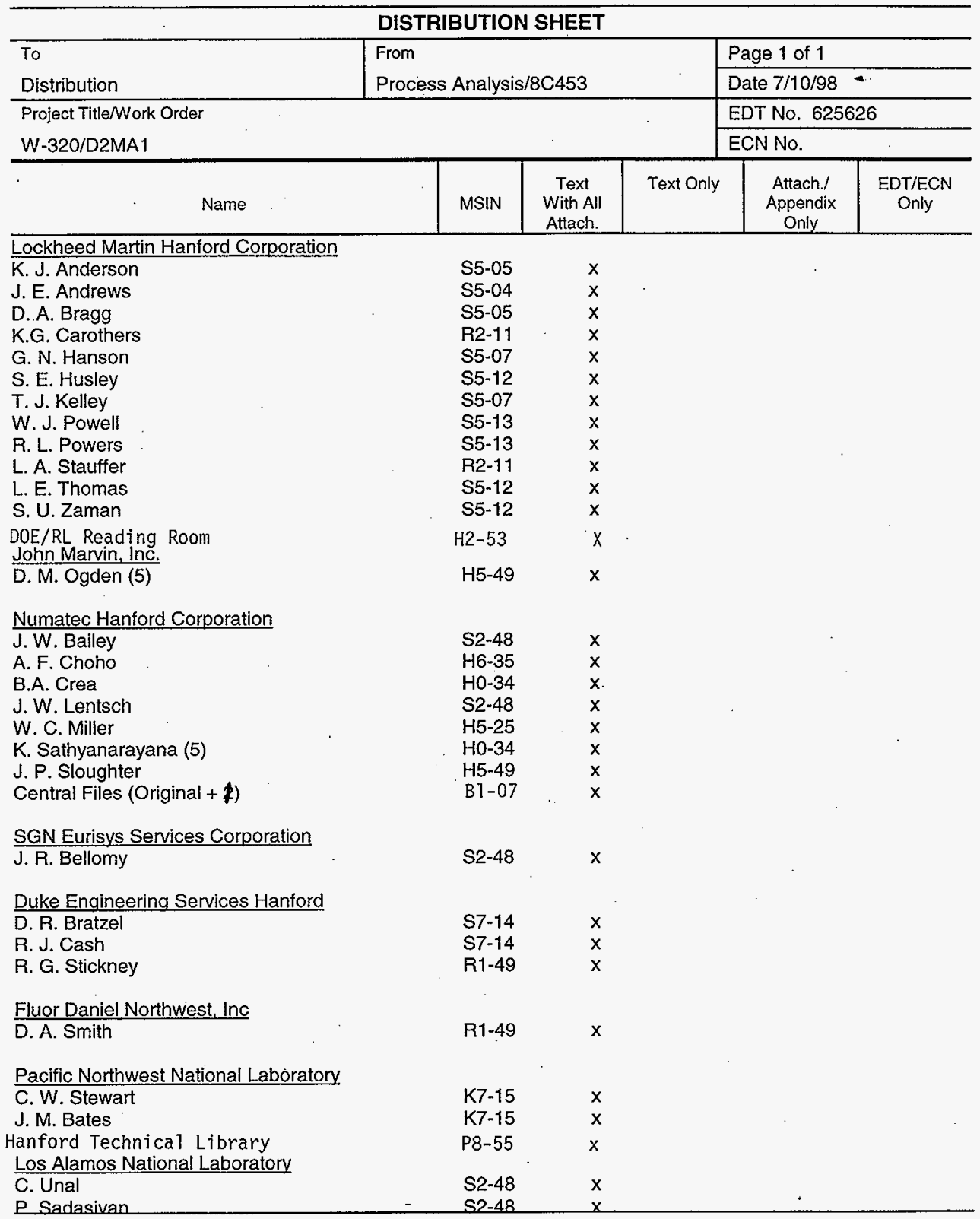

